\title{
WestVirginiaUniversity
}

THE RESEARCH REPOSITORY @ WVU

Graduate Theses, Dissertations, and Problem Reports

2019

\section{Shame and Guilt: The Good, the Bad, and the Ugly}

\author{
Raika Sadeghein \\ West Virginia University, rasadeghein@mix.wvu.edu
}

Follow this and additional works at: https://researchrepository.wvu.edu/etd

Part of the Marketing Commons, and the Social and Behavioral Sciences Commons

\section{Recommended Citation}

Sadeghein, Raika, "Shame and Guilt: The Good, the Bad, and the Ugly" (2019). Graduate Theses,

Dissertations, and Problem Reports. 3767.

https://researchrepository.wvu.edu/etd/3767

This Dissertation is protected by copyright and/or related rights. It has been brought to you by the The Research Repository @ WVU with permission from the rights-holder(s). You are free to use this Dissertation in any way that is permitted by the copyright and related rights legislation that applies to your use. For other uses you must obtain permission from the rights-holder(s) directly, unless additional rights are indicated by a Creative Commons license in the record and/ or on the work itself. This Dissertation has been accepted for inclusion in WVU Graduate Theses, Dissertations, and Problem Reports collection by an authorized administrator of The Research Repository @ WVU.

For more information, please contact researchrepository@mail.wvu.edu. 
Shame and Guilt: The Good, the Bad, and the Ugly

Raika Sadeghein

Dissertation submitted to the John Chambers College of Business and Economics at West Virginia University

in partial fulfillment of the requirements for the degree of

Ph.D. in Marketing

Paula Fitzgerald, Ph.D., Chair

Pam Ellen, Ph.D.

Annie Cui, Ph.D.

Stephen He, Ph.D.

Laurel Cook, Ph.D.

Department of Marketing

Morgantown, West Virginia

2019

Keywords: Shame, Guilt, Consumer Decision-Making, Consumer Ethics, Appeals, Consumer Morality, Consumer Social Responsibility

Copyright 2019 Raika Sadeghein 


\author{
ABSTRACT \\ Shame and Guilt: The Good, the Bad, and the Ugly \\ Raika Sadeghein
}

In the past few decades, we have witnessed a growing body of literature on emotions in the consumer behavior domain. Emotions are defined as "mental states of readiness that arise from appraisals of events or one's own thoughts" (Bagozzi, Gopinath, \& Nyer, 1999, p. 184).

Marketers have examined the role of emotions as stimuli, mediators, moderators, and responses to the environment. The broad topic of emotions includes subtopics such as impact of emotions on consumption, attitudes, and behavioral intentions, emotional responses to market stimuli, and the impact of emotions on cognition. However, although the study of emotions is pivotal to consumer researchers, the marketing literature has mostly focused on a few emotions. In this dissertation, our focus is on two emotional states of shame and guilt. Unlike marketing literature, these two emotional states are commonly investigated together in psychology and sociology literature. However, there seems to be an overemphasis on guilt in the marketing literature, while shame has not benefited from similar attention. Over three essays I summarize the literature on shame and guilt, examine these emotional states as mediators, and as interventions to induce behavior modification. 


\section{Table of Contents}

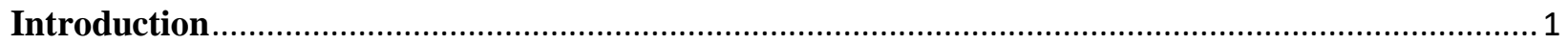

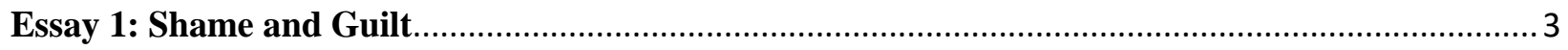

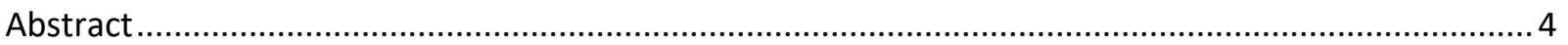

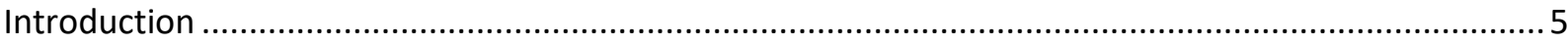

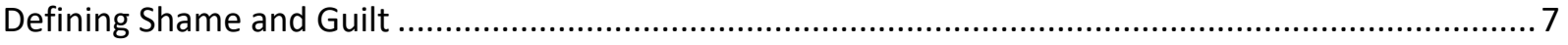

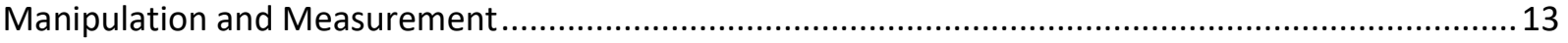

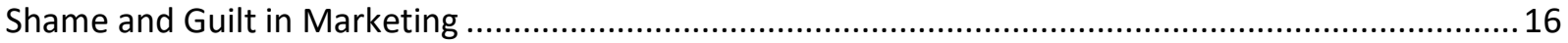

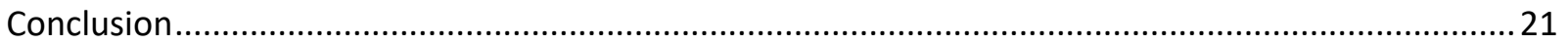

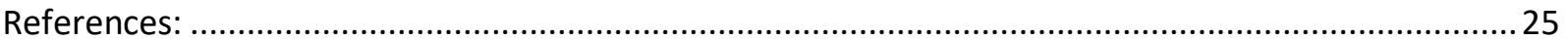

Essay 2: Behavioral Norms in Consumers' World of Power: When and Why Shame and Guilt

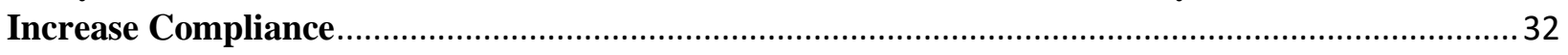

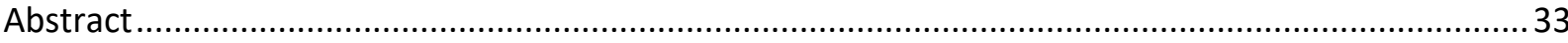

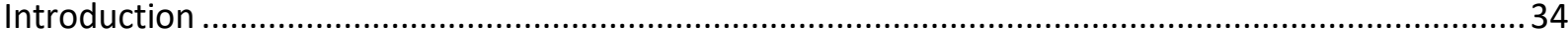

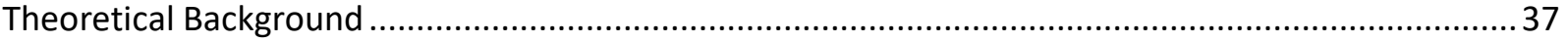

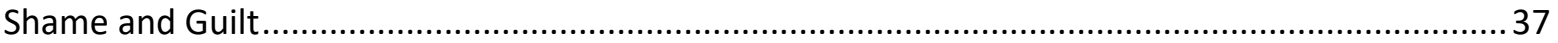

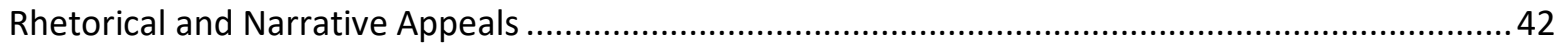

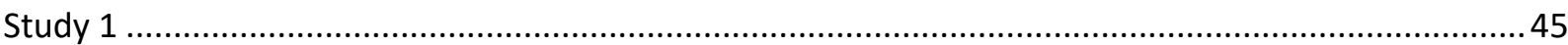

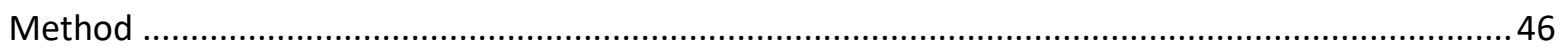

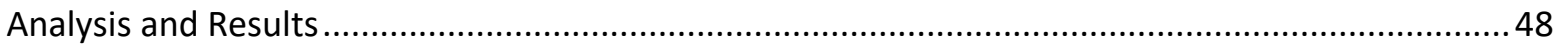

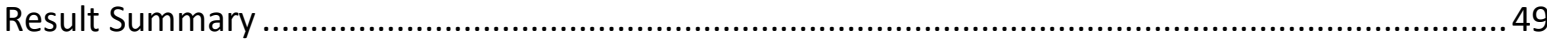

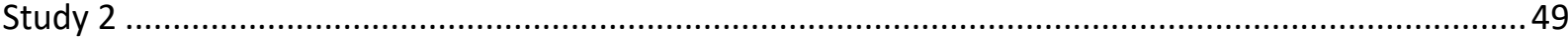

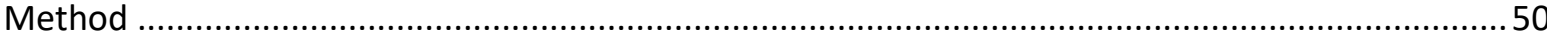

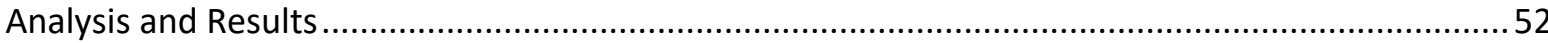

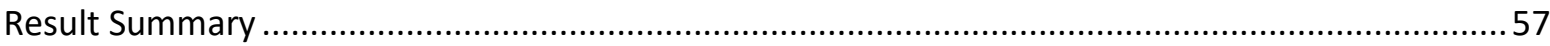

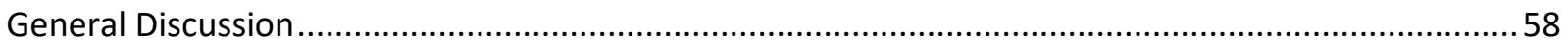

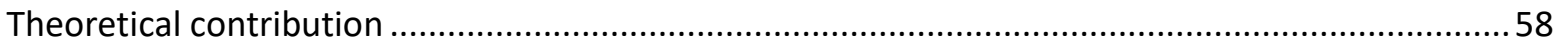

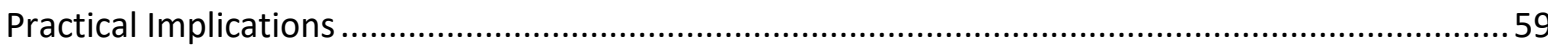

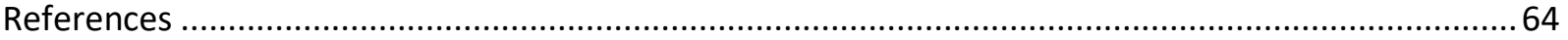

Essay 3: How Do Online Customer Reviews Impact Online Purchases? The Role of Online Review

Examination as a Guilt/Shame Reduction Strategy .................................................................... 71

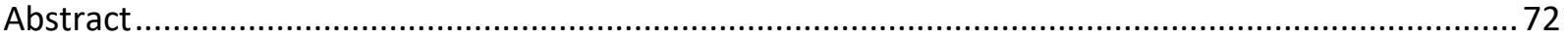




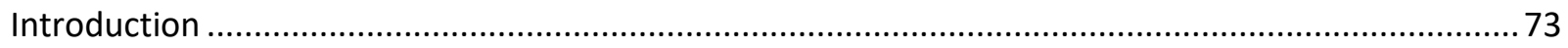

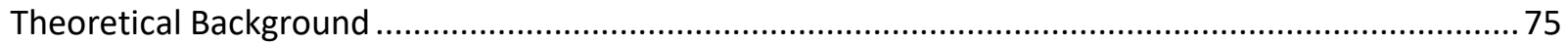

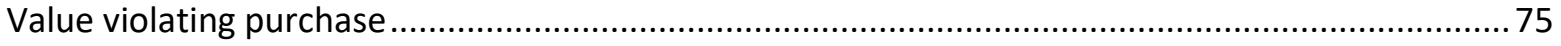

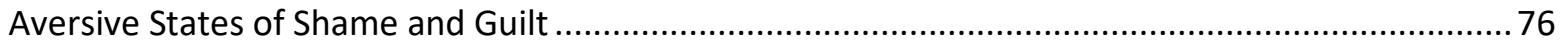

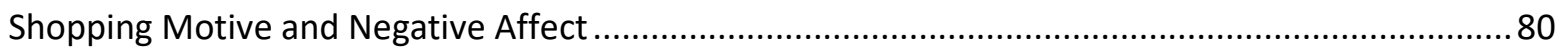

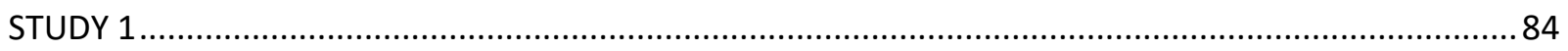

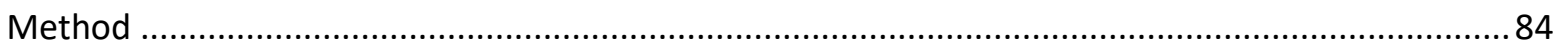

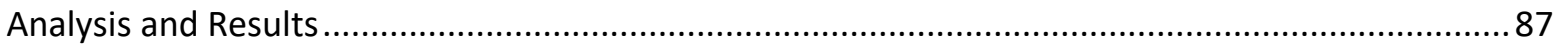

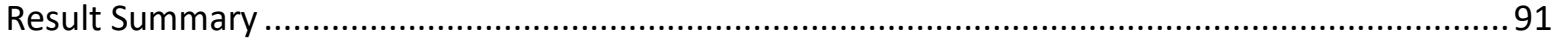

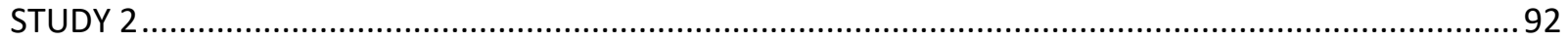

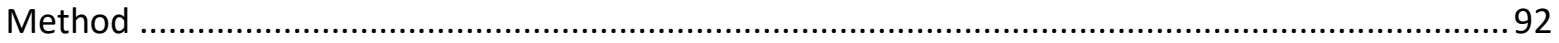

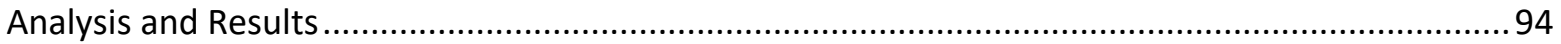

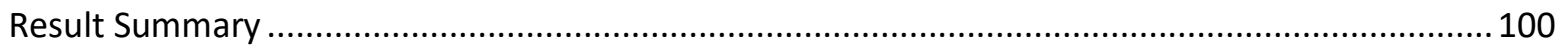

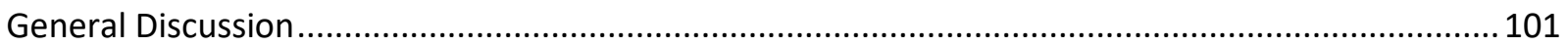

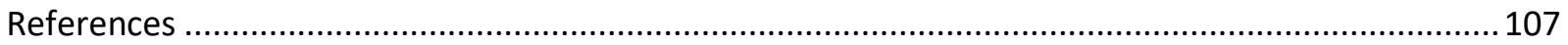




\section{Introduction}

In the past few decades, we have witnessed a growing body of literature on emotions in the consumer behavior domain. Emotions are defined as "mental states of readiness that arise from appraisals of events or one's own thoughts" (Bagozzi et al., 1999, p. 184). Marketers have examined the role of emotions as stimuli, mediators, moderators, and responses to the environment. The broad topic of emotions included subtopics such as the impact of emotions on consumption, attitudes, and behavioral intentions, emotional responses to market stimuli, and the impact of emotions on cognition. However, although the study of emotions is pivotal to consumer researchers, the literature mostly focuses on a few emotions.

In this dissertation, our focus is on two emotional states of shame and guilt. Unlike marketing literature, these two emotional states are commonly investigated together in psychology and sociology literature. However, there seems to be an overemphasis on guilt in the marketing literature, while shame has not benefitted from similar attention. Over three essays I summarize the literature on shame and guilt, examine these emotional states as mediators, and as interventions to induce behavior modification.

The first essay is a literature review, examining and summarizing the expansive literature pertaining to emotional states of shame and guilt. The goal of this essay is providing a deeper understanding of these two emotions and how they guide and shape consumer behavior. I discuss different conceptualizations of shame and guilt, and how they relate to perceptions of shame and guilt as negative emotions or moral emotions. Moreover, I draw connections between different factors that influence the positive or negative nature of shame and guilt consequences. Finally, I 
review different methods used to measure and manipulate these constructs and highlight each methods' weaknesses and strengths.

The second essay examines shame and guilt as attitudinal appeals. In this essay I discuss why consumer ethics is of increasing importance in the online world, and the fact that businesses have become more vulnerable to consumer misbehavior. The research aims to explore how shame and guilt can be used to induce compliance with social norms while attempting not to compromise attitudes towards the firm. Focusing on two appeal framings (i.e., rhetorical and narrative), I investigate which type of appeal is more effective with shame-based or guilt-based interventions.

The third essay explores shame and guilt as mediators. In this essay, shame and guilt are perceived as aversive states that mediate the effect of value congruence on online information search and purchase intention. In this essay, I note that contrary to previous literature, hedonic shopping motive is not the reason behind consumer's feelings of guilt. Guilt and shame are in fact, outcomes of a violation of values. Feelings of guilt are an outcome of private violation of values while shame is a consequence of public violation of values. However, in cases of values violation I expect hedonic shopping motive to be associated with higher levels of shame and guilt, but if there is no violation of value I don't expect any difference in emotional levels based on shopping motive. Finally, I posit that there will be a modification of online information search and examination of reviews based on feelings of shame and guilt. I expect individuals with high levels of guilt but not shame to read more reviews in order to find a justification for their valueviolating behavior. This behavior modification provides the necessary tools to reduce negative affect associated with feelings of guilt. 


\title{
Essay 1: Shame and Guilt
}

\author{
Raika Sadeghein
}




\begin{abstract}
I review a growing body of literature that examines the aversive emotions of shame and guilt and how they relate to behavioral outcomes. This review paper presents an overview of the different conceptualizations of shame and guilt, the distinction between these emotions, the consequences of the two, how they have been manipulated and measured in the literature, shame and guilt in marketing, and finally, how marketers and policy makers can help consumers properly cope with these emotions. The aim of this review is to provide a deeper understanding of these emotional states, their antecedents and consequences, and eventually find out areas where more research needs to be done.
\end{abstract}




\section{Introduction}

Consumer researchers have examined the role of various emotions on information processing, consumer judgement, intentions and behavior in the past decades. Shame and guilt are two aversive emotional states that cause pain and discomfort. The significance of emotions of shame and guilt in shaping behavior and their function as a moral compass is indisputable. There is an extensive body of literature on guilt, and its antecedents and consequences in the marketing literature. However, shame has not received the same level of attention. Literature in psychology posits that because emotions of shame and guilt are closely related, they should not be examined individually, or we would risk confounding the two emotions (Tangney \& Dearing, 2002). A detailed investigation on guilt literature in marketing verifies this point as many of the measures aimed at assessing guilt are indicative of experiences of shame. This indicates that many findings attributed to guilt, might in fact be associated with feelings of shame. As a result, it is critical to conduct a systematic review of shame and guilt literature, so we can disentangle these two emotional states. In this paper I strive to provide a deeper understanding of these emotions, and discuss how they can benefit consumers, marketers, and policy makers.

There are two views of emotions in psychology. While some believe that emotions are an outcome of evolutionary development of human species, others believe that emotions are socially and culturally constructed (Ellsworth, 1994). These two perspectives become important when considering whether there are cultural variations in how individuals experience emotions, especially for closely related emotions such as shame and guilt. Although the evolutionary development of emotions is an important stream of research, the focus of this paper is on social and cultural construction of shame and guilt and its consequences. 
Guilt and shame are self-conscious emotions that play a key role in shaping behavior (Tangney \& Dearing, 2002). Both emotions have been used for decades to enforce moral standards and deter undesirable and unethical behavior in societies. There has been considerable research devoted to the nature and implications of shame and guilt. However, there seems to be little agreement or success in terms of defining, distinguishing, and measuring these two emotions. A significant factor contributing to this disagreement is the primitive and non-verbal nature of these emotions (Lewis, 1971). Research shows that capturing emotions of shame and guilt is a difficult task for researchers mainly due to people's difficulty in identifying and articulating these emotions (Cohen, Wolf, Panter, \& Insko, 2011).

However, despite the lack of academic consensus with regards to conceptualization and operationalization of these two constructs, and people's inability to articulate emotions of shame and guilt, these emotions can be discriminated and universally experienced. A universalist orientation maintains that regardless of people's backgrounds they experience emotions in the same manner (Ekman \& Friesen, 1971). This is in keeping with research conducted by Breugelmans and Poortinga (2006) who examined whether a lack of distinct words for emotions of shame and guilt in a culture would translate into an inability to experience one of these emotions. To answer this question, Breugelmans and Poortinga (2006) conducted a cross-cultural study and used a sample of Raramuri Indians of northern Mexico, a sample of Javanese Indonesians, and a Dutch sample to establish construct equivalence across cultures. They chose the Raramuri sample due to a significant distinguishing factor, which was the fact that the Raramuri Indians do not have a word equivalent to guilt in their language. The findings indicate that even though the Raramuri Indians do not have a word for guilt and use the equivalent of shame for both emotions of shame and guilt, similar to the Javanese Indonesians and the Dutch, 
they do distinguish between emotion characteristics of shame and guilt. This finding provides support for the idea that shame and guilt are in fact two different emotions, and that emotion processes are similarly experienced regardless of the ability to articulate the emotions.

This review has three objectives: 1) to provide an overview of different conceptualizations of shame and guilt; 2) to review the literature on the consequences of these emotional states and introduce different measurements of shame and guilt; 3) to examine the shame and guilt literature in marketing and identify under-researched areas for future research.

\section{Defining Shame and Guilt}

There are three main schools of thought explaining and distinguishing between shame and guilt in psychology; 1) the self-discrepancy theory by Higgins (1987), 2) the work by Lewis (1971), and 3) the anthropological perspective. Scholars since then have attempted at examining, replicating, and extending these works.

Higgins's (1987) self-discrepancy theory posits that negative emotional responses are due to discrepancies between self-states. He writes about domains of the self and standpoints on the self to explain how these self-discrepancies result in negative states such as shame and guilt. Higgins divides domains of the self into three categories: the actual self, the ideal self and the ought self. The actual self is who you are; the ought-self is who you think you should be which involves your duties and responsibilities, and the ideal self is who you wish you could be which involves your hopes and aspirations. Consequently, standpoints on the self are categorized into two categories: own's stand point and significant others' standpoint. Based on this theory, shame is an outcome of a discrepancy between an individual's perception of his/her actual attributes (i.e., own's standpoint on actual self) and the ideal state or attributes wished for the individual by significant others (i.e., significant others' standpoint on ideal self). Guilt on the other hand, is an 
outcome of an inconsistency between an individual's perception of his/her actual attributes (i.e., own's standpoint on actual self) and the attributes the individual thinks he/she should acquire (i.e., own's standpoint on ought self) (Tangney, Niedenthal, Covert, \& Barlow, 1998).

The second school of thought involves Lewis's (1971) differentiation between shame and guilt that relates to whether the focus is on the behavior or the self. Based on her view, shame involves negative feelings about the self, whereas guilt deals with negative feelings about an action. In other words, when an individual feels shame, he/she would question and judge his/her entirety, but when someone feels guilt they would only self-criticize their behavior. Thus, shame involves global evaluation tendencies and guilt involves local evaluation tendencies (Han, Duhachek, \& Agrawal, 2014).

The final school of thought, the anthropological perspective, assumes situational factors to be the main predictors of emotions of shame and guilt (Tangney \& Dearing, 2002). In this viewpoint, what sets shame and guilt apart is the circumstances evoking emotions of shame and guilt. Some circumstances are assumed to be associated with feelings of guilt while others are believed to evoke feelings of shame (Perlman, 1958). A significant component of this distinction is the public versus private nature of these emotions. It is argued that shame is commonly experienced when public exposure is involved whereas guilt is experienced in one's own privacy (Gehm \& Scherer, 1988).

All theories are extensively used in numerous articles in a wide range of disciplines. However, each of these theories have their own limitations, and several authors have been unable to confirm these theories in their scholarly endeavors. One example of an article critiquing Higgins's (1987) theory is Tangney et al. (1998) paper. Tangney et al. (1998) found that, in contrast to Higgins's (1987) findings, all self-discrepancies are related to shame proneness and 
there is a significantly lower and even negligible relationship between guilt proneness and any self-discrepancy. The outcome of a combination of qualitative and quantitative, idiographic and nonidiographic measurement of shame and guilt indicated that consistent with Lewis's (1971) findings, guilt does not threaten the global self and the entirety of perceived self, but it negatively influences evaluations of a specific behavior having an emphasis on the wrongdoing and the consequences it might bear for others. Shame on the other hand involves self-condemnation, feelings of inferiority and unworthiness, directly relating to evaluations of self.

In contrast, Smith et al. (2002) is a proponent of Higgins's (1987) theory and argues that Lewis's (1971) distinction between shame and guilt based on an emphasis on behavior vs. self, is less than ideal because it changes the meaning of shame and guilt as noted in dictionaries backed by philosophical and scientific thinking. Smith et al. (2002) emphasize the need for a more comprehensive definition of shame where the individual experiencing shame "suffers other's disgust and anger as well as (one's) own self-loathing" (p 140). Based on dictionary definitions, what distinguishes shame and guilt is the public versus private aspect of these emotions. This distinction is consistent with the anthropological perspective which argues situations that induce shame are public, and guilt inducing situations are private. Therefore, the conceptualization of shame should be related to perceptions of damaged reputation due to public exposure of a misdeed (Smith et al., 2002). The authors relate these two aspects, the public and reputational aspect and the self-focused aspect highlighted by Lewis (1971), by noting that a person's reputation is a significant contributor to one's self perception. Consistent with this view, Smith et al. (2002) note that shame and guilt differ in that "shame results more from the public exposure of a defect, failure, or transgression" highlighting the significance of the public's perception as a 
differentiating factor between shame and guilt (p138). This is in keeping with Higgins's own (i.e, private) vs. significant others (i.e., public) standpoint

Moreover, Smith et al. (2002) critique the anthropological perspective by arguing that the content and structure of a situation cannot be accounted as the distinguishing factor between shame and guilt; the same situation can evoke feelings of shame or guilt. Similarly, Tangney et al. (1996) find that when narrative accounts of individuals experiencing shame and guilt are examined, there is not a significant difference between the audience of these two emotions. In fact, both emotions are commonly experienced in the presence of others (i.e., public). However, in line with Lewis's (1971) perspective, if the focus of the transgression is the self, feelings of shame emerge, but if the focus is on the malady of the transgression, feelings of guilt will be aroused.

Leach and Cidam (2015) note that the circumstances that are easiest to distinguish between shame and guilt are those where the wrongdoing is perceived as less reparable because, in these conditions, shame is negatively associated with constructive approach, while guilt is positively linked to constructive approach. They state that when the wrongdoing is perceived as reparable, individuals experiencing shame will behave similar to those experiencing guilt, participating in prosocial behavior.

Another point worth noting is the distinction between emotional states and dispositions. An emotional disposition involves inter-personal variation in people's ability to experience shame and guilt. This dispositional propensity is what we refer to as shame-proneness and guiltproneness (Tangney 1990). There are many factors contributing to emotional disposition to shame and guilt, some of which include temperament, parenting, and culture (Lagattuta \& Thompson, 2007). 
Brown et al. (2008) examined the impact of collective shame and guilt on reparation activities. The findings of their longitudinal study indicate that collective guilt positively influences reparative attitudes and activities towards outgroups in short term and long term, especially for individuals with low shame. Collective shame however, only influences short-term reparation activities. The reputational aspect of shame is greatly important to individuals experiencing collective shame as they feel their ingroup's reputation has been threatened. That's why the relationship between collective shame and prosocial behavior is mediated by desire to improve or maintain ingroup's reputation. As expected result showed that the impact of guilt was not mediated by the desire to maintain ingroups' reputation further supporting the personal nature of feelings of guilt.

Another area which has received little attention in the shame and guilt literature is how these negative emotions influence one another. Brown et al. (2008) investigate the influence of simultaneous feelings of shame and guilt. Tangney et al. (1992) had previously demonstrated the possibility of feeling shame and guilt at the same time by proposing guilt-free shame and shamefree guilt concepts. Brown et al. (2008) took their study to another level examining how these two feelings interact. The results of their study indicate that high levels of shame mitigate the positive impact of guilt on prosocial behavior. In other words, individuals with high levels of shame are more likely to turn to avoidance even in conditions of guilt. These studies are amongst the very few studies on the impact of simultaneous feelings of shame and guilt. Further research in this area can provide some valuable insights on how the interaction between these two feelings can be used in different settings and to affect different dependent variables.

Guilt is expected to lead to attempts at restitution to the victim, whereas shame is expected to result in avoidance and attempts at forgetting the shame causing incident 
(Niedenthal, Tangney, \& Gavanski, 1994). In addition, feelings of shame are expected to be more enduring and cause more pain because threats to self-image are harder to recover from compared to concerns for the badness of a misdeed (Tangney et al. 1996;Wicker, Payne, and Morgan 1983).

As a result, although according to Lewis (1971) individuals experiencing shame commonly resort to avoidance, if the individual can find a strategy to publicly atone their wrongdoing and redeem their public image, they would do so (Brown et al., 2008). This demonstrates the possibility of positive outcomes such as prosocial behavior as a result of shame.

The prevailing view on shame, considers it a negative emotion with undesirable consequences (Brown et al., 2008; Niedenthal et al., 1994; Tangney et al., 1992). However, de Hooge, Breugelmans, and Zeelenberg (2008) argue that contrary to popular belief, shame can have positive consequences such as motivation for prosocial behavior. They note that the endogeneity or exogeneity of the emotion influences the positive or negative consequences of a specific feeling. They propose that when the decision context and the shame-causing event are relevant (i.e., endogenous), shame acts as a commitment device motivating prosocial behavior. An example of an endogenous influence of shame could be consideration of becoming a foster parent for an individual who has made some wrong choices as a teenager growing up without parents. However, if the emotion-causing event is irrelevant to the decision context, it will be considered an exogenous emotion, leading to mainstream expectations of consequences of shame such as feeling of worthlessness, avoidance seeking, and lack of desire to redress.

Smith et al. (2002) note that "the moral emotions follow in part from the real effects the actions have on others, regardless of whether the veil of privacy is lifted ( $p$ 140). Thus, in the 
right circumstances, feelings of shame should have the same desirable consequences as other moral emotions such as guilt.

\section{Manipulation and Measurement}

Breugelmans and Poortinga (2006) used a range of cognitive, body sensations, and action tendencies characteristics to measure shame and guilt. They argued that this is the best option for cross-cultural comparison of emotions because it focuses on emotion processes which are similar across cultures and are not limited to differentiating emotion lexicons. They note five characteristics associated with shame: “(a) appraisals of being at the center of attention; (b) experiences of the self as confused, powerless, and small, and angry with others; (c) bodily sensations of blushing, feeling weak in the limbs, feeling warm, trembling, heart beating faster, and sweating; (d) action tendencies of avoiding the gaze of others, hiding oneself from others, and smiling about what happened; and (e) trying to forget about what happened", and four characteristics associated with guilt: “(a) appraisals of having done damage to someone, being responsible for what happened, experiencing the disapproval of others because of what one has done, harming one's reputation, having violated a social or moral norm, and deserving to be punished; (b) experiences of oneself as a bad person and anger at oneself; (c) action tendencies of apologizing, changing future behavior, explaining what happened to others, and punishing oneself; and (d) ruminating about what happened" (p 1114).

Higgins (1987) argued against use of nonidiographic approaches to measure selfdiscrepancies. He noted that in such approaches the adjectives checklist provided by the researcher might bias participant's responses. He explains that many of these adjectives might not be relevant or accessible to respondents without the checklist, which might lead them to provide unreliable responses. He suggests using idiographic approach to measure self-concepts 
through a qualitative Selves Questionnaire (Higgins, Klein, \& Strauman, 1985). In this questionnaire, respondents are asked to list a number of traits and attributes with regards to different self-states (i.e. actual, ought, and ideal self) from their own standpoint and from the standpoint of their significant others (e.g., their parents and close friends). Based on the type of self-discrepancies stated by respondents, he then concludes which negative emotions they are prone to (e.g., shame is a result of a self-discrepancy between an individual's own perception of their actual self and other's perception of the individual's ideal self).

Tangney et al. (1998) measured shame and guilt with four different approaches. The first approach was a quantitative approach using TOSCA (Test of Self-Conscious Affect), which is a scenario-based measure, developed by Tangney, Wagner, and Gramzow (1989) to measure shame and guilt proneness. The second method was Higgins, Klein, and Strauman (1985) qualitative Selves Questionnaire. The third approach was using an adjective ratings list were participants were given 60 adjectives and were asked to rate how accurately the adjective described them on a scale of 1 to 7 . This method was used as a comparison tool with Higgins et al.'s (1989) qualitative method to measure self-discrepancies and to infer shame and guilt. Finally, they used Symptom Checklist 90 (SCL-90) developed by (Derrogatis, Lipman, \& Covi, 1973) which asks respondents to report on 90 clinical symptoms on a 5-point scale.

Brown et al. (2008) measured guilt and shame on a collective rather than an individual level. They asked participant to rate their agreement (disagreement) with regards to shame and guilt statements such as "I feel guilty for the manner in which the Mapuche have been treated in the past by "Non-Indigenous" Chileans" (p 80).

Many scholars prime shame and guilt by asking the participants to report an incident where they felt shame and guilt (Agrawal \& Duhachek, 2010; Duhachek, Agrawal, \& Han, 
2012). Some take it a step further and examine these personal accounts to define these constructs and find aspects which distinguish these two feelings. The findings indicate that contrary to the public/private nature of shame and guilt perspective, most of the participant's accounts contain public experiences of guilt (Tangney et al., 1996). However, according to Smith et al. (2002), the problem rests in the method rather than the conceptualization. They note that participants are more likely to disclose public experiences of guilt because they are not willing to publicly admit to and confess their secret wrongdoings (i.e., incidents experienced in private). In addition, they note that these private memories might also be less salient because, as noted earlier, feelings of guilt are not as enduring and painful as feelings caused by public exposure of misdeeds.

Thus, Smith et al. (2002) measured shame and guilt-related reactions. For shame, they measured a) reactions linked to public exposure, b) reactions linked to the self, and c) anger. Reactions linked to public exposure were measured with a six-item scale where participants were asked about bodily changes that occur due to public exposure of a misdeed (e.g., racing heart rate, sweatiness, and shaking), and a four-item scale related to a desire to hide from public (e.g., a desire to be alone and a desire to escape public exposure). Reactions linked to the self was measured with six items reflecting feelings of inferiority (e.g., self-respect decrease, defective, inferior to others). They assessed anger towards others with measures such as angry at others, vengeful, and blaming others.

Shame measurements reflected different aspects of shame. For instance, private reactions to a misdeed was measured with items such as guilty conscience, and inwardly troubled. Another aspect examined whether the participants perceived the action to represent the real self or not (i.e. the action did not reflect the real self). In addition, two items evaluated concerns regarding harm to others due to a wrong doing (e.g., thought others were hurt). Finally, seeking redress 
was measured by 5 items such as a desire to undo what was done, wanting to set things right, and a desire to make amends (Smith et al., 2002).

\section{Shame and Guilt in Marketing}

As mentioned above, prior research in marketing has extensively examined the emotion of guilt, its antecedents and consequences. However, shame has not received the same level of attention. Literature in psychology posits that because emotions of shame and guilt are closely related, they should not be examined individually, or we would risk confounding the two emotions (Tangney \& Dearing, 2002). A quick overview of guilt literature in marketing confirms this point, as many of the measures aimed at assessing guilt are indicative of experiences of shame (see Table 1). There are numerous articles that have assessed guilt without consideration for shame, and in the process have failed to take into account the distinctions between shame and guilt. For example Cotte, Coulter, and Moore's (2005) measurement of guilt includes items such as "irresponsible" and "ashamed" which measure shame and not guilt. Lee-Wingate and Corfman (2010) have developed their own scale to measure guilt with items such as "hesitant" and "reluctant" which are not theoretically consistent with or representative of any conceptualization of guilt. Steenhaut and Kenhove's (2006) measure of anticipated guilt includes "I would avoid meeting people's gaze" that touches on the avoidance seeking which is a major component of shame. This indicates that many findings attributed to guilt in marketing, might in fact be associated with feelings of shame. This significantly limits our ability to contribute knowledge regarding these aversive states. Thus, a comprehensive review of these two emotions in the marketing literature is of great importance.

A first step towards this comprehensive review can be an investigation of academic papers in marketing that include both emotions of shame and guilt in their scholarly work, and 
properly measure these constructs. Bennett (1998) was the first marketing scholar to measure shame and guilt as an outcome of guilt-inducing advertisements. As expected, he found that consistent with psychology literature, consumers react differently to message content based on feelings of shame and guilt. However, it wasn't until a decade later, that measuring shame and guilt simultaneously became more common. Use of shame and guilt as pro-attitudinal and counter-attitudinal emotional appeal has become popular among scholars in recent years. Negative emotional appeals have been long studied in the literature as a means to persuade consumers to comply with socially desirable norms and to induce certain behavior such as quitting smoking or mindfully consuming alcohol (Agrawal \& Duhachek, 2010; Duhachek et al., 2012; Kees, Burton, Andrews, \& Kozup, 2010). Brennan and Binney (2010) conducted a qualitative study examining the impact of negative emotional appeals (i.e., shame, guilt, and fear) on income support recipients. Their findings indicate that negative appeals result in inaction and activation of self-protection, which works against consumer well-being.

Duhachek et al. (2012) note that, the fact that some negative emotional appeals have proven to be ineffective, might be a result of a boundary condition scholars have missed. They conducted a study examining the impact of shame and guilt appeals on effectiveness of loss or gain framing. They note that guilt is associated with high levels of self-efficacy which invokes problem-focused coping strategies, whereas shame is linked to low levels of self-efficacy which is associated with emotion focused coping. Consequently, problem focused coping has been shown to be associated with desire to alter the circumstances, while, emotion focused coping is associated with attempts to regulate emotions. The authors found that, the match between framing and emotion is a determinant of an appeal's effectiveness. When guilt appeals are paired with gain frames, they become more effective because gain frames facilitate the activation of 
problem focused appeals. Shame appeals, on the other hand, were shown to be more effective when paired with loss frames as they activate emotion focused appeals.

Agrawal and Duhachek (2010) examined the impact of compatible appeals (i.e., appeals that arouse the same emotions as the individual's incidental emotional state) on behavioral intentions. The authors suggest that compatibility of the message frame and the incidental negative emotion (i.e., shame or guilt) reduces the persuasiveness and effectiveness of the message. This is contrary to popular belief that compatibility enhances persuasion. They argue that people who are experiencing a negative emotional state tend to guard against and resist more of the same type of emotion, thus reducing the effectiveness of compatible messages. They call this mechanism "defensive processing" (p. 265). One of the outcomes of defensive processing is that individuals believe that others, unlike them, are susceptible to the negative outcomes shown in the emotional appeal. This is due to their distorted perception that they will not behave in a way that would induce more of the same type of emotion (i.e., shame or guilt). Moreover, they propose that defensive processing works as a coping strategy reducing the level of negative emotional state. In other words, the defensive processing activated by compatible message framing works as a repair mechanism to relieve some of the individual's existing negative emotions.

Bennett (1998) finds that, generally, guilt appeals are more effective and are more likely to result in desirable outcomes and compliance due to invoking feelings of empathy. Bagozzi and Moore (1994) note that if negative emotions result in empathy, the desire to help others increase, thus, higher likelihood of prosocial behavior. However, many of the advertising campaigns aimed at arousing feelings of guilt, actually result in feelings of shame in the target market which brings about negative behavior (Brennan \& Binney, 2010). 
Brennan and Binney (2010) note that targets of emotional appeals follow the emotional process proposed by Lazarus (1991), where individuals evaluate the harm and benefits after a threat before identifying and using an emotional response. However, the coping response adopted, is generally emotion focused rather than problem focused which induces "anger, retreat, and despondency" (Brennan \& Binney, 2010, p. 145). Their qualitative study indicates that use of negative emotional appeals can backfire, resulting in lower compliance and causing an array of emotions ranging from helplessness to active anger.

Despite the evidence mentioned earlier regarding the negative consequences of shame (e.g., inaction, avoidance, and anger), shame has been found to have some positive outcomes. Shame has been linked to promotion-focused motivation, empathy, cooperation, selfimprovement and prosocial motivation (de Hooge et al., 2008; de Hooge, Zeelenberg, \& Breugelmans, 2010; Leach \& Cidam, 2015). Leach and Cidam (2015) propose that there is a boundary condition to shame resulting in constructive approach that is commonly ignored. They find that shame can be constructive and result in desirable outcomes if the failure or the selfimage are perceived as reparable. These findings are consistent with those of Brown et al. (2008) who found that shame results in prosocial behavior if the transgressor is able to publicly atone their wrongdoing.

Conclusions from a study conducted by Gausel and Leach (2011) is similar to that in Brown et al. (2008) and Leach and Cidam (2015). The authors investigated in which conditions moral failure results in self-defensive motivation, and in which conditions it results in selfimprovement motivation. The authors argue that the current conceptualization of shame is rather ambiguous, and as a result, we assume that shame only results in self-protection motivations. However, they propose a new way of conceptualizing shame which distinguishes between two 
appraisals (i.e., self-defect and other condemnation), and three feelings (i.e., rejection, inferiority, and shame).

They note that individuals who are usually concerned with their self-image generally perceive a moral failure as a self-defect. However, this self-defect can also be divided into global and specific self-defect. If the individual is experiencing a global self-defect, which is what is presumed in the literature to be associated with shame, they encounter feelings of inferiority. Feelings of inferiority are extremely aversive and result in a desire to defend the self. Unfortunately, due to high levels of self-reproach involved in this emotional state, individuals are unable to make any changes or even escape the damage to their global self-image. Thus, they are left with nothing but self-criticism (Gausel \& Leach, 2011).

In contrast, individuals experiencing specific self-defect are suffering from an explicit defect threatening one's self-image, which if resolved, can ease negative emotions associated with that self-defect. Therefore, in these circumstances we expect individuals experiencing shame to adopt a self-improvement coping strategy to repair their self-image. The major difference between the specific and the global self-defect is the perceived repairability of the self-image. Contrary to specific self-defect, individuals suffering from global self-defect, believe their self-image is irreparable, thus resulting in inaction (Gausel \& Leach, 2011).

For those experiencing condemnation by others, feelings of rejection emerge. These individuals suffer threats to social-image rather than self-image. As self-improvement in these circumstances is not as helpful as circumstances of threatened self-image, they resort to selfdefensive responses, trying to protect themselves against further damage (Gausel \& Leach, 2011). 
Consequences of guilt are more similar to those of specific self-defect. As noted by Lewis (1971), the focus of guilt is the misdeed itself rather than the self-image. Since there is no threat to an individual's self-identity, redress is much easier. As a result, we see individuals experiencing shame adopt a self-improvement motivation to reform, repair and improve their social relations (Gausel \& Leach, 2011).

\section{Conclusion}

Marketing's reliance on the field of psychology is an undeniable fact. Marketing scholars commonly borrow theories from psychology and adapt it to marketing phenomena. This helps marketers move beyond predominant paradigms in their fields and enhance their ability to contribute to the knowledge base of marketing. Surprisingly, one of the areas that has been relatively untapped is the emotional state of shame. In psychology literature shame and guilt are always used together. However, we do not see a similar balance in the marketing literature. One of the reasons that shame has not been widely used in the marketing literature might be due to the highly aversive nature of this emotion which seems to be at odds with what marketers and practitioners deem appropriate. Another contributing factor could be measurement difficulty of these emotions. Tangney and Dearing (2002) note that distinguishing shame and guilt as abstract constructs is difficult even for highly educated adults. As a result, many adjective checklists that attempt at measuring shame and guilt prove to be ineffective. This poses a threat to discriminant validity, and thus many scholars avoid approaching these emotions in general.

However, with the advent of the Internet and smartphones, we have entered an era where shaming is increasingly used by different entities; from regular people, to business owners, and even government representatives (Blumentha, 2015; Krieg, 2016; Rosenberg, 2018). As a result, there is a growing need for a deeper understanding of the underpinning of this emotional state. 
Table 1- Shame and Guilt in Past Marketing Research

\begin{tabular}{|c|c|c|c|}
\hline $\begin{array}{l}\text { Self-Conscious } \\
\text { Emotion }\end{array}$ & Measurement & DV & Citation \\
\hline Guilt & $\begin{array}{l}\text { Guilty } \\
\text { Irresponsible } \\
\text { Accountable } \\
\text { Ashamed }\end{array}$ & $\begin{array}{l}\text { Attitudes toward the ad, } \\
\text { attitudes toward the } \\
\text { sponsor, corporate } \\
\text { attributions. }\end{array}$ & Cotte et al. (2005) \\
\hline Guilt & $\begin{array}{l}\text { I feel guilty about not } \\
\text { helping. } \\
\text { I feel bad about doing } \\
\text { nothing to help the } \\
\text { child/children. }\end{array}$ & $\begin{array}{l}\text { Responsibility, empathy, } \\
\text { prosocial behavior }\end{array}$ & $\begin{array}{l}\text { Basil, Ridgway, and } \\
\text { Basil (2006) }\end{array}$ \\
\hline Guilt & $\begin{array}{l}\text { Guilty } \\
\text { Sorry } \\
\text { Regretful } \\
\text { Uneasy } \\
\text { Hesitant } \\
\text { Reluctant }\end{array}$ & $\begin{array}{l}\text { Deal satisfaction, deal } \\
\text { evaluation, purchase } \\
\text { intentions }\end{array}$ & $\begin{array}{l}\text { Lee-Wingate and } \\
\text { Corfman (2010) }\end{array}$ \\
\hline Guilt & $\begin{array}{l}\text { Guilty } \\
\text { Sorry } \\
\text { Regretful } \\
\text { Uneasy } \\
\text { Hesitant } \\
\text { Reluctant }\end{array}$ & $\begin{array}{l}\text { Purchase likelihood of } \\
\text { utilitarian vs. hedonic } \\
\text { products }\end{array}$ & Choi et al. (2014) \\
\hline Guilt & $\begin{array}{l}1=\text { no guilt at all and } 7 \\
=a \text { lot of guilt } \\
1=\text { no remorse at all } \\
\text { and } 7=\text { a lot of remorse }\end{array}$ & $\begin{array}{l}\text { Preference for products } \\
\text { promoted using ethical } \\
\text { appeals }\end{array}$ & $\begin{array}{l}\text { Peloza, White, and } \\
\text { Shang (2013) }\end{array}$ \\
\hline Guilt & $\begin{array}{l}\text { I would feel remorse } \\
\text { I would feel tension } \\
\text { I would think that I } \\
\text { should not have done } \\
\text { what I did } \\
\text { I would think that I did } \\
\text { something wrong } \\
\text { I would feel like } \\
\text { punishing myself I } \\
\text { would apologize } \\
\text { I would avoid meeting } \\
\text { people's gaze }\end{array}$ & Ethical Intentions & $\begin{array}{l}\text { Steenhaut and } \\
\text { Kenhove (2006) }\end{array}$ \\
\hline
\end{tabular}




\begin{tabular}{|c|c|c|c|}
\hline Guilt & $\begin{array}{l}\text { Mentions of guilt in } \\
\text { self-report anticipation } \\
\text { of feelings (people } \\
\text { can't differentiate } \\
\text { between shame and } \\
\text { guilt) }\end{array}$ & Regret & $\begin{array}{l}\text { Kivetz and Keinan } \\
\text { (2006) }\end{array}$ \\
\hline Guilt & $\begin{array}{l}\text { I regretted making } \\
\text { purchases that I wasn't } \\
\text { unable to justify } \\
\text { logically } \\
\text { I felt guilty when I } \\
\text { made impulse } \\
\text { purchases } \\
\text { I felt guilty when } \\
\text { considering luxurious } \\
\text { products and services } \\
\text { that are pleasurable but } \\
\text { not necessary }\end{array}$ & Willingness to buy & $\begin{array}{l}\text { Mishra and Mishra } \\
\text { (2011) }\end{array}$ \\
\hline Guilt & $\begin{array}{l}\text { how guilty did you feel } \\
\text { about sampling the } \\
\text { snack? }\end{array}$ & $\begin{array}{l}\text { Self-control, willingness to } \\
\text { pay, vitality, creativity }\end{array}$ & $\begin{array}{l}\text { Chen and Sengupta } \\
\text { (2014) }\end{array}$ \\
\hline Guilt & $\begin{array}{l}\text { how would you feel } \\
\text { after eating two ounces } \\
\text { of the product? }(1=\text { not } \\
\text { guilty, } 9=\text { guilty })\end{array}$ & Consumption Volume & $\begin{array}{l}\text { Wansink and } \\
\text { Chandon (2006) }\end{array}$ \\
\hline $\begin{array}{l}\text { Shame and } \\
\text { Guilt }\end{array}$ & $\begin{array}{l}\text { Guilt } \\
\text { I feel tension about } \\
\text { something I have done } \\
\text { I cannot stop thinking } \\
\text { about something I have } \\
\text { done } \\
\text { I feel guilty } \\
\text { I feel bad about } \\
\text { something I have done } \\
\text { Shame: } \\
\text { I want to sink into the } \\
\text { floor and disappear } \\
\text { I feel ashamed } \\
\text { I feel like I am bad } \\
\text { person } \\
\text { I feel embarrassed }\end{array}$ & $\begin{array}{l}\text { Anger, perceived } \\
\text { manipulative intent, } \\
\text { perceived argument quality }\end{array}$ & $\begin{array}{l}\text { Boudewyns, Turner, } \\
\text { and Paquin (2013) }\end{array}$ \\
\hline
\end{tabular}




\begin{tabular}{|c|c|c|c|}
\hline $\begin{array}{l}\text { Shame and } \\
\text { Guilt }\end{array}$ & $\begin{array}{l}\text { TOSCA } \\
\text { Guilt: (Blameworthy, } \\
\text { Guilty, Apologetic, } \\
\text { Regretful, Repentant, } \\
\text { Liable) } \\
\text { Shame: (Ashamed, } \\
\text { Self-conscious, Angry, } \\
\text { Inadequate, Disgusted, } \\
\text { Embarrassed) }\end{array}$ & $\begin{array}{l}\text { Empathetic Response, } \\
\text { conative response }\end{array}$ & Bennett (1998) \\
\hline $\begin{array}{l}\text { Shame and } \\
\text { Guilt }\end{array}$ & $\begin{array}{l}\text { Guilt: (guilt-ridden, } \\
\text { culpable, and } \\
\text { remorseful) } \\
\text { Shame: (embarrassed, } \\
\text { ashamed, and } \\
\text { humiliated) }\end{array}$ & $\begin{array}{l}\text { Message persuasiveness, } \\
\text { message recall, defensive } \\
\text { processing, alcohol } \\
\text { consumption, }\end{array}$ & $\begin{array}{l}\text { Agrawal and } \\
\text { Duhachek (2010) }\end{array}$ \\
\hline $\begin{array}{l}\text { Shame and } \\
\text { Guilt }\end{array}$ & $\begin{array}{l}\text { Guilt: (guilt ridden, } \\
\text { culpable, and } \\
\text { remorseful) } \\
\text { Shame: (ashamed and } \\
\text { humiliated) }\end{array}$ & $\begin{array}{l}\text { Message Effectiveness, } \\
\text { emotion-focused coping, } \\
\text { problem-focused coping, } \\
\text { message fluency }\end{array}$ & $\begin{array}{l}\text { Duhachek, Agrawal, } \\
\text { and Han (2012) }\end{array}$ \\
\hline $\begin{array}{l}\text { Shame and } \\
\text { Guilt }\end{array}$ & $\begin{array}{l}\text { Guilt: (guilt ridden, } \\
\text { culpable, and } \\
\text { remorseful) } \\
\text { Shame: (ashamed and } \\
\text { humiliated) }\end{array}$ & $\begin{array}{l}\text { Local appraisal tendency, } \\
\text { global appraisal tendency, } \\
\text { construal level, choice }\end{array}$ & $\begin{array}{l}\text { Han, Duhachek, and } \\
\text { Agrawal (2014) }\end{array}$ \\
\hline $\begin{array}{l}\text { Shame and } \\
\text { Guilt }\end{array}$ & NA (Qualitative) & Compliance & $\begin{array}{l}\text { Brennan and Binney } \\
\text { (2010) }\end{array}$ \\
\hline
\end{tabular}




\section{References:}

Achar, C., So, J., Agrawal, N., \& Duhachek, A. (2016). What We Feel and Why We Buy: The Influence of Emotions on Consumer Decision-Making. Current Opinion in Psychology, 10, 166-170. http://doi.org/10.1016/j.copsyc.2016.01.009

Adaval, R. (2001). Sometimes It Just Feels Right: The Differential Inconsistent Product Information. Journal of Consumer Research, 28(june), 1-17.

Agrawal, N., \& Duhachek, A. (2010). Emotional Compatibility and the Effectiveness of Antidrinking Messages: A Defensive Processing Perspective on Shame and Guilt. Journal of Marketing Research, 47(2), 263-273. http://doi.org/10.1509/jmkr.47.2.263

Alba, J. W., \& Williams, E. F. (2012). Pleasure principles: A review of research on hedonic consumption. Journal of Consumer Psychology, 23(1), 2-18. http://doi.org/10.1016/j.jcps.2012.07.003

Ambrose, M., Hess, R. L., \& Ganesan, S. (2007). The Relationship Between Justice and Attitudes: An Examination of Justice Effects on Event and System-Related Attitudes. Organizational Behavior and Human Decision Processes, 103(1), 21-36. http://doi.org/10.1016/j.obhdp.2007.01.001

Babin, B., Darden, W., \& Griffin, M. (1994). Work and/or fun: measuring hedonic and utilitarian shopping value. Journal of Consumer Research, 20(March 1994), 644-657. Retrieved from http://www.jstor.org/stable/2489765

Bagozzi, R. P., Gopinath, M., \& Nyer, P. U. (1999). The Role of Emotions in Marketing. Journal of Academy of Marketing Science, 27(2), 184-206. http://doi.org/10.1001/jama.1953.03690150021006

Bagozzi, R. P., \& Moore, D. J. (1994). Public Service Advertisements : Emotions and Empathy Gimle Prosocial Behavior. Journal of Marketing, 58(January), 56-70. http://doi.org/10.2307/1252251

Basil, D. Z., Ridgway, N. M., \& Basil, M. D. (2006). Guilt Appeals : The Mediating Effect of Responsibility. Psychology \& Marketing, 23(12), 1035-1054. http://doi.org/10.1002/mar

Bauer, M. R. (2016). To get people to use less electricity, utility providers are employing guilt and peer pressure. Retrieved from https://qz.com/812649/electric-companies-are-guiltingcustomers-into-using-less-electricity/

Bellini, J. (2013). Apparently This Matters: ReviewerCard. Retrieved from https://www.cnn.com/2013/01/25/tech/social-media/apparently-this-mattersreviewercard/index.html

Bennett, R. (1998). Shame, guilt, \& responses to non-profict \& public sector ads. International Journal of Advertising, 17(4), 483-499. http://doi.org/10.1080/02650487.1998.11104734

Blumentha, R. L. (2015). Michael Scelfo Publicly Lays the Smackdown on Entitled Alden \& Harlow Non-Customers. Retrieved from https://boston.eater.com/2015/2/28/8126023/michael-scelfo-publicly-lays-the-smackdownon-entitled-alden-harlow\#4162106 
Boudewyns, V., Turner, M. M., \& Paquin, R. S. (2013). Shame-Free Guilt Appeals: Testing the Emotional and Cognitive Effects of Shame and Guilt Appeals. Psychology \& Marketing, 30(9), 811-825. http://doi.org/10.1002/mar

Braverman, J. (2008). Testimonials Versus Informational Persuasive Messages. Communication Research, 35(5), 666-694.

Brennan, L., \& Binney, W. (2010). Fear, guilt, and shame appeals in social marketing. Journal of Business Research, 63(2), 140-146. http://doi.org/10.1016/j.jbusres.2009.02.006

Breugelmans, S. M., \& Poortinga, Y. H. (2006). Emotion without a word: shame and guilt among Rarámuri Indians and rural Javanese. Journal of Personality and Social Psychology, 91(6), 1111-1122. http://doi.org/10.1037/0022-3514.91.6.1111

Brockner, J., \& Wiesenfeld, B. M. (1996). An Integrative Framework for Explaining Reactions to Decisions : Interactive Effects of Outcomes and Procedures. Psychological Bulletin, 120(2), 189-208.

Brown, R., González, R., Zagefka, H., Manzi, J., \& Cehajic, S. (2008). Nuestra culpa: collective guilt and shame as predictors of reparation for historical wrongdoing. Journal of Personality and Social Psychology, 94(1), 75-90. http://doi.org/10.1037/0022-3514.94.1.75

Bruner, J. S. (2009). Actual minds, possible worlds. Harvard University Press.

Buchanan, D. R. (2008). Autonomy, Paternalism, and Justice : Ethical Priorities in Public Health. Health Policy and Ethics, 98(1), 15-21. http://doi.org/10.2105/AJPH

Cheema, A., \& Bagchi, R. (2011). The Effect of Goal Visualization on Goal Pursuit : Implications for Consumers and Managers. Journal of Marketing, 75(2), 109-123.

Chen, F., \& Sengupta, J. (2014). Forced to Be Bad: The Positive Impact of Low-Autonomy Vice Consumption on Consumer Vitality. Journal of Consumer Research, 41(4), 1089-1107. http://doi.org/10.1086/678321

Choi, J., Li, Y. J., Rangan, P., Chatterjee, P., \& Singh, S. N. (2014). The Odd-Ending Price Justification Effect: The Influence of Price-Endings on Hedonic and Utilitarian Consumption. Journal of the Academy of Marketing Science, 42(5), 545-557. http://doi.org/10.1007/s11747-014-0369-6

Cohen, T. R., Wolf, S. T., Panter, A. T., \& Insko, C. A. (2011). Introducing the GASP scale: A new measure of guilt and shame proneness. Journal of Personality and Social Psychology, 100(5), 947-966. http://doi.org/10.1037/a0022641

Cotte, J., Coulter, R. A., \& Moore, M. (2005). Enhancing or disrupting guilt: The role of ad credibility and perceived manipulative intent. Journal of Business Research, 58(3 SPEC. ISS.), 361-368. http://doi.org/10.1016/S0148-2963(03)00102-4

de Hooge, I. E., Breugelmans, S. M., \& Zeelenberg, M. (2008). Not so ugly after all: when shame acts as a commitment device. Journal of Personality and Social Psychology, 95(4), 933-943. http://doi.org/10.1037/a0011991

de Hooge, I. E., Zeelenberg, M., \& Breugelmans, S. M. (2010). Restore and protect motivations 
following shame. Cognition and Emotion, 24(1), 111-127.

http://doi.org/10.1080/02699930802584466

De Wit, J. B. F., Das, E., \& Vet, R. (2008). What works best: Objective statistics or a personal testimonial? An assessment of the persuasive effects of different types of message evidence on risk perception. Health Psychology, 27(1), 110-115. http://doi.org/10.1037/02786133.27.1.110

Dennis, S. (2018). The Ticking Time Bomb Of E-commerce Returns. Retrieved October 31, 2018, from https://www.forbes.com/sites/stevendennis/2018/02/14/the-ticking-time-bombof-e-commerce-returns/\#5e0af1f04c7f

Derrogatis, L. R., Lipman, R. S., \& Covi, I. (1973). The SCL-90: An outpatient psychiatric rating scale. Psychopharmacology Bulletin, 9, 13-28.

Dhar, R., \& Wertenbroch, K. (2000). Consumer Choice Between Hedonic and Utilitarian Goods. Journal of Marketing Research, 37(1), 60-71. http://doi.org/10.1509/jmkr.37.1.60.18718

Duhachek, A., Agrawal, N., \& Han, D. (2012). Guilt Versus Shame: Coping, Fluency, and Framing in the Effectiveness of Responsible Drinking Messages. Journal of Marketing Research, 2437, 1-14. http://doi.org/10.1509/jmr.10.0244

Ekman, P., \& Friesen, W. V. (1971). CONSTANTS ACROSS CULTURES IN THE FACE AND EMOTION. Journal of Personality and Social Psychology, 17(2), 124-129.

Ellsworth, P. C. (1994). Sense, culture, and sensibility. Emotion and Culture: Empirical Studies of Mutual Influence. http://doi.org/10.1037/10152-001

Gausel, N., \& Leach, C. W. (2011). Concern for self-image and social image in the management of moral failure: Rethinking shame. European Journal of Social Psychology, 41(4), 468478. http://doi.org/10.1002/ejsp.803

Gefen, D., Karahanna, E., \& Straub, D. W. (2003). Trust and TAM in Online Shopping: An Integrated Mode. MIS Quarterly, 27(1), 51-90. http://doi.org/10.1017/CBO9781107415324.004

Gehm, T. L., \& Scherer, K. R. (1988). Relating situation evaluation to emotion differentiation: Nonmetric analysis of cross-cultural questionnaire data. In Facets of Emotion: Recent Research (pp. 61-77). Hillsdale, NJ: Erlbaum.

Goswami, S. (2014). Shaming Punishments. In The Encyclopedia of Criminology and Criminal Justice (pp. 2110-2115). http://doi.org/10.1177/0192513X12437708

Gray, J. B., Carolina, N., \& Harrington, N. G. (2011). Narrative and Framing : A Test of an Integrated Message Strategy in the Exercise Context. Journal of Health Communication, 16, 264-281. http://doi.org/10.1080/10810730.2010.529490

Green, M. C., \& Brock, T. C. (2002). In the mind's eye: Transportation-imagery model of narrative persuasion. In M. C. Green, J. J. Strange, \& T. C. Brock (Eds.), Testimonial impact: Social and cognitive foundations (pp. 315-342). Mahwah, NJ: Lawrence Erlbaum Associates. 
Gregoire, Y., \& Fisher, R. J. (2006). The effects of relationship quality on customer retaliation. Marketing Letters, 17, 31-46. http://doi.org/10.1007/s11002-006-3796-4

Hampton, J. (1984). The Moral Education Theory of Punishment. Philosophy \& Public Affairs, 13(3), 208-238.

Han, D., Duhachek, A., \& Agrawal, N. (2014). Emotions Shape Decisions through Construal Level : The Case of Guilt and Shame. Journal of Consumer Research, 41(4), 1047-1064. http://doi.org/10.1086/678300

Hayes, A. F. (2013). Introduction to Mediation, Moderation, and Conditional Process Analysis. New York, NY: The Guilford Press.

Higgins, E. T. (1987). Self-discrepancy: A theory relating self and affect. Psychological Review, 94(3), 319-340. http://doi.org/10.1037//0033-295X.94.3.319

Higgins, E. T., Klein, R., \& Strauman, T. (1985). Self-concept discrepancy theory: A psychological model for distinguishing among different aspects of depression and anxiety. Social Cognition, 3(1), 51. http://doi.org/10.1521/soco.1985.3.1.51

Homer, P. M. (1995). Ad Size as an Indicator of Perceived Advertising Costs and Effort: The Effects on Memory and Perceptions. Journal of Advertising, 24(4), 1-12.

Inman, J. J., Winer, R. S., \& Ferraro, R. (2009). The Interplay Among Category Characteristics , Customer Characteristics, and Customer Activities on In-Store Decision Making. Journal of Marketing, 73(September), 19-29.

Kalnikaite, V., Bird, J., \& Rogers, Y. (2013). Decision-making in the aisles: Informing, overwhelming or nudging supermarket shoppers? Personal and Ubiquitous Computing, 17(6), 1247-1259. http://doi.org/10.1007/s00779-012-0589-z

Kees, J., Burton, S., Andrews, J. C., \& Kozup, J. (2010). Understanding How Graphic Pictorial Warnings Work on Cigarette Packaging. Journal of Public Policy \& Marketing, 29(2), 265276. http://doi.org/10.1509/jppm.29.2.265

Khan, U., Dhar, R., \& Wertenbroch, K. (2005). A Behavioral Decision Theoretic Perspective on Hedonic and Utilitarian Choice. Inside Consumption: Frontiers of Research on Consumer Motives, Goals, and Desires, 1, 144-165.

Kivetz, R., \& Keinan, A. (2006). Repenting Hyperopia: An Analysis of Self-Control Regrets. Journal of Consumer Research, 33(2), 273-282. http://doi.org/10.1086/506308

Kivetz, R., \& Simonson, I. (2002). Earning the Right to Indulge : Effort as a Determinant of Customer Preferences Toward Frequency Program Rewards. Journal of Marketing Research, XXXIX(May), 155-170.

Krieg, G. (2016). How to make "deadbeat dads" pay in 140 characters or less. Retrieved January 3, 2019, from https:/www.cnn.com/2016/01/12/politics/deadbeat-dad-tweetsarizona/index.html

Kronrod, A., \& Danziger, S. (2013). “Wii Will Rock You!” The Use and Effect of Figurative Language in Consumer Reviews of Hedonic and Utilitarian Consumption. Journal of 
Consumer Research, 40(4), 726-739. http://doi.org/10.1086/671998

Lagattuta, K. H., \& Thompson, R. A. (2007). The development of self-conscious emotions: Cognitive processes and social influences. New York, NY: The Guilford Press.

Lazarus, R. S. (1991). Progress on a cognitive-motivational-relational theory of emotion. The American Psychologist, 46(8), 819-834. http://doi.org/10.1037/0003-066X.46.8.819

Leach, C. W., \& Cidam, A. (2015). When is shame linked to constructive approach orientation? A meta-analysis. Journal of Personality and Social Psychology, 109(6), 983-1002. http://doi.org/10.1037/pspa0000037

Lee-Wingate, S. N., \& Corfman, K. P. (2010). A Little Something for Me and Maybe for You, Too: Promotions that Relieve Guilt. Marketing Letters, 21(4), 385-395. http://doi.org/10.1007/s11002-009-9093-2

Leith, K. P., \& Baumeister, R. F. (1998). Empathy, Shame, Guilt, and Narratives of Interpersonal Conflicts: Guilt-Prone People Are Better at Perspective Taking. Journal of Personality, 66(1), 1-38. http://doi.org/10.1111/1467-6494.00001

Lewis, H. B. (1971). Shame and Guilt in Neurosis. New York: International Universities Press.

Luetge, C. (2006). An Economic Rationale for a Work and Savings Ethic? J. Buchanan's Late Works and Business Ethics. Journal of Business Ethics, 66(1), 43-51. http://doi.org/10.1007/s10551-006-9045-1

Mandel, N., Rucker, D. D., Levav, J., \& Galinsky, A. D. (2017). The Compensatory Consumer Behavior Model: How self-discrepancies drive consumer behavior. Journal of Consumer Psychology, 27(1), 133-146. http://doi.org/10.1016/j.jcps.2016.05.003

Maxham, J. G., \& Netemeyer, R. G. (2002). Modeling customer perceptions of complaint handling over time : the effects of perceived justice on satisfaction and intent. Journal of Retailing, 78, 239-252.

Maxham, J. G., \& Netemeyer, R. G. (2003). Firms Reap What They Sow : The Effects of Shared Values and Perceived Organizational Justice on Customers' Evaluations of Complaint Handling. Journal of Marketing, 67(1), 46-62.

Mazar, N., Amir, O., \& Ariely, D. (2008). The Dishonesty of Honest People: A Theory of SelfConcept Maintenance. Journal of Marketing Research, 45(6), 633-644. http://doi.org/10.1509/jmkr.45.6.633

Mishra, A., \& Mishra, H. (2011). The Influence of Price Discount Versus Bonus Pack on the Preference for Virtue and Vice Foods. Journal of Marketing Research, 48(1), 196-206. http://doi.org/10.1509/jmkr.48.1.196

Niedenthal, P. M., Tangney, J. P., \& Gavanski, I. (1994). “If only I weren't 'versus' if only I hadn't": distinguishing shame and guilt in counterfactual thinking. Journal of Personality and Social Psychology, 67(4), 585-595. http://doi.org/10.1037/0022-3514.67.4.585

Nikolova, H., Lamberton, C., \& Coleman, N. V. (2017). Stranger Danger : When and Why Consumer Dyads Behave Less Ethically Than Individuals. Journal of Consumer Research, 
O(November), 1-58. http://doi.org/10.1093/jcr/ucx108/4563318

Okada, E. M. (2005). Justification Effects on Consumer Choice of Hedonic and Utilitarian Goods. Journal of Marketing Research, 42(February), 43-53. http://doi.org/10.1509/jmkr.42.1.43.56889

Oppenheim, L. (2008). Guilt. Journal of the American Psychoanalytic Association, 56(3), 967977. http://doi.org/10.1177/0003065108323463

Otto, A., \& Kellaris, J. (2013). Sub-Ethical Choice Behavior: the Attraction Effect of Scarcity. In S. Botti \& A. Labroo (Eds.), Advances in Consumer Research, Volume 41. Duluth, MN: Advances in Consumer Research.

Payne, E. (2014). Guests BLACKMAILING hotels and restaurants with bad TripAdvisor reviews if they're not given freebies. Retrieved February 6, 2018, from http://www.dailymail.co.uk/travel/article-2623288/The-blackmailers-post-bad-reviewsunless-theyre-given-freebies-hotels-restaurants.html

Peloza, J., White, K., \& Shang, J. (2013). Good and Guilt-Free : The Role of Self-Accountability in Influencing Preferences for Products with. Journal of Marketing, 77(January), 104-119.

Perlman, M. (1958). An investigation of anxiety as related to guilt and shame. AMA Archives of Neurology \& Psychiatry, 80(6), 752-759.

Rosenberg, E. (2018). 'I am not a racist': New York lawyer apologizes for rant about Spanish speakers in viral video. Retrieved from https://www.washingtonpost.com/news/business/wp/2018/05/22/i-am-not-a-racist-newyork-lawyer-apologizes-for-rant-about-spanish-speakers-in-viralvideo/?noredirect=on\&utm_term=.358f0942c843

Rucker, D. D., \& Galinsky, A. D. (2008). Desire to Acquire: Powerlessness and Compensatory Consumption. Journal of Consumer Research, 35(2), 257-267. http://doi.org/10.1086/588569

Rucker, D. D., Galinsky, A. D., \& Dubois, D. (2012). Power and consumer behavior: How power shapes who and what consumers value. Journal of Consumer Psychology, 22(3), 352-368. http://doi.org/10.1016/j.jcps.2011.06.001

Smith, R. H., Webster, J. M., Parrott, W. G., \& Eyre, H. L. (2002). The role of public exposure in moral and nonmoral shame and guilt. Journal of Personality and Social Psychology, 83(1), 138-159. http://doi.org/10.1037/0022-3514.83.1.138

Steenhaut, S., \& Kenhove, P. Van. (2006). The Mediating Role of Anticipated Guilt in Consumers ' Ethical Decision-Making. Journal of Business Ethics, 69, 269-288. http://doi.org/10.1007/s10551-006-9090-9

Sunshine, J., \& Tyler, T. R. (2003). The Role of Procedural Justice and Legitimacy in Shaping Public Support for Policing. Law Ad Society Review, 37(3), 513-548.

Tangney, J. P., \& Dearing, R. L. (2002). Shame and Guilt. New York, NY: The Guilford Press.

Tangney, J. P., Miller, R. S., Flicker, L., \& Barlow, D. H. (1996). Are shame, guilt, and 
embarrassment distinct emotions? Journal of Personality and Social Psychology, 70(6), 1256-1269. http://doi.org/10.1037/0022-3514.70.6.1256

Tangney, J. P., Niedenthal, P. M., Covert, M. V, \& Barlow, D. H. (1998). Are shame and guilt related to distinct self-discrepancies? A test of Higgins's (1987) hypotheses. Journal of Personality and Social Psychology, 75(1), 256-268. http://doi.org/10.1037/00223514.75.1.256

Tangney, J. P., Stuewig, J., \& Mashek, D. J. (2007). Moral Emotions and Moral Behavior. Annual Review of Psychology, 58(1), 345-372. http://doi.org/10.1146/annurev.psych.56.091103.070145

Tangney, J. P., Wagner, P. E., \& Gramzow, R. (1989). The test of self-conscious affect. Fairfax, VA: George Mason University.

Tangney, J. P., Wagner, P., Fletcher, C., Gramzow, R., Bordeaux, E., Constantin, J., ... Smart, C. (1992). Shamed Into Anger? The Relation of Shame and Guilt to Anger and Self-Reported Aggression. Journal of Personality and Social Psychology, 62(4), 669-675. http://doi.org/10.1037/0022-3514.62.4.669

Tepper, B. J. (2000). Consequences of Abusive Supervision. Academy of Management Journal, 43(2), 178-190.

Thompson, R., \& Haddock, G. (2012). Sometimes stories sell: When are narrative appeals most likely to work? European Journal of Social Psychology, 42(1), 92-102. http://doi.org/10.1002/ejsp.850

Tonry, M. (2005). Obsolescence and Immanence in Penal Theory and Policy. Columbia Law Review Association, 105(4), 1233-1275.

Trevino, L. K. (1992). The Social Implications of Punishing Unethical Behavior: Observers' Cognitive and Affective Reactions. Journal of Management, 18(4), 751-768. http://doi.org/10.1177/014920639201800409

Wansink, B., \& Chandon, P. (2006). Can "Low-Fat" Nutrition Labels Lead to Obesity? Journal of Marketing Research, 43(4), 605-617. http://doi.org/10.1509/jmkr.43.4.605

Wicker, F. W., Payne, G. C., \& Morgan, R. D. (1983). Participant Descriptions of Guilt and Shame. Motivation and Emotion, 7(1), 25-39. http://doi.org/10.1177/0192513X12437708

Wilkes, R. E. (1978). Fraudulent Behavior by Consumers. Journal of Marketing, 42(4), 67-75.

Xiao, E., \& Houser, D. (2011). Punish in public. Journal of Public Economics, 95(7-8), 10061017. http://doi.org/10.1016/j.jpubeco.2010.11.021

Zillman, D., \& Brosius, H. B. (2000). Exemplification: On the influence of case reports on the perception of issues. Mahwah, New Jersley. 


\title{
Essay 2: Behavioral Norms in Consumers' World of Power: When and Why Shame and Guilt Increase Compliance
}

\author{
Raika Sadeghein
}




\begin{abstract}
Due to advances in technology consumers are gaining more power in the marketplace. As consumers' power increases, businesses are more vulnerable to unethical and socially irresponsible behavior by consumers. The objective of this research is to investigate the positive and negative ramifications of different types of strategies (i.e., guilt-based and shame-based) used by businesses to discourage consumer misconducts. In addition, the research examines whether appeal framing (i.e., narrative vs. rhetorical) influences the consequences associated with these strategies and their persuasiveness.
\end{abstract}

Keywords: Shame, guilt, emotional appeal, consumer ethics 


\section{Introduction}

The new online world has provided consumers with a unique chance of being heard. Social media and online reviews provide an opportunity for consumers to easily communicate their thoughts and attitudes towards a firm's services, products and behavior. This is only one of the factors contributing to a shift in the power dynamics in the marketplace in favor of consumers. Businesses commonly bear significant costs due to this powershift. In order to be competitive, businesses have to provide superior and often discounted products and services (e.g., free delivery and returns). Unfortunately, in addition to these costs, consumers sometimes capitalize and leverage their online power in sub-ethical ways. Otto and Kellaris (2013) define a subethical choice as a choice that is not necessarily unethical, but one that violates a standard and is not considered to be the "ideal" choice ethically. The reason for using the term sub-ethical in this context is that in many instances, consumers are not aware that their use of online power hurts businesses. This is due to a combination of consumers' increased power and under-established rules of conduct in the online world.

The sub-ethical consumer behavior ranges from something as commonplace as excessive merchandise returns (Dennis, 2018) to behavior as outrageous as review blackmail (Blumentha, 2015; Payne, 2014). These instances illustrate cases of consumers abusing their power to acquire their wants and needs in excess of their rights. Regardless of the extremity of such behavior, they pose a threat to businesses. The significance of this issue becomes evident when we live in a world where online reviews and reputation can make or break a business and this reputation is at the mercy of consumers. Whereas in the past, consumers' connections and circle of influence were limited, consumers can now, due to the power of online environment, have their voices heard by countless other consumers. As a result, consumer dishonesty and/or immorality poses a greater threat to businesses. Small and new businesses are particularly vulnerable to consumer 
power misuse as they do not possess the resources or established reputation to buffer the costs associated with instances of consumer sub-ethical behavior.

In response to consumer undesirable behavior, businesses are left with few good options. Ignoring these behavior hurts the bottom line. In addition, it can encourage repeat behavior in customers. On the other hand, confronting consumers could result in a ripple effect of negative consequences for the business. Thus, identifying and examining proper interventions to induce ethical behavior and inhibit misconduct is of great importance.

Hampton (1984) notes that whenever the ethical incentive of an unethical behavior fails to prevent an individual from performing an immoral behavior, the threats backing those imperatives deter people from carrying out the prohibited action. To put it simply, the fear of the pain that is going to be inflicted on the violator is what is going to keep people from committing misconducts. Tonry (2005) notes that punishment can be used to help violators understand "the moral character of their wrongdoing" (p. 1242). The importance and power of moral education as a component of punishment has been shown in the past. Hampton (1984) proposed the idea of moral education theory of punishment where he emphasized the significance of rehabilitation, social integration, and education of violators. However, I argue that punishment can educate the society as well as the violator. In fact, one of the mechanisms through which punishment works is creation of fear in people before they commit an unethical or unlawful behavior.

Many businesses have recently resorted to the use of negative emotional appeals, specifically shame and guilt appeals, to discourage consumer misconduct (e.g., Blumentha 2015). Although certain negative emotional appeals have been examined in the marketing literature (e.g., fear appeals) as a tool to encourage or discourage behavior (Kees et al., 2010), use of shame, a highly aversive emotion, seems to be at odds with what marketing scholars and 
practitioners deem appropriate. Shame is commonly perceived as a highly negative emotion with undesirable consequences such as feeling of worthlessness, avoidance seeking and a lack of desire to redress (de Hooge et al., 2008). In addition, because of the public exposure component of shame and the subsequent feeling of humiliation, individuals subject to shaming practices tend to feel abused and resent the person(s) causing the negative emotion (Tepper, 2000). Therefore, shaming has rarely been used in the marketing literature as a proattitudinal or counterattitudinal appeal.

The few marketing articles examining shame as a persuasive tool have investigated the use of these appeals in discouraging behavior that causes direct harm to the self (e.g., drinking behavior; Agrawal and Duhachek 2010; Duhachek, Agrawal, and Han 2012). Since the victim of these misdeeds is the self and these appeals are designed to reduce damage to the self, people are more receptive to the shame appeal in these cases and the negative repercussions are expected to be mitigated. This is because the end result of bearing the aversive state of shame is selfprotection or preservation. However, in cases of consumer misuse of power, the undesirable behavior hurts others, not the self. Unlike drinking, the recipient of the shame appeal is not the person or entity suffering from the undesirable behavior, thus compliance with the appeal would not be perceived as positively or self-serving as compliance with appeals targeting self-harming behavior. The customer engaging in sub-ethical behavior bears the costs of the shaming appeal without any perceived gain; thus, I expect this individual to be more resistant to the message in these instances.

Although we have had research in the marketing literature that has explored how the experience of shame and guilt appeals affect intention and behavior when the behavior poses harm to self, the current research establishes the possibility of using shame and guilt appeals in 
cases of harm to others and demonstrates that the negative repercussions of these negative appeals can be alleviated through modification of the emotional appeal framing.

In this study I am specifically interested in narrative and rhetorical appeal framings. A narrative appeal framing elicits consumer compliance and attitude change by use of a story portraying the consequences of the undesirable behavior. A rhetorical appeal persuades consumers by using facts, numbers and objective data to demonstrate the consequences. Research has shown that in general, emotional appeals are more effective than rational appeals (Achar, So, Agrawal, \& Duhachek, 2016; Bagozzi \& Moore, 1994). However, in this study I examine whether emotion laden appeals (shame and guilt appeals) that are delivered through an emotion accommodating medium (i.e., narrative appeals) would have a different impact on decision making than those delivered through a non-emotional, logic accommodating medium (i.e., rhetorical appeals).

In this paper, I will investigate the ways in which businesses can more effectively protect themselves against unethical consumer behavior in the age of technology. I first provide a brief overview of the shame and guilt literature, which explains the distinction between these emotions and how the psychological experience of shame and guilt influences consumer behavior. Next, I discuss the negative implications associated with the use of these negative appeals and how we can mitigate these negative consequences through changes in emotional appeal framing.

\section{Theoretical Background}

\section{Shame and Guilt}

Shame and guilt have both been used for decades in societies as a tool to prevent individuals from committing violations against norms or repeating misconducts. However, they impact behavior through different mechanisms (Duhachek et al. 2012). Shame is associated with 
violations of cultural and social norms, while guilt is associated with violations of personal values (Tangney, Stuewig, \& Mashek, 2007). In addition, feeling of shame is associated with an "egocentric" concern where one is worried about how other people will evaluate him/her due to a transgression, while feeling of guilt is "other-oriented" where the individual is concerned about the negative influence of his/her actions on others (Tangney et al., 2007).

Breugelmans and Poortinga (2006) note that characteristics associated with guilt includes doing damage to others and ruminating about what happened. Guilt-based appeals try to call on a higher sense of value in individuals by urging them to do the right thing. Many businesses try to do this by reminding consumers of important values. Examples of guilt appeals include electric companies guilting customers to reduce electricity consumption, hotels urging customers to reuse towels, and restaurants guilting customers into tipping (Bauer, 2016).

Shame on the other hand, is considered a social phenomenon (Goswami, 2014). Shame appeals are expected to reduce violations of norm because "public expressions of disapproval toward nonconformists generate remorse in the nonconformists, thus deterring them from continued nonconforming behavior" (Goswami, 2014, p. 2110). While both emotions of shame and guilt have been used in psychology and sociology literature to enhance morality, guilt is perceived as more constructive compared to shame (Leith and Baumeister 1998).

Here is an example to highlight the distinction between how guilt and shame operate. As explained earlier, guilt involves a violation of personal value. For example, eating meat is against vegetarians' personal values. So, if vegetarians eat meat, they will encounter feelings of guilt regardless of whether other people are aware of this event or not. However, that is not the case for non-vegetarians. Since, consuming meat products does not violate any of their personal values, they would not experience feelings of guilt. 
Shame on the other hand, involves violations of cultural or social values that result in public's negative evaluations and disapproval of the violator. For example, an individual might attempt to hide their passion for hunting when they are present in the company of an animal lover group. Because the group values not harming animals, discovering the individual's passion for hunting will result in the group's discontent and consequently experiencing shame by the individual, even though hunting is not against his/her personal values. Guilting and shaming appeals make use of these psychological mechanisms to drive compliance. While guilting appeals to a higher sense of value in individuals, shaming works by creating a fear of public exposure and discontent.

Moreover, shame involves negative global evaluation tendencies whereas guilt involves local evaluation tendencies (Duhachek et al., 2012; Tangney et al., 1998). In other words, feelings of shame cause negative evaluations of the self (i.e., I am a bad person), while guilt results in negative evaluations of a certain behavior (i.e., I did something wrong). The negative global evaluation tendency requires you to acknowledge your flawed self. However, guilt only requires recognition of a value violating behavior but does not threaten one's self-perception (Lewis, 1971). That is why shame is considered a more aversive and enduring state compared to guilt (Tangney et al., 1996). To prevent this highly aversive state, one is more likely to avoid the wrongdoing when anticipating shame rather than guilt. In addition, public implementation of punishment has been shown to promote norm salience which ensures the effectiveness of even weak punishments (Xiao \& Houser, 2011). This is consistent with the idea that the public humiliation component of the shaming strategies further reinforces this negative state regardless of the severity of punishment. Thus, I expect: 
H1: Shame (vs. guilt) appeals will lead to lower (higher) likelihood of engaging in unethical behavior.

There are increasing instances of public shaming used to thwart violators of social norms. This is mainly due to the fact that shaming has proven effective in the past. Individuals have used public shaming to address negative behavior in everyday life which is evident in videos of undesirable behavior such as racism going viral (Rosenberg, 2018). The common goal of all shaming attempts is to discourage people from engaging in what others consider undesirable or even immoral behavior.

Similarly, shame-based strategies are being increasingly used by businesses to protect themselves from unethical consumers. An example of this type of punishment would be the reaction of a Boston chef to two unruly customers who blackmailed the restaurant with threats of negative Yelp reviews unless their demands were met. The solution of the chef to prevent such instances from happening again was to publicly shame the customers by posting their photos on social media and describing their unethical behavior (Blumentha, 2015).

Although shaming strategies seem to be effective in reducing undesirable behavior, traditional marketers have avoided using shaming strategies because of the potential negative ramifications. This is consistent with what marketing literature suggests. Wilkes's (1978) found that consumers who observe fraudulent behavior against a business are very tolerant of such misconducts which could be due to consumers' perception that businesses deserve such behavior because of their self-serving nature. In addition, firm's attempts at convincing the public of a customer's wrongdoing are mostly attributed to self-interest seeking which leads to negative affect. Even if other consumers are persuaded of another customer's misconduct, they would still 
perceive the business's action as an attempt to protect itself from unethical behavior and thus, self-serving (Wilkes 1978).

However, in today's world some businesses may not see any option other than resorting to shaming strategies. Smith et al. (2002) note that the common motivation behind shaming strategies is that the transgressor does not show any signs of regret or remorse, giving the observer of the behavior the impression that the unethical or undesirable behavior is not causing the transgressor any shame or guilt. As a result, the observer, which is the business in this context, feels tempted to elicit these feelings by publicly exposing the transgression.

Shaming in the form of public humiliation might be effective in inducing compliance to norms; however, research shows that public criticism is commonly perceived as abuse (Tepper, 2000). Research findings indicate that the public's reaction to a disciplinarian is mainly predicted by perceived legitimacy of the disciplinarian, this in turn, is strongly influenced by fairness of the procedures used by the disciplinarian (Sunshine \& Tyler, 2003). If the audience perceives the admonishment used to thwart an individual from committing a misconduct to be too severe, the punished individual might perceive it as "unjustified humiliation." This in turn will create a shift in focus, where the individual can only see the mistreatment rather than the misconduct. This is why shaming usually involves negative repercussions for the shamer because any action aiming to publicly expose someone may be perceived as hostile and unfair (Smith et al. 2002). Therefore, I expect:

H2: Shame (vs. guilt) appeals will lead to a) less (more) desirable attitude toward the business and b) higher (lower) retaliation intentions.

As noted earlier, the perception of unjustified humiliation is what causes negative affect towards the disciplinarian. Procedural justice refers to the fairness of the procedures used by 
businesses to handle customer sub-ethical behavior. Enhancing perceptions of procedural justice has been shown to improve customer satisfaction with conflict resolution attempts and overall firm satisfaction (Maxham \& Netemeyer, 2002). Low perceptions of procedural justice, on the other hand, adversely impact trust in, satisfaction with, and assessment of the disciplinary figure (Ambrose, Hess, \& Ganesan, 2007). Therefore, low perceptions of procedural justice leads to negative attitudes toward the disciplinarian. In conflict resolution between businesses and customers, if a business can establish fairness of procedures, there is higher likelihood of positive attitude towards the business even if the customer is not satisfied with the resolution outcome. Brockner and Wiesenfeld (1996) note that even when the outcome favorability is low, perceptions of procedural justice can make up for the outcome dissatisfaction and result in positive reactions toward the business. Thus, I expect individuals subjected to shame-based appeals to have stronger negative attitudes towards the business than individuals subjected to guilt-based appeals explain why procedural justice matters.

H3: Perceptions of procedural justice mediate the effect of emotional appeal on costumer attitudes toward the business and retaliation intentions.

\section{Rhetorical and Narrative Appeals}

Rhetorical appeals refer to actions of a firm aimed at reducing violations of social norms and unethical behavior by providing objective data explaining the consequences of non-compliance. Green and Brock (2002) note that rhetorical arguments advocate a certain position and contain rhetorical elements such as reasoning, arguments, and evidence to support those arguments. Narrative appeals, on the other hand, report a narrative as an exemplar of what is to be expected in case of violations of norms (e.g., experiencing negative emotions such as shame and guilt) in order to discourage such behavior. The major difference between rhetorical and narrative appeals 
is the transportability impact of narrative appeals. While rhetorical appeals aim at inhibiting misconduct by creating a fear of future dismay and punishment through reporting objective data (e.g., statistics), narrative appeals are painting a picture of a customer experience who was penalized due to unethical behavior to induce compliance with norms. Bruner (2009) argued that the critical difference between narrative and rhetoric lies within their standards of truth. A rhetorical appeal contains arguments and provides some sort of empirical proof to support those arguments. A narrative appeal on the other hand does not directly establish truth, but rather verisimilitude.

Due to their objective nature, rhetorical appeals are "less emotionally evocative" (Thompson \& Haddock, 2012, p. 95), and activate problem-focused coping. This type of coping mechanism focuses on actions and benefits, and how an individual can adapt to adverse situations and reap the benefits (Lazarus, 1991). Thus, I expect this type of appeal to promote adaptation and compliance with social norms. However, because the primary focus of this type of coping is the problem and finding a solution, and not the actors or the treatment, consumers' attitudes towards the firm are not expected to change.

Narrative appeals however, transport individuals into the narrative world which entails higher levels of involvement in addition to higher risk perceptions associated with incompliance (De Wit, Das, \& Vet, 2008). This high involvement in turn, takes individuals into the emotional journey of the narrative, evoking emotion-focused coping (Thompson and Haddock 2012). The individual's focus in this type of coping is emotion regulation (Duhachek, Agrawal, and Han 2012). Based on exemplification theory, generally, messages containing narratives are much more effective than factual messages because narratives facilitate message processing. In addition, the affective reactivity and high cognitive involvement evoked by the narratives will 
consequently lead to higher elaboration and contemplation of message content (Gray, Carolina, \& Harrington, 2011). Moreover, the qualitative content of narratives is more relatable compared to quantitative facts. Individuals reading a narrative, make a connection to the characters in the story, especially if they can identify with the character. This connection enables the readers to recall the content more easily and vividly (Zillman \& Brosius, 2000).

I suggest that narrative shame and guilt appeals are aversive stimuli that induce conformity through negative reinforcement and vicarious learning. Modification of outcome expectancy in vicarious learning works by creating the fear of punishment in observers of a misconduct. This leads them to imagine suffering the punishment if they committed the same violation. In other words, individuals reading the narrative will be "transported" into the narrative by becoming completely immersed (Thompson \& Haddock, 2012). I expect narrative framing to work best for guilt appeals rather than shame appeals. A study conducted by Braverman (2008) found that testimonial (narrative) messages were more persuasive than informational messages when individuals subject to the message were less involved with the message. As noted in $\mathrm{H} 1$, I expect guilting messages to be less persuasive than shame messages in reducing consumer misconducts. By framing these messages as narratives, we can increase the level of involvement with the appeal, thus increasing the level of effectiveness in these messages.

Conversely, I believe that using a narrative framing for shame appeals would result in higher retaliation intentions and negative affect towards the business. Research has shown that observers can learn vicariously to behave ethically through observation of other's punishment (Trevino, 1992). This vicarious learning occurs as a result of changes in outcome expectancy. However, as a part of vicarious learning, individuals imagine and/or fear a situation in which they have committed the same misconduct and are experiencing the same punishment. Due to the 
highly aversive state of shame, anticipation of public exposure can create a sense of resentment toward the authority figure reinforcing the expected outcome. In addition, as explained earlier, narrative framing transports the reader into the story resulting in higher involvement, elaboration and contemplation of message content. Therefore, I believe these higher levels of involvement, and elaboration of content would cultivate negative emotions and a sense of resentment towards the appeal's communicating business, thus, negatively affecting attitudes towards the firm.

Rhetorical framing, on the other hand should not create the same sense of resentment for shaming appeals. Rhetorical frame is not as emotionally evocative. This results in the individuals focusing on the message content rather than the treatment of the misbehavior or the disciplinarian. Rhetorical framing also avoids reader's self-identification with the violator and hence reduces negative repercussions associated with it. However, this framing is not expected to increase the effectiveness of guilt messages. Unlike narrative framing, rhetorical faming does not increase involvement with the message, which is what guilting appeals lack. Thus, I expect:

H4: The influence of shame and guilt appeals on a) unethical behavior, b) attitude toward the business, and c) retaliation intentions will vary as a function of appeal framing. A shame appeal would be more effective when rhetorically framed, while a narrative framing works best for guilt appeals.

H5: Perceptions of procedural justice will mediate the effect of emotional appeal $\mathrm{x}$ appeal framing on attitudes toward the business and retaliation intentions.

\section{Study 1}

Experiment 1 was conducted to test our first hypothesis and examine whether shaming strategies would outperform guilting strategies in reducing unethical behavior. To this end, I 
gave students a chance to cheat on a test and randomly assigned them to one of the three conditions (i.e., shame, guilt, and control) in order to test our hypothesis. I expected that the participants who were subject to the shaming appeal would be less likely to cheat compared to the individuals in the other two conditions.

\section{Method}

Design. One hundred and twelve undergraduate business students (60\% female)

participated in the experiment for extra course credit and a chance to win an Amazon gift card of \$100. Our single-factor between-subjects design experiment consists of: 1) a baseline control condition, 2) a guilt treatment condition, and 3) a shame treatment condition. Participants were randomly assigned to one of the three conditions: guilt $(n=35)$, shame $(n=43)$, or control $(n=34)$. Consistent with Nikolova, Lamberton, and Coleman (2017), the conditions were randomized between sessions not within sessions because of the differences in the logistics required by each condition. The study design was adapted from Nikolova et al. (2017), which was originally modeled after Mazar, Amir, and Ariely (2008) problem solving task. The task provides the participants an opportunity to untruthfully inflate their performance on a test for a greater chance of receiving monetary compensation.

Procedure. Participants were told that they would be completing a pen and paper, general knowledge quiz. The quiz consisted of 16 multiple choice questions, and 20 brand logos to be identified. The cover story stated that the researchers were interested in the association between general knowledge level and brand logo identification. Researchers noted that those who perform in the top $50 \%$ would be entered into a drawing for a chance to win a \$100 Amazon gift card. It was pointed out that the better they do on the quiz, the higher their chances to be entered into the drawing. They were told that due to high number of participants in the study, the researchers did 
not have the resources to grade all quizzes. As a result, after the task completion, they would be presented with the correct responses, and are asked to grade themselves. To avoid hindsight bias participants were told that they will only receive credit for answers that are clearly and accurately marked and written on the answer sheet (Fischhoff and Beyth 1975). The participants received two cards with matching numbers (i.e., participant's identification number), one used to disclose the self-report score, and the other used for identification purposes. The unethical opportunity occurred in the self-report score where participants could untruthfully inflate their scores. Monetary incentive for higher performance provided the impetus for cheating.

Procedure for the control condition. Participants in the control condition were told that researchers would randomly select a few responses and discard responses where there is a mismatch between the actual score earned and the self-report score in order to ensure fairness.

Procedure for the guilt condition. Participants assigned to the guilt condition were reminded that actions matter and being untruthful destroys chances of those who truly deserve to be in the drawing. Moreover, they were informed of the random monitoring process. An "honor code" procedure adapted from Mazar et al. (2008) was employed to further evoke feelings of guilt at the point of temptation. Students in the guilt condition saw the statement "a good person has a conscience" at the top of their test sheet in addition to a statement requiring their acknowledgement of the researchers' right to random monitoring of the responses. Student were asked to sign below these statements.

Procedure for the shame condition. Participants assigned to the shame condition were reminded that reputation matters and being untruthful will reflect negatively on them. In addition, similar to the guilt condition they were notified of the random monitoring process to ensure fairness. However, they were told that this was done by asking a few participants to stay 
in the room after responses were collected, so that the researcher could examine the accuracy of the reported score in the presence of the participant. A similar "honor code" procedure was employed with a statement noting "a good person values her/his reputation" to evoke feelings of shame at the temptation point, as well as the monitoring acknowledgement statement. Students were asked to sign below these statements.

The incentive for cheating (i.e., chance to be in the drawing), and the likelihood and severity of punishment were the kept the same (i.e., being omitted from the drawing) for all conditions. In addition, the punishment is small enough not to entirely prevent participants from cheating. However, the method of application is different based on condition.

After the test, participants were presented with the correct responses, and were given time to report the correct number of responses. I asked participants to double-check their score to prevent false reports. Responses were marked as unethical if the participant falsely inflated their score.

A pretest evaluated the stimuli to ascertain the validity of the shame and guilt manipulations. Consistent with our prediction participants correctly identified that the statement "a good person has a conscience" elicits emotions of guilt, whereas the statement "a good person values her/his reputation" elicits emotions of shame.

\section{Analysis and Results}

I used a chi-square test to analyze occurrence of unethical behavior. Results revealed that 16 $\%$ of the participants in the shame condition versus $49 \%$ of participants in the guilt condition, and $41 \%$ of the control group participants were untruthful in reporting their performance. I used a logistic regression analysis to predict participants' unethicality. Results indicated that individuals in the control group $\left(b=1.28, \exp (b)=3.60\right.$, Wald $\left.\chi^{2}(2)=5.62, p<.05\right)$ and the guilt 
group $\left(b=1.58, \exp (b)=4.86\right.$, Wald $\left.\chi^{2}(2)=8.76, p<.01\right)$ were significantly more likely to falsely report their performance than participants in the shame condition. In fact, the shame condition, reduced the likelihood of behaving unethically by 3.6 times compared to the control condition, and by 5 times compared to the guilt condition ${ }^{1}$.

\section{Result Summary}

In support of $\mathrm{H} 1$, study 1 shows that participants who anticipate shame behave more ethically relative to participants in the guilt condition. Results indicated that there was no significant difference in unethicality (i.e., cheating behavior) between the guilt and the control condition. In other words, anticipation of guilt did not significantly reduce unethical behavior. In the next study I replicate this effect in a different context adding a boundary condition (i.e., narrative vs. rhetorical appeal framing) to examine whether framing of the shame or guilt messages could influence the effectiveness and other outcomes associated with these emotional appeals.

\section{Study 2}

Study 2 extends study 1 in three important ways. First, I explore two additional dependent variables (i.e., attitudes toward the business and retaliation intentions) that assess the negative implications associated with the use of negative emotional appeals. Furthermore, I investigate whether these negative implications can be mitigated through modification of the appeal framing. More specifically, I examine the effectiveness of narrative and rhetorical appeal framing in alleviating some of these potential negative repercussions.

Finally, I examine the process evidence for our conceptual model. Specifically, I predict that in order to improve attitudes toward the business and decrease retaliation intentions,

1 Odds ratio of cheating/not cheating (control) $=41 / 59=.69$, Odds ratio of cheating/not cheating (Shame)= $16 / 84=.19$, Odds ratio of cheating/not cheating (guilt) $=49 / 51=.96$; The ratio of the odds for control to the odds for shame $->.69 / .19=3.63$; The ratio of the odds for guilt to the odds for shame $\rightarrow .96 / .19=5.05$. 
perceptions of procedural justice should be improved. I expect perceptions of procedural justice to underlie the effects on consumer outcomes (e.g., attitudes toward the business, and retaliation intentions).

\section{Method}

Participants ( $\mathrm{n}=254,55 \%$ females, $\left.\mathrm{M}_{\mathrm{age}}=35.7\right)$ were recruited from Amazon MTurk in exchange for a small monetary compensation. I used TurkPrime (www.turkprime.com) to automate the recruiting process, anonymize responses, and restrict survey dissemination to workers with HIT approval rates of $90 \%$ or higher and with number of HITs lower than 1,000 to avoid professional Turkers. Participants were randomly assigned to one of the four experimental conditions in a 2 (emotional appeal: shame/guilt) x 2 (appeal framing: narrative/rhetorical) between-subjects design. At the beginning of the study, participants were asked to indicate their gender so that the experimental stimuli would match the participant's gender. Twenty seven participants $(11 \%)$ were excluded from subsequent analyses because they missed more than one of the attention checks.

All participants were presented with a review blackmailing scenario - they have read online how some consumers use their "review power" to convince businesses to give them free products or services. They decide to give this a try at a new restaurant in town. After the meal, they tell the waiter that unless they get free dessert they will post a terrible review online. The restaurant accedes to their demand. However, while waiting for their free dessert the participant sees a poster on the wall. The poster contains the experimental manipulations.

Consistent with Thompson and Haddock's (2012) approach, the narrative frame was adapted from a real-life story published in a news article. The narrative framing manipulation, based on an Eater Boston article, used a story about a customer who blackmailed a restaurant with 
negative reviews and the business owner's response to the blackmailing behavior (Blumentha 2015). In the shaming narrative condition, the businesses response was to post the incident on social media with the blackmailer's picture to publicize his/her identity, hence shaming the individual. In the narrative guilt condition, the business's response involved posting the incident on social media, however, the post focused on the anonymous blackmailer's wrongdoing rather than his/her identity. The rhetorical appeals were developed by taking the information from the narrative appeals and presenting it in a parallel form framed as facts and research results. Both types of appeals indicated the same action (i.e., social media post pointing out the action vs. social media post pointing out the identity of the transgressor) as the appropriate action to be taken by the business (for experimental stimuli, see Appendix A).

Next, respondents were told that after reading the poster they realize that they have two options: 1) ignore the poster and carry out their blackmailing plan since they have already succeeded, or 2) reconsider their decision, and ask the waiter to add the dessert to their bill. They were asked to indicate the degree to which they were likely to reconsider their decision ( $1=$ extremely unlikely, 7= extremely likely). I then, used Homer (1995) scale to measure attitude toward the business. Six items comprising 7-point scales captured respondent's attitude toward the restaurant (e.g., 1= "negative, unpleasant, unfavorable," and 7= "positive, pleasant, favorable"; $\alpha=.97)$. The retaliation intention scale was adapted from Gregoire and Fisher's (2006) retaliatory behavior(revenge) measure. Five 7-point items (e.g. "Based on the information I read regarding the restaurant's method of dealing with review blackmailers, I want to punish the restaurant in some way) captured participants' retaliation intentions $(1=$ strongly disagree and $7=$ strongly agree; $\alpha=.98$ ). Three 7-point Likert scale items adapted from Maxham and Netemeyer (2002, 2003) assessed participant's perceptions of procedural justice (e.g. "I believe this 
restaurant has fair policies and practices to handle problems"; $\alpha=.93$ ). Finally, (Cohen et al., 2011) guilt and shame proneness (GASP) measures were used to assess individual tendencies to experience shame and guilt ( $\alpha=.67$ and $\alpha=.83$ respectively).

\section{Analysis and Results}

Manipulation checks. To measure the effectiveness of our manipulations, I asked the participants to indicate the emotion being elicited by the poster they saw in the restaurant. Eighty eight percent of the participants in the shame condition and $80 \%$ of the participants in the guilt condition correctly identified the emotion elicited by the manipulation $(\chi 2=74.26, p<.001$, Cramer's V=.65).

In addition, at the end of the survey I asked participants to recall the poster's suggestion regarding the best way to deal with review blackmailers. I conducted a two-way contingency table analysis to examine whether participants could correctly recall their experimental condition; $88 \%$ of the participants in the shame condition and $92 \%$ of the participants in the guilt condition correctly identified their experimental condition $(\chi 2=157.32, \mathrm{p}<.001$, Cramer's V= .83). Finally, I asked the participants to remember the content of the poster (i.e., 1) a story about a customer blackmailing the restaurant; 2) benefits of working as a service staff; 3) business owners mistreating service staff; or 4) research results about customers blackmailing businesses). Ninety four percent of participants correctly recalled the narrative manipulation and 60\% correctly recognized the rhetorical manipulation $(\chi 2=98.50, \mathrm{p}<.001$, Cramer's $\mathrm{V}=.66)$.

\section{Behavioral Intention}

I hypothesized that shame appeals will lead to lower likelihood of engaging in unethical behavior compared to guilt appeals. In addition, I predicted that the influence of shame and guilt appeals on unethical behavior varies as a function of appeal framing. A shame appeal would be 
more effective when rhetorically framed, while a narrative framing works best for guilt appeals. Counter to our expectation, behavioral intentions did not significantly differ based on emotional appeal $(p=.65)$. In addition, there were no main effect of appeal framing $(p=.64)$ or an interactive effect of emotional appeal and appeal framing $(\mathrm{p}=.77)$ on behavioral intentions. However, by examining the means of behavioral intentions I can see that participants in all conditions report high level of behavioral intentions and these numbers are well above the mid-point (e.g., $M_{\text {guilt }}=$ 6.05, and $\mathrm{M}_{\text {shame }}=6.19$ ).

\section{Attitude Towards the Firm}

A one-way ANOVA on attitude towards the business revealed a significant main effect of shame-guilt condition $(F(1,221)=37.51, p<.001, \eta 2=.14)$, as shown in figure 1 . Consistent with $\mathrm{H} 2 \mathrm{a}$, the individuals in the shame condition $(\mathrm{M}=4.37, \mathrm{SD}=1.63)$ had significantly less positive attitude towards the business than individuals in the guilt condition $(\mathrm{M}=5.62, \mathrm{SD}=$ 1.48). In addition, in support of $\mathrm{H} 3 \mathrm{~b}$, study 2 found support for a two-way interaction between emotional appeal (i.e., shame vs. guilt) and appeal framing (i.e., narrative vs. rhetorical) (F $(1,221)=4.33, \mathrm{p}<.05, \eta 2=0.02)$. Further contrasts reveal that framing the guilt message as a narrative appeal $(M=5.96)$ rather than a rhetorical appeal $(M=5.26)$ significantly improves attitudes towards the business $(\mathrm{F}(1,221)=5.68, \mathrm{p}<.05, \eta 2=0.02)$. However, emotional appeal framing did not significantly influence attitudes towards the business in the shame condition $(\mathrm{p}=$ 0.59 ; see figure 2). 
Figure 1- Attitude Toward the Business

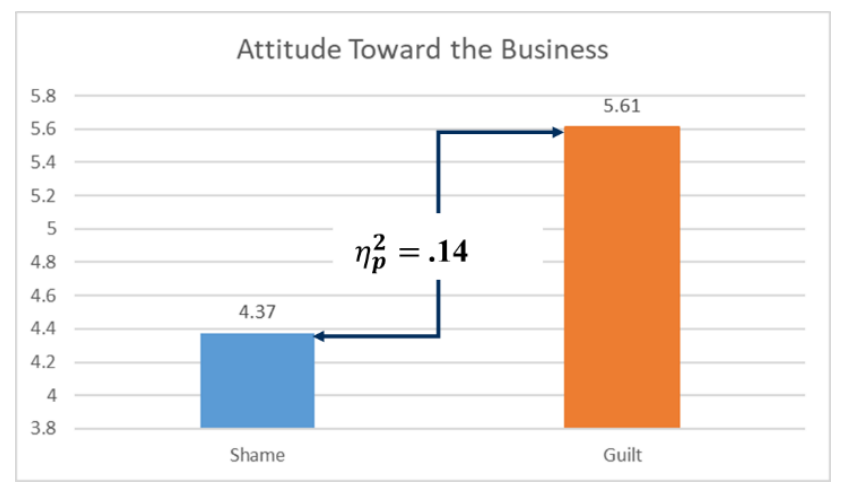

Figure 2- The Moderating Effect of Appeal Framing on Attitude Toward the Business

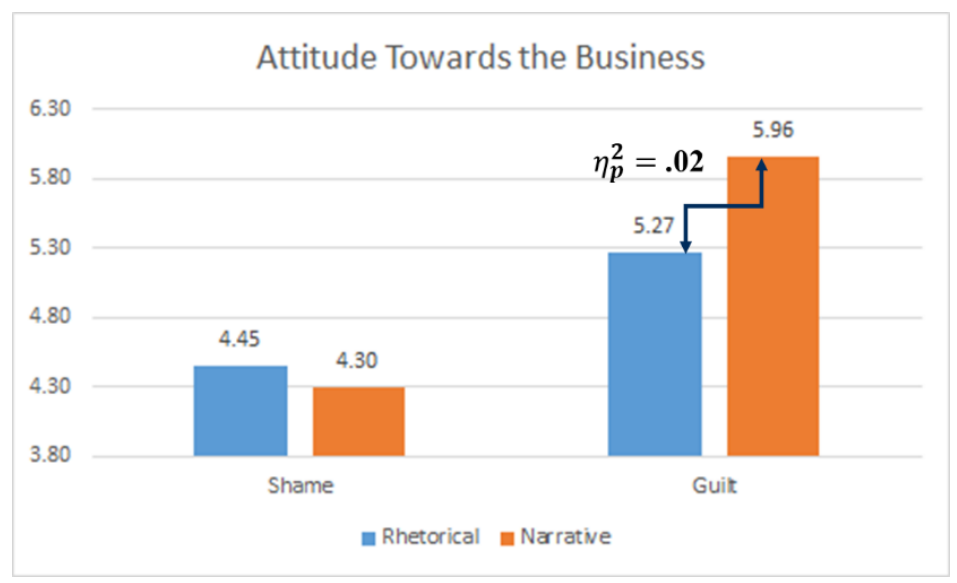

\section{Retaliation Intentions}

I hypothesized that individuals subject to shame appeals will have higher retaliation intentions compared to recipients of guilt appeals. Consistent with this hypothesis (H2b), I found a significant main effect of shame-guilt condition $(F(1,221)=14.89, p<.001, \eta 2=.06$; Figure 3$)$ where individuals in the shame condition expressed higher desire to engage in retaliatory behavior $(\mathrm{M}=2.66, \mathrm{SD}=1.47)$ compared to individuals in the guilt condition $(\mathrm{M}=1.91, \mathrm{SD}=$ 1.48). Counter to our hypothesis $(\mathrm{H} 3 \mathrm{c})$ the influence of shame and guilt appeals on retaliation intentions did not vary as a function of appeal framing $(\mathrm{F}(1,221)=.04, \mathrm{p}=.833)$. 
Figure 3- Retaliation Intentions

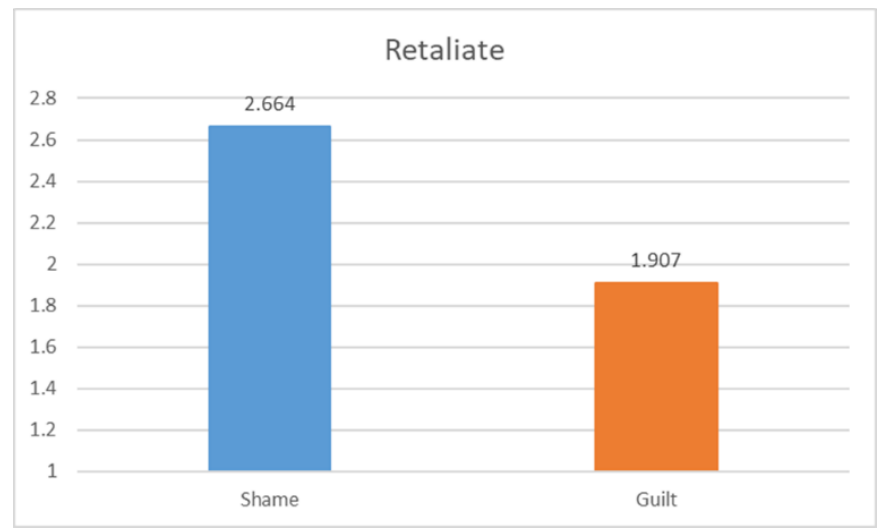

\section{Perceptions of Procedural justice}

I hypothesized that people who are subject to shame appeals have lower beliefs in the fairness of the procedures taken by the business aiming to resolve issues. This in turn, results in lower attitudes towards the business and higher retaliation intentions. Consistent with our mediation hypothesis (H3), I found that respondents in the shame condition indicated lower perceptions of procedural justice compared to individuals in the guilt condition $\left(\mathrm{M}_{\text {shame }}=5.49\right.$, $\mathrm{SD}=1.07$ vs. $\left.\mathrm{M}_{\text {guilt }}=6.26, \mathrm{SD}=1.06 ; \mathrm{F}(1,223)=29.89, \mathrm{p}<.001, \eta 2=.12\right)$. A bias-corrected mediation analysis (Hayes 2013; Process Macro Model 4) indicates that perceptions of procedural justice mediate the effect of shame vs. guilt appeal on attitude towards the business $(\mathrm{axb}=.66,95 \% \mathrm{CI}[.41, .93])$ and retaliation intentions ( $\mathrm{axb}=-.19,95 \% \mathrm{CI}[-.38,-.05])$.

I further hypothesized that the indirect effect of emotional appeal on attitudes toward the business and retaliation intentions will be moderated by narrative vs. rhetorical appeal framing (H5). I used Hayes's (2013) PROCESS macro (Model 8) to estimate bias-corrected bootstrapped confidence intervals ( $\mathrm{n}=5,000$ samples) to examine the conditional indirect effect. As seen in Table 1 the conditional indirect effect of the emotional appeal - appeal framing on attitudes 
toward the business $(b=.57,95 \%$ CI [.07,1.10]; Figure 4$)$ and retaliation intentions $(b=-.18,95 \%$ CI [-.43, -.02]; Figure 5) were statistically significant. I explored the nature of the conditional indirect effects by comparing the slopes at different levels of the appeal framing (i.e., narrative and rhetorical). Consistent with our theorizing, a conditional indirect model with bootstrapping (Hayes, 2013) revealed that the indirect effect of guilt vs. shame appeal on attitude towards the business and retaliation intentions was significant for both types of appeals.

However, the superiority of the guilt appeal compared to the shame appeal was further magnified when the appeals were framed as a narrative rather than a rhetorical (see table 1). To ensure the results were not due to within-subjects variation of susceptibility to shame and guilt, all analyses were conducted adjusting for participant's shame and guilt proneness.

Figure 4- The Mediating Role of Procedural Justice on Attitudes Towards the Business

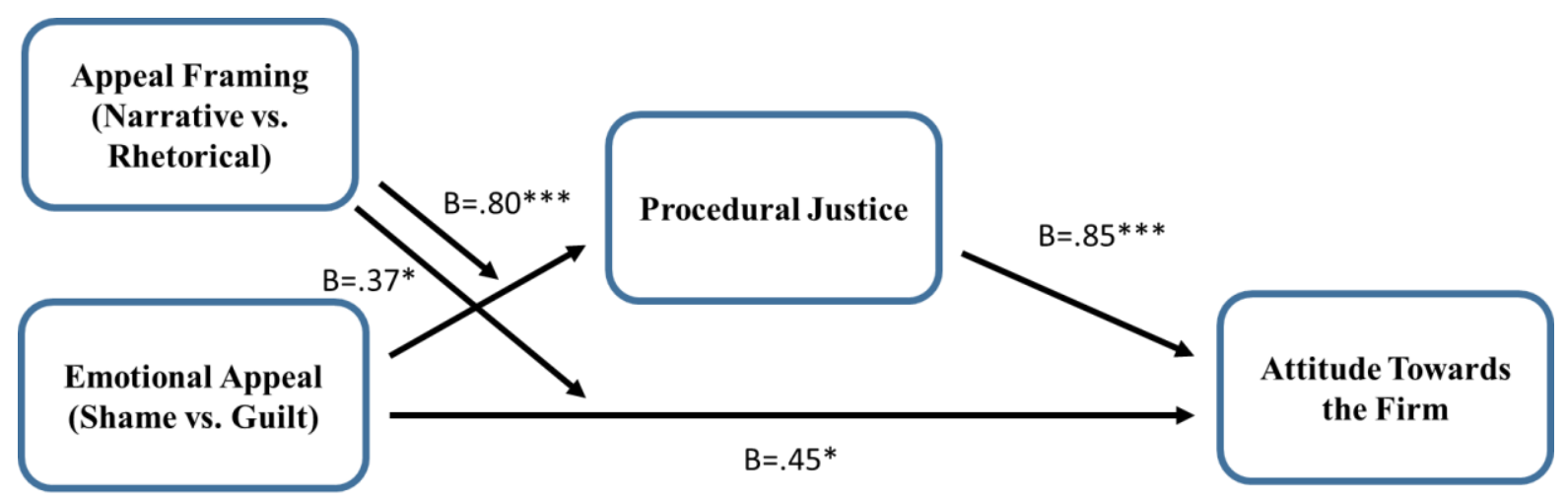


Figure 5- The Mediating Role of Procedural Justice on Retaliation Intentions

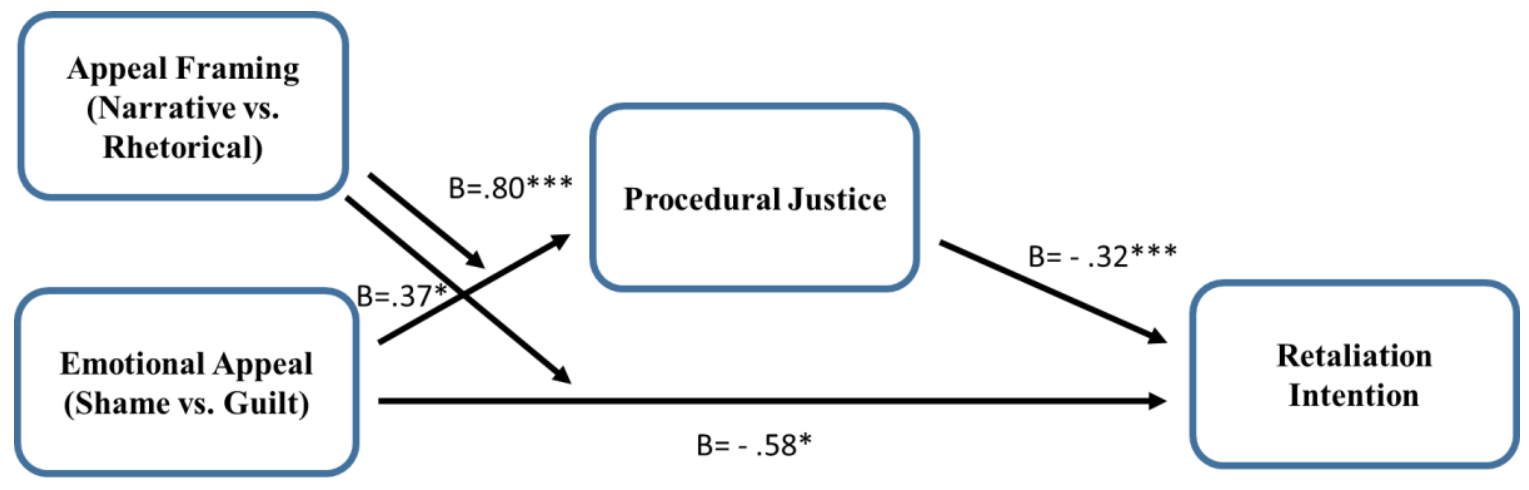

\section{Result Summary}

Study 2 tested the behavioral intentions and negative outcomes associated with negative emotional appeals. Counter to our expectation I could not replicate our study 1 findings, and did not find support for $\mathrm{H} 1$ which predicted shame appeals to be more effective than guilt appeal in reducing behavioral intentions to engage in unethical behavior. Although, as explained earlier results indicated the majority of participants had the intention to change their behavior and behave ethically. This is in keeping with Tangney et al.'s (2007) finding that in the morality domain there is sometimes a disconnect between intentions and behavior. People tend to have good intentions, want to do the right thing and comply with moral standards, however, when it comes to behavior, I see that people do not always live up to their standards.

In support of $\mathrm{H} 2$, I find that shame appeals result in less desirable attitude towards the business and higher retaliation intentions compared to guilt appeals. In addition, results support our process hypothesis, where I expected perceptions of procedural justice to mediate the relationship between emotional appeal and consumer outcomes. I found that emotional appeals can positively influence attitudes and retaliation intentions by improving perceptions of procedural justice. Moreover, in partial support of H4, I find that the impact of emotional appeal on attitudes towards the business is moderated by appeal framing. Results indicate that framing a 
guilt appeal as a narrative significantly improves attitudes toward the business. However, contrary to our hypothesis the impact of emotional appeal on retaliation intentions did not vary as a function of appeal framing. Finally, in support of H5, I find that perceptions of procedural justice mediate the interaction between emotional appeal and appeal framing on both attitudes toward the business and retaliation intentions.

\section{General Discussion}

The prevalence of unethicality in the online world is demonstrated through various news articles. This is partly due to under-established rules and norms that govern the online environment. Many articles have studied drivers of ethics violations, but there is little known about how businesses can protect themselves against these violations. This becomes specifically important due to consumers' increased power in the online world. The increased power has created a sense of entitlement in consumers to a point where they believe that solely being a customer and writing online reviews warrants them the right to request or secure free or discounted products or services. As demonstrated by Wilkes (1978), businesses are rarely seen as victims when they have been taken advantage of. Instead, consumer believe the businesses get what they deserve in these situations. The public's attribution of self-interest seeking to businesses' every behavior makes it difficult for them to take actions against the violators, and to protect themselves and their staff. In this research I examined different strategies for businesses to regain some of their lost power in the online world.

\section{Theoretical contribution}

This article contributes to theory relating to emotional appeals and appeal framing in the context of consumer misconduct. Prior research has used negative emotional appeals to induce attitude change for self-harming behavior. I extend previous research on negative emotional appeals by using highly aversive emotions such as shame and guilt to decrease the likelihood of 
ethical violations by consumers, when these ethical violations harm others and not the self. I demonstrate that although shame appeals reduce the likelihood of engaging in ethical misconducts, its use can bear negative repercussion for the business.

In addition, this research extends our understanding of how appeal framing can improve message effectiveness and alleviate negative outcomes associated with negative emotional appeals. Prior research has shown that narrative framing increases the level of involvement, elaboration, and contemplation of message content (Gray et al., 2011). I build on this literature and provide evidence that use of narrative framing improves the effectiveness of guilt appeals. I demonstrate that although guilt appeals might lack the impetus to prevent ethical misconducts compared to shame appeals, framing these appeals as a narrative can improve consumers attitudes towards the business and reduce retaliation intentions. In addition, I find that rhetorical appeals' lack of emotional evocativeness can help alleviate some of the negative affect provoked by use of shame appeals.

I also identified the mechanism through which emotional appeals influence consumer outcomes such as attitudes towards the business and retaliation intentions. I demonstrate that the right fit between the emotional appeal and appeal framing can enhance perceptions of procedural justice which in turn results in improved attitudes towards the business and lower retaliation intentions.

\section{Practical Implications}

As explained throughout this paper, one of the issues faced by businesses today is consumer entitlement which sometimes lead to sub-ethical behavior. A ReviewerCard, which is an ID card for prolific reviewers, is an illustration of this sense of entitlement. Reviewers use this card to inform businesses that they are going to put the business under scrutiny and the business should 
put forth their best effort to impress the reviewer. The founder of ReviewerCard notes that using the card to receive free products or superior service is not a form of blackmail; "It's not a threat. It's a way to get the service you deserve" (Bellini, 2013). Another example involves excessive product returns. Safdar (2018) reports that in 2017 merchandise returns cost US retailers $\$ 22.8$ billion. Although the majority of consumers believe they are entitled to merchandise return as well as many other free or discounted services, they fail to take into account the negative impact their entitled mentality has on business. If the theory discussed in this paper can only help reduce excessive merchandise returns by $.0005 \%$, it saves US retailers $\$ 1$ million annually.

In response to consumer entitled mentality, many businesses have resorted to use of highly aversive emotional appeals such as shame and guilt. However, over two studies I show that although these emotional appeals might be effective in reducing consumer unethicality, they involve negative repercussions for the business such as retaliation intentions. In this paper I aim to provide insights into how managers can employ appeal framing to more effectively communicate their emotional appeal content. Our results indicate that a rhetorical framing for shame appeals, alleviates some of the negative repercussions associated with this highly aversive emotion. Moreover, the guilt appeal would be more effective if framed as a narrative. 
Table 1- Conditional indirect effects of shame vs. guilt emotional appeals on attitudes toward the firm and retaliation intentions at values of the emotional appeal framing

\begin{tabular}{|c|c|c|c|c|c|c|c|c|c|}
\hline & \multirow[b]{2}{*}{ Values } & \multicolumn{4}{|c|}{ Attitude Toward the Firm } & \multicolumn{4}{|c|}{ Retaliation Intentions } \\
\hline & & Effect & SE & $\begin{array}{l}\text { Lower } \\
\text { level CI }\end{array}$ & $\begin{array}{l}\text { Upper } \\
\text { Level CI }\end{array}$ & Effect & SE & $\begin{array}{l}\text { Lower } \\
\text { level CI }\end{array}$ & $\begin{array}{l}\text { Upper } \\
\text { Level CI }\end{array}$ \\
\hline & Rhetorical & 0.38 & .15 & 0.09 & .67 & -.12 & .06 & -.27 & -.02 \\
\hline $\begin{array}{l}\text { Appeal } \\
\text { Framing }\end{array}$ & Narrative & .95 & .21 & .55 & 1.39 & -.30 & .12 & -.59 & -.09 \\
\hline
\end{tabular}

Note. Bootstrapped estimates for the standard error (SE) are presented. 


\section{Appendix A}

Guilt appeal/Narrative Framing and Shame Appeal/Rhetorical Framing

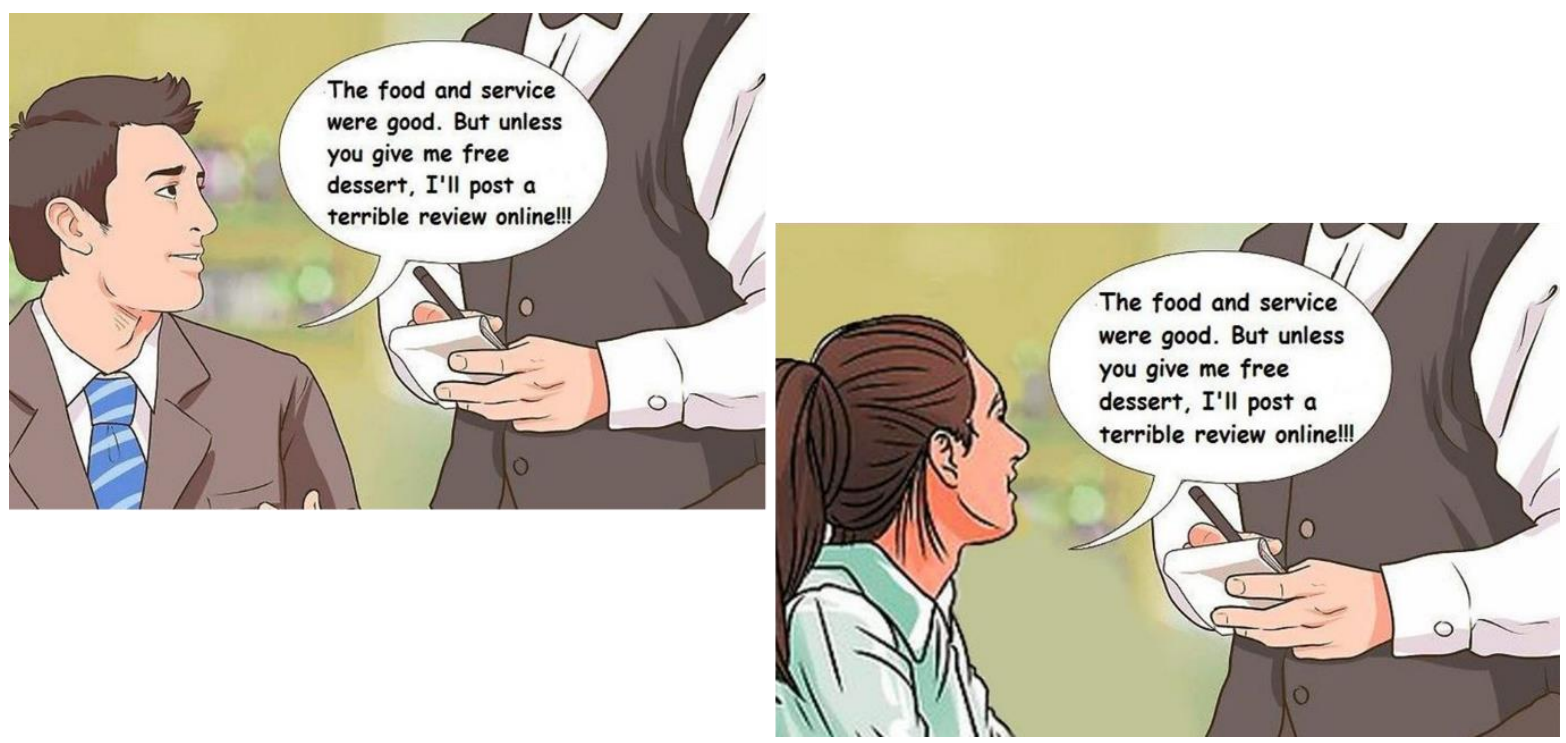




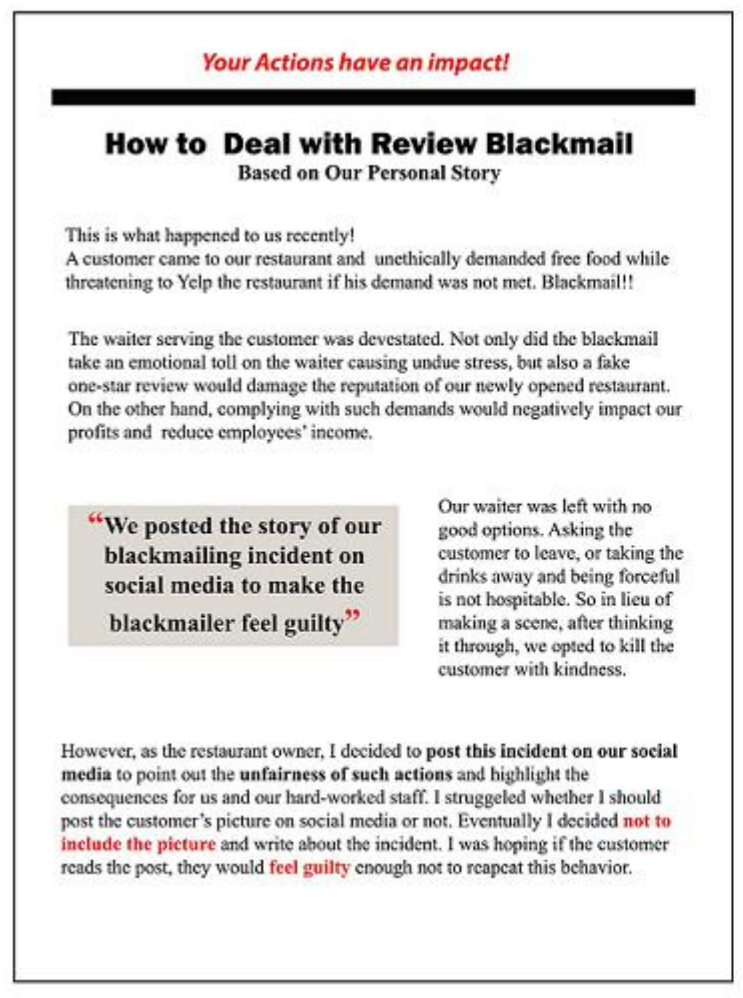

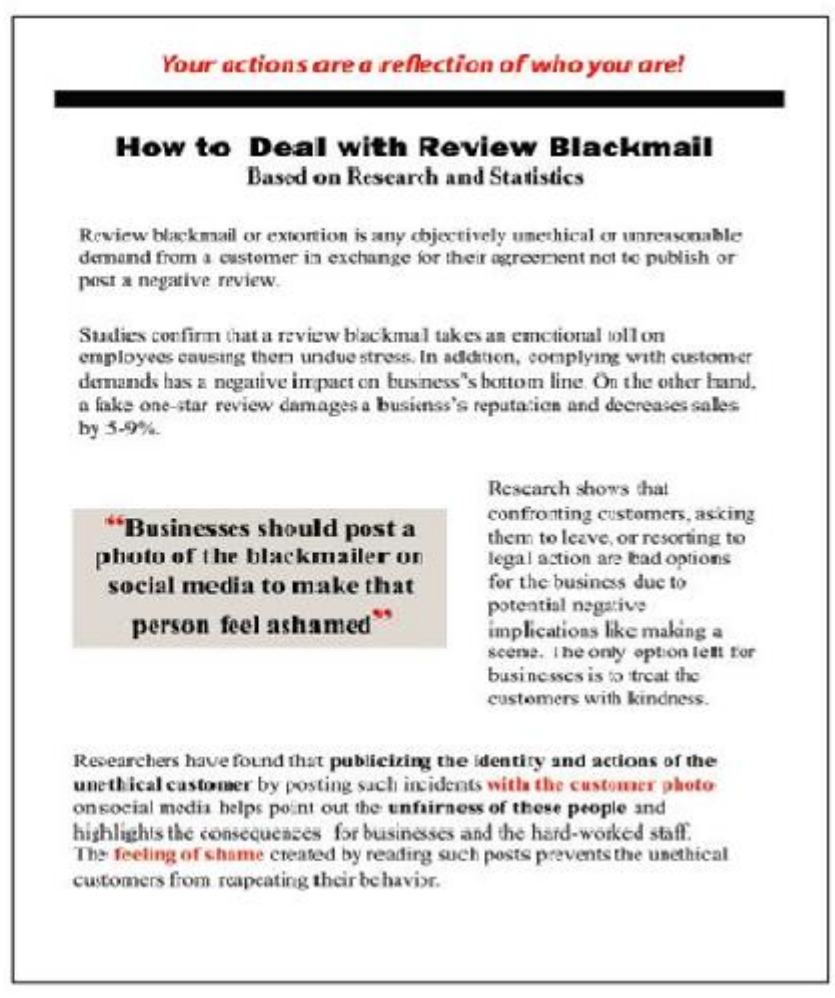




\section{References}

Achar, C., So, J., Agrawal, N., \& Duhachek, A. (2016). What We Feel and Why We Buy: The Influence of Emotions on Consumer Decision-Making. Current Opinion in Psychology, 10, 166-170. http://doi.org/10.1016/j.copsyc.2016.01.009

Adaval, R. (2001). Sometimes It Just Feels Right : The Differential Inconsistent Product Information. Journal of Consumer Research, 28(june), 1-17.

Agrawal, N., \& Duhachek, A. (2010). Emotional Compatibility and the Effectiveness of Antidrinking Messages: A Defensive Processing Perspective on Shame and Guilt. Journal of Marketing Research, 47(2), 263-273. http://doi.org/10.1509/jmkr.47.2.263

Alba, J. W., \& Williams, E. F. (2012). Pleasure principles: A review of research on hedonic consumption. Journal of Consumer Psychology, 23(1), 2-18. http://doi.org/10.1016/j.jcps.2012.07.003

Ambrose, M., Hess, R. L., \& Ganesan, S. (2007). The Relationship Between Justice and Attitudes: An Examination of Justice Effects on Event and System-Related Attitudes. Organizational Behavior and Human Decision Processes, 103(1), 21-36. http://doi.org/10.1016/j.obhdp.2007.01.001

Babin, B., Darden, W., \& Griffin, M. (1994). Work and/or fun: measuring hedonic and utilitarian shopping value. Journal of Consumer Research, 20(March 1994), 644-657. Retrieved from http://www.jstor.org/stable/2489765

Bagozzi, R. P., Gopinath, M., \& Nyer, P. U. (1999). The Role of Emotions in Marketing. Journal of Academy of Marketing Science, 27(2), 184-206. http://doi.org/10.1001/jama.1953.03690150021006

Bagozzi, R. P., \& Moore, D. J. (1994). Public Service Advertisements : Emotions and Empathy Gimle Prosocial Behavior. Journal of Marketing, 58(January), 56-70. http://doi.org/10.2307/1252251

Basil, D. Z., Ridgway, N. M., \& Basil, M. D. (2006). Guilt Appeals : The Mediating Effect of Responsibility. Psychology \& Marketing, 23(12), 1035-1054. http://doi.org/10.1002/mar

Bauer, M. R. (2016). To get people to use less electricity, utility providers are employing guilt and peer pressure. Retrieved from https://qz.com/812649/electric-companies-are-guiltingcustomers-into-using-less-electricity/

Bellini, J. (2013). Apparently This Matters: ReviewerCard. Retrieved from https://www.cnn.com/2013/01/25/tech/social-media/apparently-this-mattersreviewercard/index.html

Bennett, R. (1998). Shame, guilt, \& responses to non-profict \& public sector ads. International Journal of Advertising, 17(4), 483-499. http://doi.org/10.1080/02650487.1998.11104734

Blumentha, R. L. (2015). Michael Scelfo Publicly Lays the Smackdown on Entitled Alden \& Harlow Non-Customers. Retrieved from https://boston.eater.com/2015/2/28/8126023/michael-scelfo-publicly-lays-the-smackdownon-entitled-alden-harlow\#4162106 
Boudewyns, V., Turner, M. M., \& Paquin, R. S. (2013). Shame-Free Guilt Appeals: Testing the Emotional and Cognitive Effects of Shame and Guilt Appeals. Psychology \& Marketing, 30(9), 811-825. http://doi.org/10.1002/mar

Braverman, J. (2008). Testimonials Versus Informational Persuasive Messages. Communication Research, 35(5), 666-694.

Brennan, L., \& Binney, W. (2010). Fear, guilt, and shame appeals in social marketing. Journal of Business Research, 63(2), 140-146. http://doi.org/10.1016/j.jbusres.2009.02.006

Breugelmans, S. M., \& Poortinga, Y. H. (2006). Emotion without a word: shame and guilt among Rarámuri Indians and rural Javanese. Journal of Personality and Social Psychology, 91(6), 1111-1122. http://doi.org/10.1037/0022-3514.91.6.1111

Brockner, J., \& Wiesenfeld, B. M. (1996). An Integrative Framework for Explaining Reactions to Decisions : Interactive Effects of Outcomes and Procedures. Psychological Bulletin, 120(2), 189-208.

Brown, R., González, R., Zagefka, H., Manzi, J., \& Cehajic, S. (2008). Nuestra culpa: collective guilt and shame as predictors of reparation for historical wrongdoing. Journal of Personality and Social Psychology, 94(1), 75-90. http://doi.org/10.1037/0022-3514.94.1.75

Bruner, J. S. (2009). Actual minds, possible worlds. Harvard University Press.

Buchanan, D. R. (2008). Autonomy, Paternalism, and Justice : Ethical Priorities in Public Health. Health Policy and Ethics, 98(1), 15-21. http://doi.org/10.2105/AJPH

Cheema, A., \& Bagchi, R. (2011). The Effect of Goal Visualization on Goal Pursuit : Implications for Consumers and Managers. Journal of Marketing, 75(2), 109-123.

Chen, F., \& Sengupta, J. (2014). Forced to Be Bad: The Positive Impact of Low-Autonomy Vice Consumption on Consumer Vitality. Journal of Consumer Research, 41(4), 1089-1107. http://doi.org/10.1086/678321

Choi, J., Li, Y. J., Rangan, P., Chatterjee, P., \& Singh, S. N. (2014). The Odd-Ending Price Justification Effect: The Influence of Price-Endings on Hedonic and Utilitarian Consumption. Journal of the Academy of Marketing Science, 42(5), 545-557. http://doi.org/10.1007/s11747-014-0369-6

Cohen, T. R., Wolf, S. T., Panter, A. T., \& Insko, C. A. (2011). Introducing the GASP scale: A new measure of guilt and shame proneness. Journal of Personality and Social Psychology, 100(5), 947-966. http://doi.org/10.1037/a0022641

Cotte, J., Coulter, R. A., \& Moore, M. (2005). Enhancing or disrupting guilt: The role of ad credibility and perceived manipulative intent. Journal of Business Research, 58(3 SPEC. ISS.), 361-368. http://doi.org/10.1016/S0148-2963(03)00102-4

de Hooge, I. E., Breugelmans, S. M., \& Zeelenberg, M. (2008). Not so ugly after all: when shame acts as a commitment device. Journal of Personality and Social Psychology, 95(4), 933-943. http://doi.org/10.1037/a0011991

de Hooge, I. E., Zeelenberg, M., \& Breugelmans, S. M. (2010). Restore and protect motivations 
following shame. Cognition and Emotion, 24(1), 111-127.

http://doi.org/10.1080/02699930802584466

De Wit, J. B. F., Das, E., \& Vet, R. (2008). What works best: Objective statistics or a personal testimonial? An assessment of the persuasive effects of different types of message evidence on risk perception. Health Psychology, 27(1), 110-115. http://doi.org/10.1037/02786133.27.1.110

Dennis, S. (2018). The Ticking Time Bomb Of E-commerce Returns. Retrieved October 31, 2018, from https://www.forbes.com/sites/stevendennis/2018/02/14/the-ticking-time-bombof-e-commerce-returns/\#5e0af1f04c7f

Derrogatis, L. R., Lipman, R. S., \& Covi, I. (1973). The SCL-90: An outpatient psychiatric rating scale. Psychopharmacology Bulletin, 9, 13-28.

Dhar, R., \& Wertenbroch, K. (2000). Consumer Choice Between Hedonic and Utilitarian Goods. Journal of Marketing Research, 37(1), 60-71. http://doi.org/10.1509/jmkr.37.1.60.18718

Duhachek, A., Agrawal, N., \& Han, D. (2012). Guilt Versus Shame: Coping, Fluency, and Framing in the Effectiveness of Responsible Drinking Messages. Journal of Marketing Research, 2437, 1-14. http://doi.org/10.1509/jmr.10.0244

Ekman, P., \& Friesen, W. V. (1971). CONSTANTS ACROSS CULTURES IN THE FACE AND EMOTION. Journal of Personality and Social Psychology, 17(2), 124-129.

Ellsworth, P. C. (1994). Sense, culture, and sensibility. Emotion and Culture: Empirical Studies of Mutual Influence. http://doi.org/10.1037/10152-001

Gausel, N., \& Leach, C. W. (2011). Concern for self-image and social image in the management of moral failure: Rethinking shame. European Journal of Social Psychology, 41(4), 468478. http://doi.org/10.1002/ejsp.803

Gefen, D., Karahanna, E., \& Straub, D. W. (2003). Trust and TAM in Online Shopping: An Integrated Mode. MIS Quarterly, 27(1), 51-90. http://doi.org/10.1017/CBO9781107415324.004

Gehm, T. L., \& Scherer, K. R. (1988). Relating situation evaluation to emotion differentiation: Nonmetric analysis of cross-cultural questionnaire data. In Facets of Emotion: Recent Research (pp. 61-77). Hillsdale, NJ: Erlbaum.

Goswami, S. (2014). Shaming Punishments. In The Encyclopedia of Criminology and Criminal Justice (pp. 2110-2115). http://doi.org/10.1177/0192513X12437708

Gray, J. B., Carolina, N., \& Harrington, N. G. (2011). Narrative and Framing : A Test of an Integrated Message Strategy in the Exercise Context. Journal of Health Communication, 16, 264-281. http://doi.org/10.1080/10810730.2010.529490

Green, M. C., \& Brock, T. C. (2002). In the mind's eye: Transportation-imagery model of narrative persuasion. In M. C. Green, J. J. Strange, \& T. C. Brock (Eds.), Testimonial impact: Social and cognitive foundations (pp. 315-342). Mahwah, NJ: Lawrence Erlbaum Associates. 
Gregoire, Y., \& Fisher, R. J. (2006). The effects of relationship quality on customer retaliation. Marketing Letters, 17, 31-46. http://doi.org/10.1007/s11002-006-3796-4

Hampton, J. (1984). The Moral Education Theory of Punishment. Philosophy \& Public Affairs, 13(3), 208-238.

Han, D., Duhachek, A., \& Agrawal, N. (2014). Emotions Shape Decisions through Construal Level : The Case of Guilt and Shame. Journal of Consumer Research, 41(4), 1047-1064. http://doi.org/10.1086/678300

Hayes, A. F. (2013). Introduction to Mediation, Moderation, and Conditional Process Analysis. New York, NY: The Guilford Press.

Higgins, E. T. (1987). Self-discrepancy: A theory relating self and affect. Psychological Review, 94(3), 319-340. http://doi.org/10.1037//0033-295X.94.3.319

Higgins, E. T., Klein, R., \& Strauman, T. (1985). Self-concept discrepancy theory: A psychological model for distinguishing among different aspects of depression and anxiety. Social Cognition, 3(1), 51. http://doi.org/10.1521/soco.1985.3.1.51

Homer, P. M. (1995). Ad Size as an Indicator of Perceived Advertising Costs and Effort: The Effects on Memory and Perceptions. Journal of Advertising, 24(4), 1-12.

Inman, J. J., Winer, R. S., \& Ferraro, R. (2009). The Interplay Among Category Characteristics , Customer Characteristics, and Customer Activities on In-Store Decision Making. Journal of Marketing, 73(September), 19-29.

Kalnikaite, V., Bird, J., \& Rogers, Y. (2013). Decision-making in the aisles: Informing, overwhelming or nudging supermarket shoppers? Personal and Ubiquitous Computing, 17(6), 1247-1259. http://doi.org/10.1007/s00779-012-0589-z

Kees, J., Burton, S., Andrews, J. C., \& Kozup, J. (2010). Understanding How Graphic Pictorial Warnings Work on Cigarette Packaging. Journal of Public Policy \& Marketing, 29(2), 265276. http://doi.org/10.1509/jppm.29.2.265

Khan, U., Dhar, R., \& Wertenbroch, K. (2005). A Behavioral Decision Theoretic Perspective on Hedonic and Utilitarian Choice. Inside Consumption: Frontiers of Research on Consumer Motives, Goals, and Desires, 1, 144-165.

Kivetz, R., \& Keinan, A. (2006). Repenting Hyperopia: An Analysis of Self-Control Regrets. Journal of Consumer Research, 33(2), 273-282. http://doi.org/10.1086/506308

Kivetz, R., \& Simonson, I. (2002). Earning the Right to Indulge : Effort as a Determinant of Customer Preferences Toward Frequency Program Rewards. Journal of Marketing Research, XXXIX(May), 155-170.

Krieg, G. (2016). How to make "deadbeat dads" pay in 140 characters or less. Retrieved January 3, 2019, from https:/www.cnn.com/2016/01/12/politics/deadbeat-dad-tweetsarizona/index.html

Kronrod, A., \& Danziger, S. (2013). “Wii Will Rock You!” The Use and Effect of Figurative Language in Consumer Reviews of Hedonic and Utilitarian Consumption. Journal of 
Consumer Research, 40(4), 726-739. http://doi.org/10.1086/671998

Lagattuta, K. H., \& Thompson, R. A. (2007). The development of self-conscious emotions: Cognitive processes and social influences. New York, NY: The Guilford Press.

Lazarus, R. S. (1991). Progress on a cognitive-motivational-relational theory of emotion. The American Psychologist, 46(8), 819-834. http://doi.org/10.1037/0003-066X.46.8.819

Leach, C. W., \& Cidam, A. (2015). When is shame linked to constructive approach orientation? A meta-analysis. Journal of Personality and Social Psychology, 109(6), 983-1002. http://doi.org/10.1037/pspa0000037

Lee-Wingate, S. N., \& Corfman, K. P. (2010). A Little Something for Me and Maybe for You, Too: Promotions that Relieve Guilt. Marketing Letters, 21(4), 385-395. http://doi.org/10.1007/s11002-009-9093-2

Leith, K. P., \& Baumeister, R. F. (1998). Empathy, Shame, Guilt, and Narratives of Interpersonal Conflicts: Guilt-Prone People Are Better at Perspective Taking. Journal of Personality, 66(1), 1-38. http://doi.org/10.1111/1467-6494.00001

Lewis, H. B. (1971). Shame and Guilt in Neurosis. New York: International Universities Press.

Luetge, C. (2006). An Economic Rationale for a Work and Savings Ethic? J. Buchanan's Late Works and Business Ethics. Journal of Business Ethics, 66(1), 43-51. http://doi.org/10.1007/s10551-006-9045-1

Mandel, N., Rucker, D. D., Levav, J., \& Galinsky, A. D. (2017). The Compensatory Consumer Behavior Model: How self-discrepancies drive consumer behavior. Journal of Consumer Psychology, 27(1), 133-146. http://doi.org/10.1016/j.jcps.2016.05.003

Maxham, J. G., \& Netemeyer, R. G. (2002). Modeling customer perceptions of complaint handling over time : the effects of perceived justice on satisfaction and intent. Journal of Retailing, 78, 239-252.

Maxham, J. G., \& Netemeyer, R. G. (2003). Firms Reap What They Sow : The Effects of Shared Values and Perceived Organizational Justice on Customers' Evaluations of Complaint Handling. Journal of Marketing, 67(1), 46-62.

Mazar, N., Amir, O., \& Ariely, D. (2008). The Dishonesty of Honest People: A Theory of SelfConcept Maintenance. Journal of Marketing Research, 45(6), 633-644. http://doi.org/10.1509/jmkr.45.6.633

Mishra, A., \& Mishra, H. (2011). The Influence of Price Discount Versus Bonus Pack on the Preference for Virtue and Vice Foods. Journal of Marketing Research, 48(1), 196-206. http://doi.org/10.1509/jmkr.48.1.196

Niedenthal, P. M., Tangney, J. P., \& Gavanski, I. (1994). “If only I weren't 'versus' if only I hadn't": distinguishing shame and guilt in counterfactual thinking. Journal of Personality and Social Psychology, 67(4), 585-595. http://doi.org/10.1037/0022-3514.67.4.585

Nikolova, H., Lamberton, C., \& Coleman, N. V. (2017). Stranger Danger : When and Why Consumer Dyads Behave Less Ethically Than Individuals. Journal of Consumer Research, 
$O$ (November), 1-58. http://doi.org/10.1093/jcr/ucx108/4563318

Okada, E. M. (2005). Justification Effects on Consumer Choice of Hedonic and Utilitarian Goods. Journal of Marketing Research, 42(February), 43-53. http://doi.org/10.1509/jmkr.42.1.43.56889

Oppenheim, L. (2008). Guilt. Journal of the American Psychoanalytic Association, 56(3), 967977. http://doi.org/10.1177/0003065108323463

Otto, A., \& Kellaris, J. (2013). Sub-Ethical Choice Behavior: the Attraction Effect of Scarcity. In S. Botti \& A. Labroo (Eds.), Advances in Consumer Research, Volume 41. Duluth, MN: Advances in Consumer Research.

Payne, E. (2014). Guests BLACKMAILING hotels and restaurants with bad TripAdvisor reviews if they're not given freebies. Retrieved February 6, 2018, from http://www.dailymail.co.uk/travel/article-2623288/The-blackmailers-post-bad-reviewsunless-theyre-given-freebies-hotels-restaurants.html

Peloza, J., White, K., \& Shang, J. (2013). Good and Guilt-Free : The Role of Self-Accountability in Influencing Preferences for Products with. Journal of Marketing, 77(January), 104-119.

Perlman, M. (1958). An investigation of anxiety as related to guilt and shame. AMA Archives of Neurology \& Psychiatry, 80(6), 752-759.

Rosenberg, E. (2018). 'I am not a racist': New York lawyer apologizes for rant about Spanish speakers in viral video. Retrieved from https://www.washingtonpost.com/news/business/wp/2018/05/22/i-am-not-a-racist-newyork-lawyer-apologizes-for-rant-about-spanish-speakers-in-viralvideo/?noredirect=on\&utm_term=.358f0942c843

Rucker, D. D., \& Galinsky, A. D. (2008). Desire to Acquire: Powerlessness and Compensatory Consumption. Journal of Consumer Research, 35(2), 257-267. http://doi.org/10.1086/588569

Rucker, D. D., Galinsky, A. D., \& Dubois, D. (2012). Power and consumer behavior: How power shapes who and what consumers value. Journal of Consumer Psychology, 22(3), 352-368. http://doi.org/10.1016/j.jcps.2011.06.001

Smith, R. H., Webster, J. M., Parrott, W. G., \& Eyre, H. L. (2002). The role of public exposure in moral and nonmoral shame and guilt. Journal of Personality and Social Psychology, 83(1), 138-159. http://doi.org/10.1037/0022-3514.83.1.138

Steenhaut, S., \& Kenhove, P. Van. (2006). The Mediating Role of Anticipated Guilt in Consumers ' Ethical Decision-Making. Journal of Business Ethics, 69, 269-288. http://doi.org/10.1007/s10551-006-9090-9

Sunshine, J., \& Tyler, T. R. (2003). The Role of Procedural Justice and Legitimacy in Shaping Public Support for Policing. Law Ad Society Review, 37(3), 513-548.

Tangney, J. P., \& Dearing, R. L. (2002). Shame and Guilt. New York, NY: The Guilford Press. Tangney, J. P., Miller, R. S., Flicker, L., \& Barlow, D. H. (1996). Are shame, guilt, and 
embarrassment distinct emotions? Journal of Personality and Social Psychology, 70(6), 1256-1269. http://doi.org/10.1037/0022-3514.70.6.1256

Tangney, J. P., Niedenthal, P. M., Covert, M. V, \& Barlow, D. H. (1998). Are shame and guilt related to distinct self-discrepancies? A test of Higgins's (1987) hypotheses. Journal of Personality and Social Psychology, 75(1), 256-268. http://doi.org/10.1037/00223514.75.1.256

Tangney, J. P., Stuewig, J., \& Mashek, D. J. (2007). Moral Emotions and Moral Behavior. Annual Review of Psychology, 58(1), 345-372. http://doi.org/10.1146/annurev.psych.56.091103.070145

Tangney, J. P., Wagner, P. E., \& Gramzow, R. (1989). The test of self-conscious affect. Fairfax, VA: George Mason University.

Tangney, J. P., Wagner, P., Fletcher, C., Gramzow, R., Bordeaux, E., Constantin, J., ... Smart, C. (1992). Shamed Into Anger? The Relation of Shame and Guilt to Anger and Self-Reported Aggression. Journal of Personality and Social Psychology, 62(4), 669-675. http://doi.org/10.1037/0022-3514.62.4.669

Tepper, B. J. (2000). Consequences of Abusive Supervision. Academy of Management Journal, 43(2), 178-190.

Thompson, R., \& Haddock, G. (2012). Sometimes stories sell: When are narrative appeals most likely to work? European Journal of Social Psychology, 42(1), 92-102. http://doi.org/10.1002/ejsp.850

Tonry, M. (2005). Obsolescence and Immanence in Penal Theory and Policy. Columbia Law Review Association, 105(4), 1233-1275.

Trevino, L. K. (1992). The Social Implications of Punishing Unethical Behavior: Observers' Cognitive and Affective Reactions. Journal of Management, 18(4), 751-768. http://doi.org/10.1177/014920639201800409

Wansink, B., \& Chandon, P. (2006). Can "Low-Fat" Nutrition Labels Lead to Obesity? Journal of Marketing Research, 43(4), 605-617. http://doi.org/10.1509/jmkr.43.4.605

Wicker, F. W., Payne, G. C., \& Morgan, R. D. (1983). Participant Descriptions of Guilt and Shame. Motivation and Emotion, 7(1), 25-39. http://doi.org/10.1177/0192513X12437708

Wilkes, R. E. (1978). Fraudulent Behavior by Consumers. Journal of Marketing, 42(4), 67-75.

Xiao, E., \& Houser, D. (2011). Punish in public. Journal of Public Economics, 95(7-8), 10061017. http://doi.org/10.1016/j.jpubeco.2010.11.021

Zillman, D., \& Brosius, H. B. (2000). Exemplification: On the influence of case reports on the perception of issues. Mahwah, New Jersley. 
Essay 3: How Do Online Customer Reviews Impact Online Purchases? The Role of Online Review Examination as a Guilt/Shame Reduction Strategy

\author{
Raika Sadeghein
}




\begin{abstract}
This essay investigates how aversive states of shame and guilt mediate the effect of value congruence and shopping motive (i.e., hedonic vs. utilitarian) on purchase intention and online information search (i.e., examining consumer reviews). Although the prevailing view in shopping motive literature implies negative affect such as guilt to be an outcome of hedonic shopping, I argue that it is the value violation associated with hedonic shopping that results in feelings of guilt or shame. In instances of value violation, utilitarian motive will also result in feelings of shame or guilt. To alleviate these aversive emotions and mitigate their negative effect on purchase intention, consumers turn into online information search. A value violating purchases causes the individual to read more online consumer reviews because the content of the reviews can provide the justification (i.e., quantifiable benefit) they need for their value violating-purchase. A value violation can result in shame or guilt depending on the publics vs. private nature of behavior. In instances of guilt, the quantifiable benefits found through information search can positively influence purchase intentions because they serve as the justification the shopper needs. However, shameful behavior cannot be as easily atoned through information search because shame involves public perceptions of self which is more difficult to alter. Thus, we do not see the same improvement in purchase intentions due to modification of online information search, as in instances of guilt.
\end{abstract}




\section{Introduction}

Which desert should I go with, the low-calorie healthy almond-date bar or the more delicious, high calorie Italian cream cake? Should I buy the regular laptop which provides all the features I need, or do I buy the high-tech gaming laptop which I can enjoy in addition to getting my tasks done? More importantly, will I feel guilty or ashamed after these purchases?

Consumer choice researchers have been interested in the relationship between shopping motive (i.e., utilitarian vs. hedonic) and the aversive state of guilt (e.g., Choi et al. 2014; Okada 2005). This research stream often examines how hedonic purchases lead to feelings of guilt unless the shopper can formulate some sort of justification (e.g., I have gone to the gym today, so it's okay if I choose a delicious high-calorie dessert). However, this stream of research commonly ignores the significance of shoppers' personal values and belief system. In this study, I argue that feelings of guilt are not a consequence of hedonic shopping per se, but rather a byproduct of the value violation occurring in association with the hedonic shopping motive and purchase behavior. For instance, do consumers generally feel guilty after purchasing a high-tech gaming laptop, or do they feel guilty if this purchase is violating one of their values (e.g., financial mindfulness)? I argue that unless the purchase defies a personal goal or value, it will not result in aversive emotions such as shame or guilt.

In fact, research has demonstrated that in many instances purchase intention and satisfaction with hedonic purchases are higher than utilitarian purchases (Khan, Dhar, and Wertenbroch 2005). Okada (2005) found a reversal in relative preference between hedonic and utilitarian purchases when both choices were presented together versus when they were presented individually. Consumers tend to have a higher preference for the hedonic item if it is presented alone. However, when consumers are given a choice between a hedonic and a utilitarian item, 
they prefer the utilitarian item. Okada $(2005,45)$ argues that this preference reversal occurs because joint presentation of alternatives creates a contrast effect that "highlights the discretionary nature of the hedonic alternative." I argue that this contrast effect also reminds consumers of their personal goals and values which makes it more salient that, with this purchase they are violating one or more of those values. Thus, resulting in lower preference toward the hedonic option.

In this research, I am extending Okada's (2005) work by showing that it is the violation of value that drives consumer's willingness to pay, purchase intention, and satisfaction with the purchase. In cases where no value violation has occurred, I don't expect to see any significant difference between utilitarian and hedonic motives. However, I expect a significantly higher preference towards, and satisfaction with, the utilitarian alternative in instances where a violation of value has occurred. This is because when the discretionary nature of a hedonic motive combines with a value violation in a purchase, it deters consumers from making the purchase decision or being satisfied with the product or service post-purchase.

In addition, the present paper seeks to better understand consumers' decision-making process for online purchases. I am specifically interested in examining how people might utilize online consumer reviews to serve as a decision context for justification of the value-violating purchase. I investigate the role of guilt and shame as outcomes of value violation. Research shows both emotions of shame and guilt as consequences of self-discrepancies (Niedenthal, Tangney, and Gavanski 1994); self-discrepancy occurs when an individual believes he/she is deviating from held values which creates a discrepancy between the actual self and the ideal self. Research in psychology points out the criticality of including both measurements of shame and guilt in a study, even if the focal variable of interest is only one of these emotions, otherwise the 
researcher risks confounding the two emotions (Tangney and Dearing 2002). In addition, these emotions are associated with different outcomes, and thus provide quite important and distinct implications. As a result, I examine both emotions in this study.

Through the integration of the literature on emotions of shame and guilt and consumer choice literature, a framework is proposed that (1) examines the effect of public versus private violation of values on evoking feelings of guilt or shame, (2) investigates whether a utilitarian or hedonic shopping motive impacts the relationship between values congruence and feelings of shame or guilt, and finally (3) explores the influence of guilt and shame on consumer's willingness to pay, review examination, and purchase intention.

\section{Theoretical Background}

\section{Value violating purchase}

A self-discrepancy is defined as an incongruity between an individual's actual and ideal self; in other words, the inconsistency between who the individual is and who she/he aspire to be (Higgins 1987). Self-discrepancy occurs when an individual perceives a gap between her/his held values, and their current standing which might be due to a misfit between values and deeds. This gap could be in any domain (e.g., financial, health related, educational, or even moral), and is considered an aversive state. As such, the individual experiencing the self-discrepancy will attempt to either avoid circumstances triggering a self-discrepancy, or try to reduce selfdiscrepancy through different coping mechanisms (Mandel et al. 2017). The impact of selfdiscrepancy on consumption behavior has been studied in the marketing literature (e.g., Rucker and Galinsky 2008; Rucker, Galinsky, and Dubois 2012). Impulse shopping is a great example of a situation that has the potential to trigger self-discrepancy. The spontaneity and absence of prior elaboration on the purchase increases the risk of violation of values (Inman, Winer, and Ferraro 2009). The focus of this study however, is not self-regulation attempts after a self-discrepancy 
has occurred. I concentrate on the decision-making process involving anticipated selfdiscrepancy.

In general, consumers tend to avoid purchases that involve values violations because they are motivated to avoid the aversive state of self-discrepancy. Because they do not intend to make a purchase, they are less likely to take the effort to examine online reviews. And finally, even if a consumer is considering a value violating purchase, she/he is expected to be willing to pay a lower amount for the product/service compared to when they are not violating a value. This lower price can help them self-regulate and provide the justification they need to reduce selfdiscrepancy (Mandel et al. 2017). Thus, I expect:

H1: Value violation will lead to lower (a) purchase intentions, (b) willingness to pay, and (c) desire to examine online reviews and ratings.

\section{Aversive States of Shame and Guilt}

Consumer choice theory considers shame as a significant predictor of consumer attitudes, intention, and behavior. However, this stream of research fails to take into account the impact of shame as a consequence of shopping motive. Shame and guilt are closely related emotions that are both outcomes of value violation and self-discrepancy (Higgins 1987). If a behavior violates a value that creates a discrepancy between an individual's ideal-self or ought-self (i.e., who you wish or think you should be, based on your values) and the actual self (i.e., who you are), that individual feels shame or guilt. The significance of including shame in this literature stream becomes evident when we look at the different coping strategies people use to deal with these aversive emotional states (Duhachek, Agrawal, and Han 2012). Thus, it is reasonable to assume, these two emotions might have important yet different implications for consumer outcomes. As a result, I investigate both emotions as an outcome of value violation in this paper. 
The prevailing view of shame and guilt considers them as "moral emotions that arise from discrepancies between our behavior or characteristics of ourselves and our moral standards" (Tangney et al. 1998, 256). These emotions entail negative affect towards the self and the task evoking these emotions and thus are considered aversive (Leach and Cidam 2015). Goswami (2014) notes that feelings of shame are evoked by violations of cultural or social values, while guilt is more internally oriented and arises from violations of personal values. However, there is a significant overlap between cultural, social and personal values. Individuals internalize norms and values of the society from a young age, making it hard to distinguish whether the violated norm is a personal value or a societal or cultural one (Leith and Baumeister 1998). As Smith et al. (2002) state "moral dictates have been internalized and help ensure adherence to these dictates independent of public surveillance" (140).

A distinguishing factor between shame and guilt is what Higgins (1987) calls the standpoint dimension, the point of view of the person(s) threatening the perceptions of the self (Tangney et al. 1998). Higgins (1987) notes that shame is "associated with people believing that they have lost standing or esteem in the opinion of others ( $\mathrm{p} 322$ ). Thus, the major driver of shame is the public perception of the self (i.e., standpoint of significant others). If this perception is threatened, we feel shame. Guilt, on the other hand, affects an individual's own perception of the self (Tangney et al. 1998). In other words, if an individual violates a personal value or norm affecting his/her own self-perception, it evokes feelings of guilt. If this violation of value occurs in public, and self-perception is threatened, not because of self-discontentment but because others' perception of the self has been compromised, we feel shame. I therefore predict that:

H2: The public vs. private nature of action moderates the relationship between violation of value and feelings of guilt or shame. A public violation of value is positively associated with 
feelings of shame, whereas a private violation of value is positively associated with feelings of guilt.

As mentioned earlier, I expect feelings of guilt or shame to be associated with a value violation. Guilt and shame have been shown to influence consumer choice and decrease satisfaction with purchases. Both emotions are aversive, and result in pain and discomfort (Tangney and Dearing 2002). In order to avoid the aversive states of shame and guilt, and the consequent dissatisfaction, consumers are less likely to engage in shopping behavior that involves a value violation.

In addition, literature suggests that in circumstances involving feelings of guilt, shoppers have a need to justify their purchase and to provide a logical excuse for their decision. This is to disguise the spontaneous, emotional and discretionary nature of their purchase (Okada 2005). Mishra and Mishra (2011) find that price discounting is an effective guilt reducing strategy. Paying a lower amount than the actual worth of a product, gives consumers the excuse they need to justify their value violating purchase. Thus, I expect than in conditions of value violation, consumers are willing to pay a lower price for a product/service in order to reduce the amount of shame and guilt they might encounter.

Another strategy that could help consumers alleviate the discomfort associated with anticipated guilt is modification of online information search. I argue that the online environment provides a great context for finding a justification for the value violating behavior. When a violation of value occurs, in order to reduce the fear of punishment or anticipated guilt associated with failing to comply with rules, consumers modify their online information search to find a disguise and justification for their behavior. The content of online reviews can help the consumer find "a proper reason" to disguise the discretionary nature of the value violating purchase. 
Shame, however, has been shown to be accompanied by an "unwillingness to seek redress" (Oliver and Westbrook 1993, 25). As a result, contrary to feelings of guilt, I do not expect to see a change in information search behavior from consumers with high levels of shame. These individuals believe that they have lost their standing in their reference group because they have failed to comply with commonly-held values and norms (Higgins 1987). These individuals believe that a loss in standing cannot be easily remedied leading them to a state of inactivity and dormancy. In addition, shame generally focuses on self-perception whereas guilt deals with perceptions of behavior (Lewis 1971). In other words, redressing a wrong doing potentially mitigates feelings of guilt, but reducing feelings of shame requires changing other's perceptions of self. Therefore, we see an unwillingness to redress in cases of shame, because redeeming a loss of esteem in others' perceptions can be a rather difficult task (Oliver and Westbrook 1993). Thus, in these cases, I do not expect to see a change in information search behavior, because such behavior would not alter public's perception. However, similar to guilt, anticipated shame is an aversive state, which reduces consumer's intention to purchase in order to avoid such feelings. Thus, I expect:

H3: Guilt will mediate the relationship between value violation and (a) purchase intentions, (b) willingness to pay, and (c) desire to examine online reviews and ratings, and this indirect effect varies as a function of behavior (i.e., public vs. private).

H4: Shame will mediate the relationship between value violation and (a) purchase intentions, (b) willingness to pay, but will not mediate the relationship on (c) desire to examine online reviews and ratings, and this indirect effect varies as a function of behavior (i.e., public vs. private). 


\section{Shopping Motive and Negative Affect}

Early work in the utilitarian/hedonic domain, associated hedonism and utilitarianism with product type (e.g., Khan et al. 2005; Okada 2005). For example, a restaurant gift card was considered a hedonic product whereas a grocery store gift card was considered a utilitarian product. However, recent studies demonstrated that hedonism and utilitarianism are linked to shopping motive rather than product type (Alba and Williams 2012). The same product can be purchased and consumed with hedonic and/or utilitarian shopping motives. Babin, Darden, and Griffin (1994) distinguish between utilitarian and hedonic shopping motive. They define a utilitarian motive as a "conscious pursuit of an intended consequence" and a hedonic motive as “an outcome related more to spontaneous hedonic responses" (Babin et al. 1994, 645). Many studies have indicated the emotional nature of hedonic experiences and the rational nature of utilitarian experiences (Adaval 2001; Dhar and Wertenbroch 2000; Kivetz and Simonson 2002). In hedonism, product consumption is related to emotions, whereas in utilitarianism, product consumption is more of a rational decision considering the price, the bargain made and the desired functionality of the product (Babin et al. 1994). Choi et al. (2014) notes that it is also important to consider that utilitarian and hedonic purchases are not necessarily two sides of a dichotomy. In fact, a purchase can involve hedonic and utilitarian motives simultaneously. For instance, a consumer might be interested in buying a shoe because it is durable and looks good.

Consumer choice literature has identified guilt as an outcome of hedonic shopping motive that negatively impacts consumer preferences, purchase intention, willingness to pay, and satisfaction with the product (Kivetz and Keinan 2006; Kivetz and Simonson 2002; Okada 2005). Kivetz and Keinan (2006) found that in general, hedonic shoppers exhibit more guilt than utilitarian shoppers. Researchers note that it is more difficult to quantify benefits of hedonic products relative to utilitarian products (Okada 2005). Therefore, hedonic shopping motives 
provoke a sense of guilt (Kivetz and Simonson 2002). This aversive emotion may also be a result of the cultural values of hard work and parsimony (Okada 2005). According to Buchanan (2008) and based on puritan ethic, a community is more successful if they devote more time to hard work, save more, and refrain from leisure (Luetge 2006). Most people have learned these values and internalized them from childhood.

Ethical norms discourage alternative to rules (Luetge 2006). They create a sense of consequences, costs or penalties associated with defiance of rules. These consequences or penalties are not necessarily externally executed. More often than not, they are generated internally. Arnold Rothstein defines guilt as an unconscious fear of punishment (Oppenheim 2008). When people believe they are doing something they are not supposed to do (in this case shopping for pleasure and spending money on unnecessary items), they feel they are to blame. Consequently, in order to reduce the fear of punishment or guilt associated with violating the rules, consumers turn look for a justification for their behavior. In other words, in order to alleviate the guilt associated with hedonic shopping, consumers try to justify their hedonic purchases by explanations such as "I was just trying to help out, it was for a good cause (charity)," "I have worked really hard, I deserve it," "It was a great bargain; I might not need it now, but I am sure I will not find it at the same price when I need it." If consumers are unable to come up with such justifications, the anticipated guilt, cognitive dissonance and lowered perceptions of self significantly reduces preference towards hedonic alternatives and purchase intentions (Khan et al. 2005; Kivetz and Keinan 2006).

Previous literature has assumed that it is the pleasure associated with hedonic shopping that causes feelings of guilt. However, guilt is a byproduct of violation of value (Goswami 2014). If no value is being violated, shopping for pleasure should result in positive affect and satisfaction 
(Alba and Williams 2012). Therefore, I expect similar levels of consumer outcome (i.e., purchase likelihood, willingness to pay, and desire to examine online reviews) for both hedonic and utilitarian shopping when there is no value violation involved. However, I expect that in cases of value violation, a hedonic shopping motive exacerbates the negative consumer outcomes compared to utilitarian purchase which is due to the compounding effect of value violation and discretionary nature of hedonic shopping. Thus, I expect:

H5: Shopping motive moderates the relationship between value congruence and (a) purchase intention, (b) willingness to pay, and (c) desire to examine online reviews and ratings. A utilitarian motive is expected to reduce the negative impact of a non-congruent value on consumer outcomes while a hedonic motive is expected to exacerbate this effect.

As explained above, hedonic shopping motive is inherently accompanied with violating values of hard work and parsimony by itself, which will add to the personal value a shopper might be violating by purchasing a certain product or service. A violation of values should evoke negative feelings of guilt or shame even for consumers with a utilitarian motive. However, due to the fun and discretionary nature of hedonic shopping, we expect higher levels of guilt and shame as a result of value violation.

Based of the above reasoning, I expect these aversive emotions to have downstream effects on consumer outcomes. Shame and guilt are highly aversive states that motivate avoidance of the pain inflicting source, the purchase behavior in this context. Thus, I expect lower purchase likelihood and willingness to pay as outcomes of shame and guilt.

On the other hand, as noted above, if a consumer anticipating guilt can provide justification for the purchase, this should alleviate the expected negative affect. As noted earlier, online 
reviews provide the best context for finding appropriate justifications for the value violating behavior. These justifications are the quantifiable benefits of a certain product or service. Reading the reviews gives shoppers the chance to confirm or disconfirm the appropriateness of a product or service based on the information received from the reviews.

A consumer whose purchase does not involve a values violation does not need to go through the difficulty of finding these justifications. He/she can rely on heuristics facilitating their decision making (e.g., average star ratings) to uncomplicate an overwhelming body of information in consumer reviews (Kalnikaite, Bird, and Rogers 2013). Thus, consistent with previous literature I predict that:

H6: Guilt will mediate the relationship between value violation and (a) purchase intentions, (b) willingness to pay, and (c) desire to examine online reviews and ratings, and this indirect effect varies as a function of shopping motive (i.e., hedonic vs. utilitarian).

H7: Shame will mediate the relationship between value violation and (a) purchase intentions, (b) willingness to pay, but will not mediate the relationship on (c) desire to examine online reviews and ratings, and this indirect effect varies as a function of shopping motive (i.e., hedonic vs. utilitarian).

\section{OVERVIEW OF STUDIES}

I test the proposed framework in two studies. Study 1 demonstrates that value congruence is a significant predictor of purchase likelihood, willingness to pay, and reading online reviews. In addition, it identifies the mechanisms through which public/private violations of value influence consumer outcomes. More specifically, I demonstrate that that individuals feel shame as a result of losing esteem in front of their peers (i.e., public violation of value). Guilt on the other hand, is 
cause by privately violating a personal value. Study 2 further confirms the relationship between values violation and consumer outcomes and the mediating role of guilt and shame. In addition, in study 2 I examine the impact of utilitarian and hedonic shopping motive on the dependent variables and whether the relationship between value congruence and consumer outcomes vary as a function of shopping motive. The objective is to illustrate that the main driver of consumer outcomes (i.e., purchase likelihood, willingness to pay, and review examination) and negative emotional states is the values violation rather than hedonism or utilitarianism.

\section{STUDY 1}

Study 1 examines how value congruence/non-congruence influences consumers' purchase intention, willingness to pay and information search, and whether this relationship varies when the behavior is public versus private. I hypothesize that a non-congruent value will negatively influence purchase decision and this is driven by emotions of shame and guilt. I predict that these emotions of shame and guilt are caused by the interaction between an individual's value and the public vs. private nature of his/her behavior. I expect a non-congruent public behavior to result in shame while a non-congruent private behavior results in guilt.

\section{Method}

Two hundred and four people (113 females) from Amazon Mechanical Turk participated in this study for a small monetary compensation. Participants were randomly assigned to one of four conditions in a 2 (value: congruent vs. non-congruent) x 2 (behavior: public vs. private) between-subjects design. Participants were told they were shopping online when they saw a pair of running shoes that caught their eyes. They were not looking for running shoes, but they really liked this pair. Then participants proceeded to see 20 pairs of running shoes and were told that 
these are the shoes they saw while shopping online and asked to choose the one they liked best. Participants who did not like any of the shoes presented were not included in the study. In order to avoid brand bias, none of the shoes presented to participants had any brand logos or had design features unique to a specific brand. Participants in the congruent value condition read that while thinking about whether or not to buy the shoes, "[they] remember that at a recent health checkup, [their] doctor cautioned [them] about [their] health because [they] have gained weight." In the non-congruent condition, they read that "[they] remember that [they] have been cautioned about [their] finances because [their] income has been significantly reduced since [they] changed jobs"; adapted from Choi et al. 2014 (see Appendix A for complete stimuli).

Participants then read that due to their health/financial circumstances, they have decided to download an app that would help them stay on track. This app would either allow them to create support groups and start goal-related challenges with the group (i.e., public behavior), or start the challenge individually (i.e., private behavior). In the public condition, the individuals in the support group would assess the participant's goal-related behavior and give him/her an approval or disapproval rating, while in the private condition the approval/disapproval rating would be given by the app. After reading the scenario, participants in the public condition were asked to name five people they would like to include in the support group, and the participants in the private condition named their last five meals.

Participants were reminded that in order to make their final purchase decision there are three things to consider: (1) they really like these shoes, (2) their approval rating, and (3) the fact that their purchase behavior is public/private. They were then asked to indicate what they wanted to do next: (a) proceed to checkout, (b) examine star ratings, (c) read customer reviews, or (d) remove the item from the cart. Participants selecting to examine star ratings, saw a 4.5/5 star 
rating and then selected whether they wanted to read customer reviews, buy the product, or remove the item from the cart. Those selecting the "read customer reviews" option went through similar steps after reading favorable customer reviews. Purchase likelihood was measured using three items $(\alpha=.97)$ to answer, "Under these circumstances, the chance of you purchasing these running shoes is" (e.g., (1) very unlikely to (7) very likely). I measured willingness to pay by asking participants, "How much are you willing to pay for this shoe?" Review examination was measured using aggregate scores of the 5 questions were participants had the option to examine reviews. Participants were then asked to indicate whether they would feel shame, guilt or neither if they decide to by the shoes. In addition, state shame and guilt were measured using items adapted from TOSCA-3 (Tangney and Dearing 2002; Tangney et al. 2000) to assess emotional states of shame and guilt after reading the scenarios. Five items comprising 7-point scales answering to "Considering your goal, if you decide to buy the shoe, to what extent would you agree with the following statements?" captured respondent's shame (e.g., I'm irresponsible; 1= strongly disagree to $7=$ =strongly agree; $\alpha=.89$ ). Participants' guilt was assessed by answering to the same questions with five items on a 7-point scale (e.g., I would feel unhappy and eager to correct the situation by cancelling my order; $1=$ strongly disagree to $7=$ strongly agree; $\alpha=.93$ ). To address the alternative explanation that results are due to individuals' dispositional sensitivity to financial or health-related goals, participants were asked to indicate their level of physical activity " How often do you exercise?" (1= Never to 5= Everyday) and their level of financial planning (1= Poor to 7= Extremely well). Consistent with Han et al. (2014) a subset of scenarios by (Tangney and Dearing 2002; Tangney et al. 2000) were used to control for participant's shame and guilt proneness. I measured goal attainment motive with 6-items adopted from Cheema and Bagchi (2011) on a 7-point scale (e.g., It is difficult to take the goal seriously; $\alpha=$ 
.84). Finally, product attitude was measured using three items (e.g., "How would you evaluate this shoe?"; $1=$ Very bad to 7=Very good; $\alpha=.80$ ).

\section{Analysis and Results}

Manipulation Check. To check for a successful manipulation of value congruence vs. non-congruence, I asked participants to indicate their expectation of approval or disapproval rating. Ninety six percent of the individuals in the congruent value condition indicated that they expected to receive an approval rating and $83 \%$ of the individuals in the non-congruent value condition expected disapproval $\left(\chi^{2}=130.77, \mathrm{p}<.001\right.$, Cramer's $\left.\mathrm{V}=.80\right)$. In addition, participants were asked to indicate whether buying the running shoes would be consistent with their goal or not, with $96 \%$ of the individuals in the congruent value condition correctly responding "yes", and $69 \%$ of individuals in the non-congruent value condition selecting "no" $\left(\chi^{2}=92.37, \mathrm{p}<.001\right.$, Cramer's V=.67). I asked participants to recall the goal they were trying to achieve based on the scenario and $90 \%$ of the individuals in the congruent value condition correctly identified "improving health" and $83 \%$ in the non-congruent condition correctly identified "financial mindfulness" as the goal $(\chi 2=133.13, \mathrm{p}<.001$, Cramer's $\mathrm{V}=.81)$.

To assess successful manipulations of public vs. private behavior, participants were asked "Based on the scenario, is your purchase behavior public (i.e., select family and friends in the support group know) or private (nobody knows)?" Ninety percent of the individuals in the public condition, and $66 \%$ of the individuals in the private condition correctly responded to the question $\left(\chi^{2}=68.00, \mathrm{p}<.001\right.$, Cramer's $\left.\mathrm{V}=.57\right)$. Finally, I conducted a two-way contingency table analysis to assess the significance of those participants who correctly identified the source of approval/disapproval rating; 92\% (the app) and $84 \%$ (friends and family in the support group) correctly recalled their experimental condition $\left(\chi^{2}=119.97, \mathrm{p}<.001\right.$, Cramer's $\left.\mathrm{V}=.76\right)$. 
Purchase Likelihood. For all analyses, I start by testing all covariates (i.e., shame proneness, guilt proneness, goal attainment motive, product attitude, financial planning, physical activity, race, age, income, education, gender, involvement, mood) to assess whether they are significant predictors of the dependent variables. Attitude towards the product was the only significant predictor of purchase likelihood among covariates. Therefore, it was retained as a covariate in the analysis. In support of H1 (a), I observe a significant effect of value violation on purchase likelihood $\left(\mathrm{F}(1,199)=124.75, \mathrm{p}<.001, \eta^{2}=.38\right)$. Participants in the value violation (i.e., non-congruence) condition reported significantly lower purchase likelihood compared to those in the value congruent condition $\left(\mathrm{M}_{\text {non-congruent }}=3.60\right.$ and $\left.\mathrm{M}_{\text {congruent }}=6.05\right)$.

Willingness to Pay. H1 (b) predicted that when individuals are violating a value, they would be willing to pay a lower price for a product compared to when they are not violating a value. I find a marginally significant effect to support this hypothesis $\left(F(1,196)=3.60, p=.06, \eta^{2}=\right.$ $.02)$. Results indicate that value violation reduced participants' willingness to pay by $\$ 23\left(\mathrm{M}_{\mathrm{non}}\right.$ congruent=60.54 and $\mathrm{M}_{\text {congruent }}=83.37$ ).

Review Examination. I predicted that a value violation will result in lower likelihood of examining online reviews and star ratings. I find a marginally significant effect of value violation on review examination $\left(\mathrm{F}(1,199)=3.70, \mathrm{p}=.06, \eta^{2}=.02\right)$. Results indicate that participants in the value violation condition were less likely to read reviews or examine star ratings compared to individuals in the congruent value condition $\left(\mathrm{M}_{\text {non-congruent=.39 and }} \mathrm{M}_{\text {congruent }}=.55\right)$.

State Shame and Guilt. $\mathrm{H} 2$ predicted that a public behavior that is not congruent with one's values would result in shame, while guilt would arise if the same behavior is private. In addition, I expected a behavior that is congruent with one's values not to result in shame or guilt. In partial support of my hypothesis, I found a significant main effect of value congruence on 
feelings of shame $\left(F(1,197)=69.93, p<.001, \eta^{2}=.26\right)$ and guilt $\left(F(1,197)=142.96, p<.001, \eta^{2}=\right.$ .42). Individuals in the non-congruent value condition reported higher levels of shame

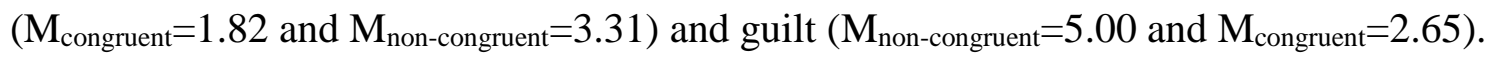

However, the interaction between value congruence and public vs. private nature of the behavior did not significantly predict emotions of shame or guilt. In other words, a non-congruent value resulted in higher levels of shame and guilt regardless of the public or private nature of the behavior.

Guilt Mediation. H3(a) predicted that guilt mediates the relationship between value congruence and purchase likelihood, and this effect varies based on the nature of behavior (i.e., public vs. private). However, because $\mathrm{H} 2$ was rejected, I have already established that the impact of value congruence on emotions of shame and guilt do not vary as a function of privacy or publicity of the behavior. Therefore, I expect that there would be no conditional indirect effect between value congruence and purchase likelihood ${ }^{2}$. I modified the analysis to further probe the relationship between value congruence and purchase likelihood and test whether guilt mediates this relationship regardless of the nature of the behavior. I used Hayes's (2013) PROCESS macro (Model 4) to estimate bias-corrected bootstrapped confidence intervals ( $\mathrm{n}=5,000$ samples) to examine the indirect effect. Consistent with my expectation, I find a significant indirect effect of value congruence on purchase likelihood $(b=-1.11,95 \% \mathrm{CI}=[-1.58,-.72]$; see Table 1$)$. Results indicate that a non-congruent value results in higher levels of guilt $(b=2.38, t(200)=11.83$, $\mathrm{p}<.001,95 \% \mathrm{CI}=[1.98,2.78])$ which subsequently reduces purchase likelihood $(\mathrm{b}=-.47, \mathrm{t}(199)$ $=-6.21, \mathrm{p}<.001,95 \% \mathrm{CI}=[-.61,-.32])$.

\footnotetext{
2 A conditional indirect analysis using PROCESS Model 8 confirmed our expectation that the conditional indirect effect on purchase likelihood is non-significant (Index of moderated mediation $=-.21,95 \% \mathrm{CI}=[-.59, .10]$ )
} 
Consistently, the analysis was modified to test the indirect effect of value congruence on willingness to pay ${ }^{3}$. My initial analysis using PROCESS Macro model 8 indicated that although there was no conditional indirect effect, but the interaction between value congruence and behavior nature was a significant predictor of willingness to pay. Thus, PROCESS Macro model 5 was used to test this conditional effect in addition to the mediating role of guilt. Results show that a non-congruent value increases guilt $(b=2.33, t(198)=12.42, p<.001,95 \% \mathrm{CI}=[1.96$, 2.70]), and interestingly guilt increases willingness to pay $(b=9.23, t(195)=2.03, p<.05,95 \%$ $\mathrm{CI}=[.27,18.18]) . \mathrm{I}$ also find that there is a significant interaction between the nature of the behavior (i.e., public vs. private) and value congruence $(b=-56.27, t(195)=-2.36, p<.05,95 \%$ CI $=[-103.24,-9.31])$. Results indicate that a non-congruent value significantly decreases willingness to pay when the behavior is public $(\mathrm{b}=-72.52, \mathrm{t}(195)=-3.54, \mathrm{p}<.001,95 \% \mathrm{CI}=[-$ $112.90,-32.14])$, but this effect is non-significant when the behavior is private $(\mathrm{p}=.40)$. Moreover, the indirect effect of value congruence on willingness to pay is not significant $($ Indirect effect $=21.48, \mathrm{SE}=15.90,95 \% \mathrm{CI}=[-2.42,62.40])$.

Finally, I used PROCESS macro (model 4) to test the indirect effect of value congruence on review examination. There was a significant negative indirect effect on review examination (see Table 1), where a non-congruent value resulted in higher levels of guilt $(\mathrm{b}=2.38, \mathrm{t}(200)=$ $11.83, \mathrm{p}<.001,95 \% \mathrm{CI}=[1.98,2.78])$ which consequently resulted in lower levels of review examination $(\mathrm{b}=-.06, \mathrm{t}(199)=-2.14, \mathrm{p}<.05,95 \% \mathrm{CI}=[-.12,-.01])$.

Shame Mediation. Using PROCESS macro in SPSS (Model 5; Hayes, 2013), I examined the mediating effect of shame on purchase likelihood. Consistent with my expectations, and in

\footnotetext{
${ }^{3}$ A conditional indirect analysis using PROCESS Model 8 confirmed our expectation that the conditional indirect effect on willingness to pay is non-significant (Index of moderated mediation $=3.23,95 \% \mathrm{CI}=[-1.17,19.25]$ ).
} 
partial support of H4(a), I found a significant indirect effect on purchase likelihood (indirect effect $=-.31, \mathrm{SE}=.15,95 \% \mathrm{CI}=[-.65,-.05])$. A values violation leads to higher levels of shame $(\mathrm{b}=1.50, \mathrm{t}(198)=8.32, \mathrm{p}<.001)$ that subsequently reduce purchase likelihood $(\mathrm{b}=-.21, \mathrm{t}(198)=-$ $2.41, \mathrm{p}<.05)$. In addition, results indicate that there is a significant conditional direct effect where the impact of value congruence varies as a function of public vs. private nature of the behavior. Contrasts show that this effect is significant at both levels of the moderator; public ( $b=-2.49, \mathrm{t}$ $(195)=-7.36, \mathrm{p}<.001)$ and private $(\mathrm{b}=-1.77, \mathrm{t}(195)=-5.45, \mathrm{p}<.001)$.

To test H4(b) PROCESS macro Model 5 was used to investigate whether the impact of values congruence on consumers' willingness to pay is mediated through emotional state of shame. Although values congruence is a significant predictor of shame $(b=1.41, t(198)=8.90$, $\mathrm{p}<.001)$, and shame is a significant predictor of willingness to pay $(\mathrm{b}=10.41, \mathrm{t}(195)=1.94$, $\mathrm{p}=.05$ ), these effects did qualify for a significant mediation (indirect effect $=14.71, \mathrm{SE}=12.36$, $95 \% \mathrm{CI}=[-4.45,44.27])$.

Finally, I predicted that shame would not mediate the relationship between value violation and review examination. In support of H4(c), I find a non-significant mediation effect of value congruence on review examination $(95 \% \mathrm{CI}=[-.17, .03])$.

\section{Result Summary}

This study experimentally supports my hypothesis that value violation is a significant predictor of purchase likelihood. Results indicate that the impact of value violation on willingness to pay and review examination is only marginally significant, though the trends were consistent with my expectation in that a value violation results in lower willingness to pay and review examination. Counter to my expectation, value congruence and public vs. private nature of the behavior did not interact to influence emotions of shame and guilt. However, I did find a 
main effect of value violation on both emotions. In other words, participants reported higher levels of shame and guilt when the purchase decision involved violation of a value. I also found support for the mediating effect of guilt on consumer outcomes. An interesting finding in this experiment was the direction of the impact of shame and guilt on willingness to pay. To put it simply, a violation of value resulted in higher levels of shame which in turn lead to higher willingness to pay. Consistent with my predictions, although shame did not mediate the relationship between value congruence and willingness to pay, but the direct effect of shame on willingness to pay was positive. These effects might be due to compensatory consumption, where people use consumption as a coping strategy to alleviate negative intense emotions such as shame (Mandel et al. 2017). Finally, I found support for my prediction that shame will results in inaction when it comes to review examination.

\section{STUDY 2}

In this study I examine whether shopping motive moderates the relationships between values congruence and consumer outcomes. My theory predicts that a hedonic shopping motive strengthens while a utilitarian motive attenuates the impact of values violation on consumer outcomes. This study demonstrates that it is not the nature of the hedonic or utilitarian alternative that predicts consumer preference or satisfaction, but rather the perceptions of values violation associated with the utilitarian or hedonic alternative. This study helps us establish that there is a boundary condition (i.e. values violation) to Okada's (2005) work.

\section{Method}

Participants were 200 American adults recruited through Amazon Mechanical Turk in exchange for a small monetary compensation. Nine participants were excluded from analysis because they missed all the manipulation checks, resulting in a final sample of 191 participants. Cell sizes ranged between 47 and 49. More than half of the sample participants were females 
$(62 \%)$; the mean age of the respondents was $37(\mathrm{SD}=12)$; the median income was $\$ 50,000$ $\$ 59,999$; and $66 \%$ had obtained a college degree.

Participants were randomly assigned to a 2 (value: congruent vs. non-congruent) $\mathrm{x} 2$ (shopping motive: hedonic vs. utilitarian) between-subjects design. Participants were first shown a message that was aimed to prime a congruent or non-congruent value. Both messages involved a scenario regarding the participant's New Year's resolution. In the congruent value condition, participants read that "[they] have decided that life is too short and want to start living in the moment and not sacrifice today's happiness for the hope of a better future" and one specific thing that they have thought of, is doing something nice for themselves every day. The non-congruent value condition noted that "[they] have decided to start thinking long-term. [they] are not going to sacrifice long-term success and happiness for short-term satisfaction anymore," and the specific thing they want to do is start saving money to achieve their goals. All participants then proceeded to a question asking them to list three examples of how they are going to act on their New Year's resolution. They were then told that from prior experience, they have learned that if they are not thinking about their resolution regularly, they are not going to follow through. Thus, a crucial part of realizing their goal is a regular review of their resolution before making any decision. After participants read this message, they were told that the next section would present them with an example of a day-to-day decision they may face. The decision involved purchasing a laptop. Consistent with Kronrod and Danziger (2013), I used the same product and modified the shopping motive in order to remove any confounds that might exist due to differences between hedonic and utilitarian products. The hedonic and utilitarian shopping motive manipulations were adapted from Choi et al. (2014). Participants in the utilitarian motive condition were asked to imagine that they want to purchase a new laptop because they are 
experiencing sluggish and unresponsive performance with their current laptop. Those in the hedonic motive condition were told that although their current laptop still performs well, they want to purchase a new laptop because their current one is quite old fashioned. I then showed participants a laptop and told them that after searching online and comparing different laptops, they have decided that compared to other models, this laptop is the best option for them. Similar to study one, participants were then asked to indicate what they wanted to do next in order to make their final decision: (a) proceed to checkout, (b) examine star ratings, (c) read customer reviews, or (d) remove the item from the cart. Participants selecting to examine star ratings, saw a 4.5/5 star rating and then selected whether they wanted to read customer reviews, buy the product, or remove the item from the cart. Those selecting the "read customer reviews" option went through similar steps after reading favorable customer reviews that complemented both utilitarian and hedonic aspects of the laptop. Purchase likelihood, willingness to pay, state shame and guilt measures were identical to study 1. Covariates (i.e., shame proneness, guilt proneness, product attitude, level of financial planning, and goal attainment motive) were also measured similar to study 1 . In addition, in this study I added a measure to assess participant's trust in the writers of online reviews. Three items on a 7-point scale (e.g., My typical approach is to trust writers of the online reviews until they prove I should not trust them.; $1=$ completely disagree to 7=completely agree; $\alpha=.78$ ) adapted form Gefen, Karahanna, and Straub (2003) measured trust in reviewers. I also asked participants whether they make New Year's resolution, if so, how seriously they take their New Year's resolution, and their past performance with regards to following through with their New Year's resolution.

\section{Analysis and Results}

Manipulation Check. As a manipulation check, I asked participants whether they thought buying the laptop is consistent with their New Year's resolution. Eighty percent of the 
participants in the congruent value condition answered "yes" to this question and 76\% of those in the non-congruent value condition responded "no" to the same question $\left(\chi^{2}=60.07, \mathrm{p}<.001\right.$, Cramer's V $=.56$ ). Participants were also asked to recall their New Year's resolution. I conducted a two-way contingency table analysis to examine whether participants could correctly recall their experimental condition; $90 \%$ of those in the congruent value condition correctly chose "cherish life and live in the moment" as their New Year's resolution, and 99\% of the participants in the non-congruent value condition correctly selected "think long term and save money" as their New Year's resolution $\left(\chi^{2}=176.17, \mathrm{p}<.001\right.$, Cramer's V= .96).

To assess the efficacy of the shopping motive manipulations and assess whether my scenarios resulted in different perceptions of necessity for hedonic and utilitarian motives, I adapted Voss et al.'s (2003) measures of utilitarian (e.g., Under the circumstances, I think buying this laptop will be: necessary; $1=$ not at all to $7=$ extremely) and hedonic shopping motives (Under the circumstances, I think buying this laptop will be: fun; $1=$ not at all to $7=$ extremely). The manipulation was successful; those in the utilitarian condition reported higher perceptions of necessity, practicality and functionality $(\mathrm{M}=4.56)$ compared to participants in the hedonic condition $\left(\mathrm{M}=3.70 ; \mathrm{F}(1,188)=21.89, \mathrm{p}<.001, \eta^{2}=.10\right)$. Similarly, those in the hedonic condition reported higher expectations of fun and enjoyment with the purchase $(M=4.67)$ compared to participants in the utilitarian condition $(\mathrm{M}=4.35 ; \mathrm{F}(1,188)=3.00, \mathrm{p}=.08)$. Finally, participants were asked to recall the reason they were buying the laptop; $97 \%$ of the individuals in the utilitarian condition correctly selected the reason as "Your current laptop is sluggish and unresponsive," and 94\% of the individuals in the hedonic condition correctly recalled the reason as "Your current laptop is old fashioned" $\left(\chi^{2}=162.21, \mathrm{p}<.001\right.$, Cramer's V= .92). 
Purchase Likelihood. Similar to study 1, for all analyses, I start by testing all covariates (i.e., shame proneness, guilt proneness, goal attainment motive, product attitude, trust in reviewers, New Year's resolution experience, financial planning, race, age, income, education, gender, involvement, mood) to assess whether they are significant predictors of the dependent variables. Product attitude and trust in reviewers were significant predictors of purchase likelihood, thus, the two variables were added as covariates to all analysis involving purchase likelihood. Replicating Study 1 results, I find a significant effect of value congruence on purchase likelihood $\left(\mathrm{F}(1,185)=27.13, \mathrm{p}<.001, \eta^{2}=.13\right)$. In addition, results indicate that participants in the utilitarian condition reported higher purchase likelihood $(\mathrm{M}=5.44)$ compared to those in the hedonic condition $\left(\mathrm{M}=4.84 ; \mathrm{F}(1,185)=11.29, \mathrm{p}<.01, \eta^{2}=.06\right)$. Moreover, a significant interaction between value congruence and shopping motive supports H5 (a) (F $\left.(1,185)=9.34, p<.01, \eta^{2}=.05\right)$. Follow-up contrast tests show that, consistent with my expectation, a utilitarian motive mitigates the negative impact of a non-congruent value on purchase likelihood to the point that the difference between the value congruent and value noncongruent conditions becomes non-significant ( $\mathrm{p}=.12$ ). Hedonic motive, on the other hand, exacerbates the relationship between values congruence and purchase likelihood. Participants with a hedonic motive who were in the non-congruent value condition reported significantly lower purchase likelihood $(\mathrm{M}=4.10)$ compared to those in the congruent value condition $(\mathrm{M}=$ $\left.5.59 ; \mathrm{F}(1,185)=34.48, \mathrm{p}<.001, \eta^{2}=.16\right)$. Finally, I find support for my expectation that unless there is a value violation a hedonic motive does not reduce purchase likelihood. In other words, in the value congruent condition there were no difference in purchase likelihood among participants with a hedonic shopping motive and those with a utilitarian shopping motive $(\mathrm{p}=.83)$. However, when participants were violating a value, a hedonic shopping motive resulted 
in lower purchase likelihood $(M=4.10)$ compared to a utilitarian shopping motive $(M=5.24 ; \mathrm{F}$ $\left.(1,185)=20.61, \mathrm{p}<.001, \eta^{2}=.10\right)$.

Willingness to Pay. The impact of value was not significant as a main effect, though the trend was for willingness to pay to be greater in the values congruent than values non-congruent condition $(\mathrm{F}(1,185)=.81, \mathrm{p}=0.37)$. Participants in the non-congruent value condition reported lower willingness to pay $(M=\$ 614)$ than those in the congruent value condition $(M=\$ 731)$. In addition, I did not find a significant effect of shopping motive $(\mathrm{p}=.93)$ or an interactive effect of value congruence $x$ shopping motive on willingness to pay $(\mathrm{p}=.27)$ which rejects $\mathrm{H} 5(\mathrm{~b})$ hypothesis.

Review Examination. As expected, there is a significant effect of shopping motive on review examination $\left(\mathrm{F}(1,186)=9.13, \mathrm{p}<.01, \eta^{2}=.05\right)$. Participants in the utilitarian condition showed higher interest in examining online reviews $(M=2.85)$ compared to those in the hedonic condition $(M=2.21)$. In addition, I find a significant interaction between value congruence and shopping motive $\left(\mathrm{F}(1,186)=6.49, \mathrm{p}<.05, \eta^{2}=.03\right)$ supporting $\mathrm{H} 5(\mathrm{c})$. Contrasts show that there is no significant difference in review examination between participants with a hedonic and utilitarian shopping motive when there is no value violation involved $(p=.73)$. However, when the purchase decision involves violation of a value, participants in the utilitarian condition showed higher levels of review examination $(M=3.15)$ compared to those in the hedonic condition $\left(\mathrm{M}=1.98 ; \mathrm{F}(1,186)=15.70, \mathrm{p}<.001, \eta^{2}=.08\right)$. Interestingly I also find that regardless of whether there is a value violation involved or not, there is no difference in review examination for participants with a hedonic shopping motive $(\mathrm{p}=.12)$. However, individuals with a utilitarian shopping motive were more interested in examining reviews when the value was non-congruent $(\mathrm{M}=3.16)$ rather than congruent $\left(\mathrm{M}=2.54 ; \mathrm{F}(1,186)=4.17, \mathrm{p}<.05, \eta^{2}=.02\right)$. 
State Shame and Guilt. Similar to Study 1, a non-congruent value was shown to increase feelings of shame $\left(\mathrm{F}(1,186)=37.97, \mathrm{p}<.001, \eta^{2}=.17\right)$ and guilt $\left(\mathrm{F}(1,183)=76.50, \mathrm{p}<.001, \eta^{2}=\right.$ .29). In addition, consistent with previous shopping motive literature, I find a significant main effect of shopping motive on emotions of guilt $\left(\mathrm{F}(1,183)=10.16, \mathrm{p}<.01, \eta^{2}=.05\right)$ and shame $(\mathrm{F}$ $\left.(1,186)=5.62, \mathrm{p}<.05, \eta^{2}=.03\right)$. Participants in the hedonic condition reported higher levels of guilt $(M=4.05)$ compared to those in the utilitarian condition $(M=3.46)$. I see the same pattern with shame where a hedonic motive results in higher levels of shame $(M=2.77)$ compared to a utilitarian motive $(M=2.34)$.

Guilt Mediation. H6 (a) predicted that guilt mediates the relationship between value congruence and purchase likelihood and this effect is moderated by shopping motive. Similar to S1, guilt was tested as a mediator of value congruence on purchase likelihood and I assessed whether some of the variance in purchase likelihood is explained by the interaction between value congruence and shopping motive (Model 5; Hayes 2013). In support of H6(a) I find that guilt mediates the relationship between value congruence and purchase likelihood (indirect effect $=-.27, \mathrm{SE}=.12,95 \% \mathrm{CI}=[-.53,-.05])$. In addition, results indicate that a part of the variance explained in purchase likelihood is a result of the moderating effect of shopping motive on value congruence $(b=-1.08, t(182)=-3.05, p<.01)$. Contrasts show that there is no significant difference in purchase likelihood for participants with a utilitarian shopping motive, regardless of whether the purchase involved a value violation or not. However, when the participant had a hedonic shopping motive, a non-congruent value significantly reduced purchase likelihood $(b=-$ $1.18, \mathrm{t}(183)=-4.32, \mathrm{p}<.001)$.

H6(b) predicted a conditional indirect effect where guilt mediates the relationship between value congruence and shopping motive on willingness to pay. Contrary to this 
hypothesis, a bias-corrected $95 \%$ confidence interval showed that guilt does not mediate the relationship between value congruence and willingness to pay $(95 \% \mathrm{CI}=[-106.58,501.36])$.

Finally, H6(c) predicted that a non-congruent value will results in higher levels of guilt, which, in turn, reduces review examination. The mediation was assessed with bias-corrected confidence intervals based on a 5000-bootstrap sample (Model 5; Hayes 2013). Results indicate that guilt does not mediate the relationship between value congruence and review examination $(95 \% \mathrm{CI}=[-.46, .13])$, thus rejecting $\mathrm{H} 6(\mathrm{c})$.

Shame Mediation. In support of H7(a), I find that shame mediates the relationship between value congruence and purchase likelihood (indirect effect $=-.19, \mathrm{SE}=.08,95 \% \mathrm{CI}=[-$ $.38,-.05])$. A values violation significantly increases feelings of shame $(b=1.12, \mathrm{t}(186)=5.81$, $\mathrm{p}<.001)$ which subsequently reduces purchase likelihood $(b=-.17, t(183)=-2.44, \mathrm{p}<.05)$. In addition, similar to the guilt mediation results, part of the variance explained in purchase likelihood is a result of the moderating effect of shopping motive and value congruence $(b=-1.11$, $\mathrm{t}(183)=-3.17, \mathrm{p}<.01)$. Contrasts show that there is no significant difference in purchase likelihood for participants with a utilitarian shopping motive, regardless of whether the purchase involved a value violation or not. However, when the participant had a hedonic shopping motive, a non-congruent value significantly reduced purchase likelihood $(b=-1.23, \mathrm{t}(183)=-4.67$, $\mathrm{p}<.001)$.

H7(b) examines the mediating effect of shame on participant's willingness to pay. I predicted that a non-congruent value will results in higher levels of shame which reduces participant's willingness to pay. Results indicate a significant impact of value congruence on shame $(b=1.15, t(186)=6.04, p<.001)$, and a significant effect of shame on willingness to pay $(b=123.34, t(183)=2.51, p<.05)$. The mediation was assessed with bias-corrected confidence 
intervals based on a 5000-bootstrap sample (Model 5; Hayes 2013). Results indicate that although the main effects of value congruence on shame, and shame on willingness to pay were significant, shame does not mediate the relationship between value congruence and willingness to pay $(95 \% \mathrm{CI}=-59.65,502.21])$, thus rejecting $\mathrm{H} 7(\mathrm{~b})$.

Finally, $\mathrm{H} 7$ (c) predicted that shame would not mediate the relationship between value congruence and review examination. A bias-corrected 95\% confidence interval (Model 5; Hayes 2013) supports my hypothesis $(95 \% \mathrm{CI}=[-.39, .03])$.

\section{Result Summary}

The results of experiment 2 replicate the main effects from experiment 1. I found a significant effect of value congruence on purchase likelihood and review examination, thus supporting H1(a) and H1(c). However, consistent with Study 1, value congruence did not influence willingness to pay rejecting $\mathrm{H} 1(\mathrm{~b})$.

Moreover, in this study I demonstrated the discounting effect of utilitarian shopping motive on the negative impact of value violations. Results indicate that if an individual has a utilitarian shopping motive, a non-congruent value does not reduce purchase likelihood. However, as expected, this is not the case for hedonic shopping motive. A non-congruent value results in a reduction of purchase likelihood for those with a hedonic shopping motive.

Another important contribution of this study is that I find changes in how consumers examine review information as a result of an interaction between value congruence and shopping motive. Consistent with my hypothesis, I see that a utilitarian shopping motive results in higher levels of review examination when the value is non-congruent rather than congruent. This is in keeping with my notion that consumer reviews can be used as a justification apparatus. Individuals in the values violation condition spend more time examining reviews to help them 
alleviate some of the discomfort caused by the anticipated self-discrepancy. However, I could not find support for the prediction that this process occurs due to emotions of shame and guilt.

\section{General Discussion}

Prior research has investigated the impact of shopping motive on consumer choice, attitudes, and behavioral outcomes. However, consumer choice literature has not explored the significance of personal values on consumer outcomes. In this paper I investigate the impact of value congruence on consumer intentions and behavior. I examine aversive states of shame and guilt as psychological processes that mediate the effect of value congruence on consumer purchase intention, willingness to pay and review examination. I extend previous research by showing that guilt and shame are not an outcome of hedonic shopping motives, but the byproduct of the violation of values occurring in association with hedonic shopping.

This research also provides a deeper understanding of consumers' decision-making process for online purchases by demonstrating the online consumer reviews' potential to serve as a justification apparatus for value-violating purchase. Han, Duhachek, and Rucker (2015) argue that when a discrepancy between a person's current state and end state exists, whether this discrepancy is real or perceived, that person is experiencing a psychological threat. A purchase decision that involves violation of personal values creates a discrepancy between ones held values and their current state. Because the state caused by psychological threats is aversive and uncomfortable, consumers tend to use coping mechanisms to alleviate the pain associated with these threats. Consumers anticipate the self-discrepancy threat and discomfort associated with purchases that involve a violation of values, and thus tend to avoid making such purchases, especially if they have a hedonic shopping motive. However, Okada (2005) found that this discomfort can be attenuated if the shopper can formulate a justification for the purchase. In this 
study, I demonstrated that in the online environment, online consumer reviews can serve as a coping mechanism that provide such justification and mitigate the negative affect and anticipated discomfort associated with a value-violating purchase.

I also demonstrate the significant and distinct outcomes and implications of aversive states of shame and guilt. We found that although both emotions result in negative consumer outcomes (e.g., purchase likelihood), but they have unique consequences for online information search (i.e., review examination). Results indicated that guilt but not shame results in changes in online review examination. This is consistent with research on shame that shows withdrawal, and lack of willingness to redress as consequences of shame (Oliver and Westbrook 1993).

Redressing a wrong doing (i.e., the value violating purchase in this context) by finding quantifiable benefits can potentially mitigates feelings of guilt. However, reducing feelings of shame requires changing other's perceptions of self. Therefore, we see an unwillingness to redress in cases of shame, because redeeming a loss of esteem in others' perceptions can be a rather difficult task. 
Figure 1- Conceptual Model (H1-H4)

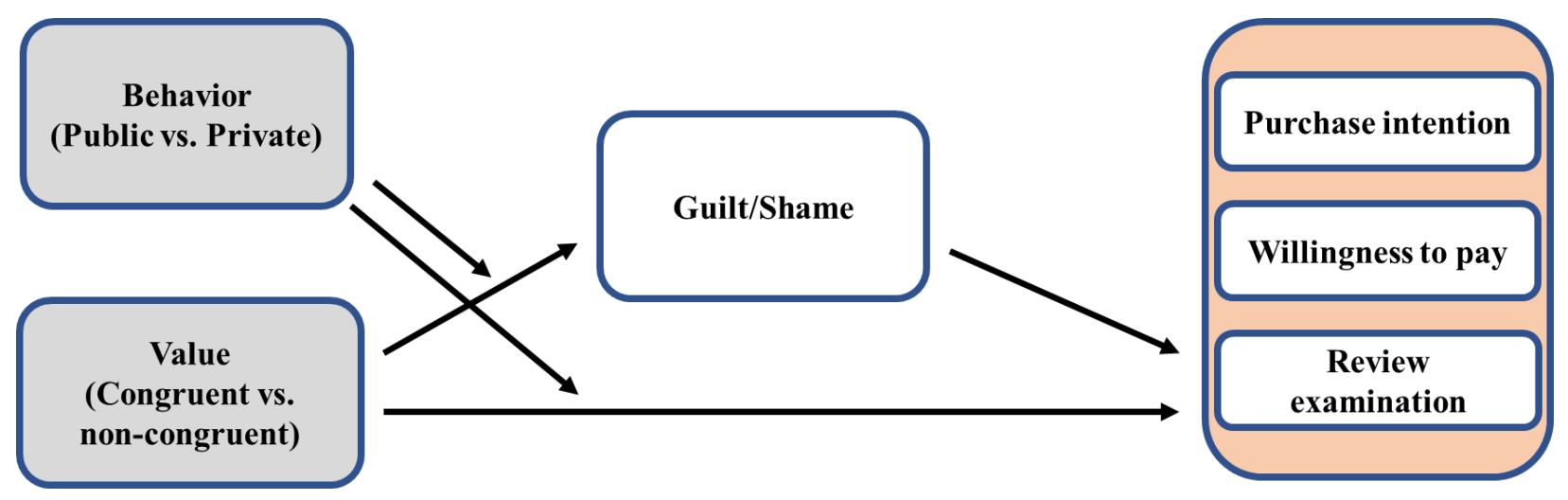

Figure 2- Conceptual Model (H5-H7)

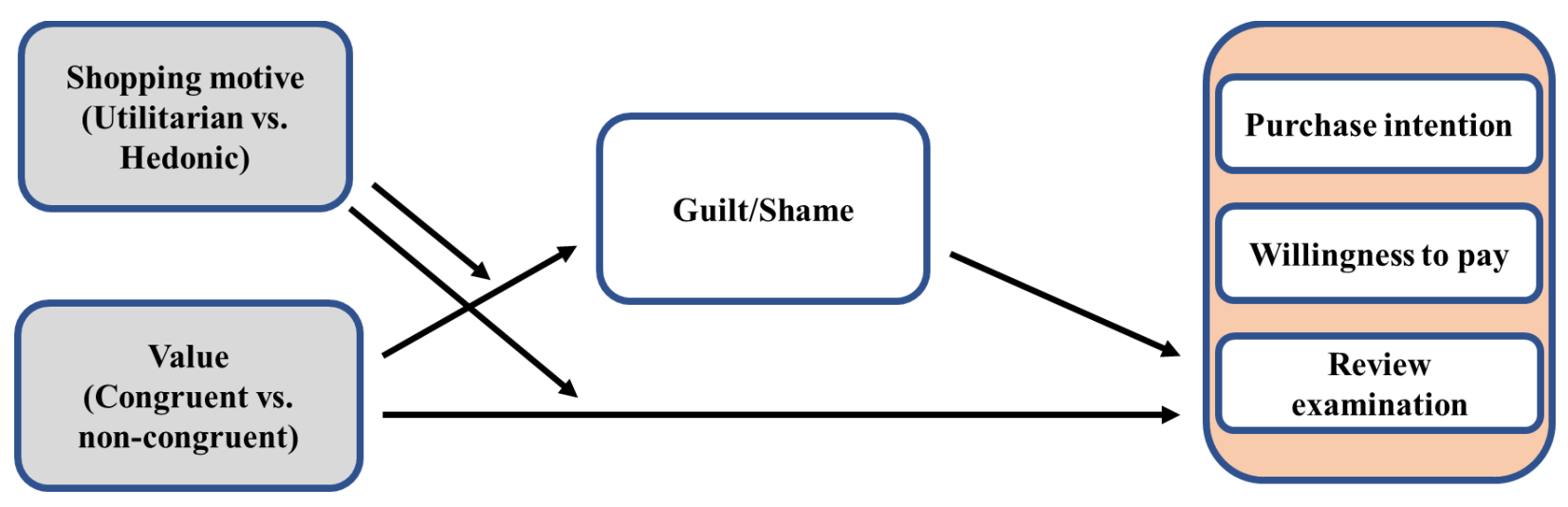


TABLE 1

Study 1: Bootstrap Tests of Indirect Effect of Value Congruence on Consumer Outcomes Through Guilt

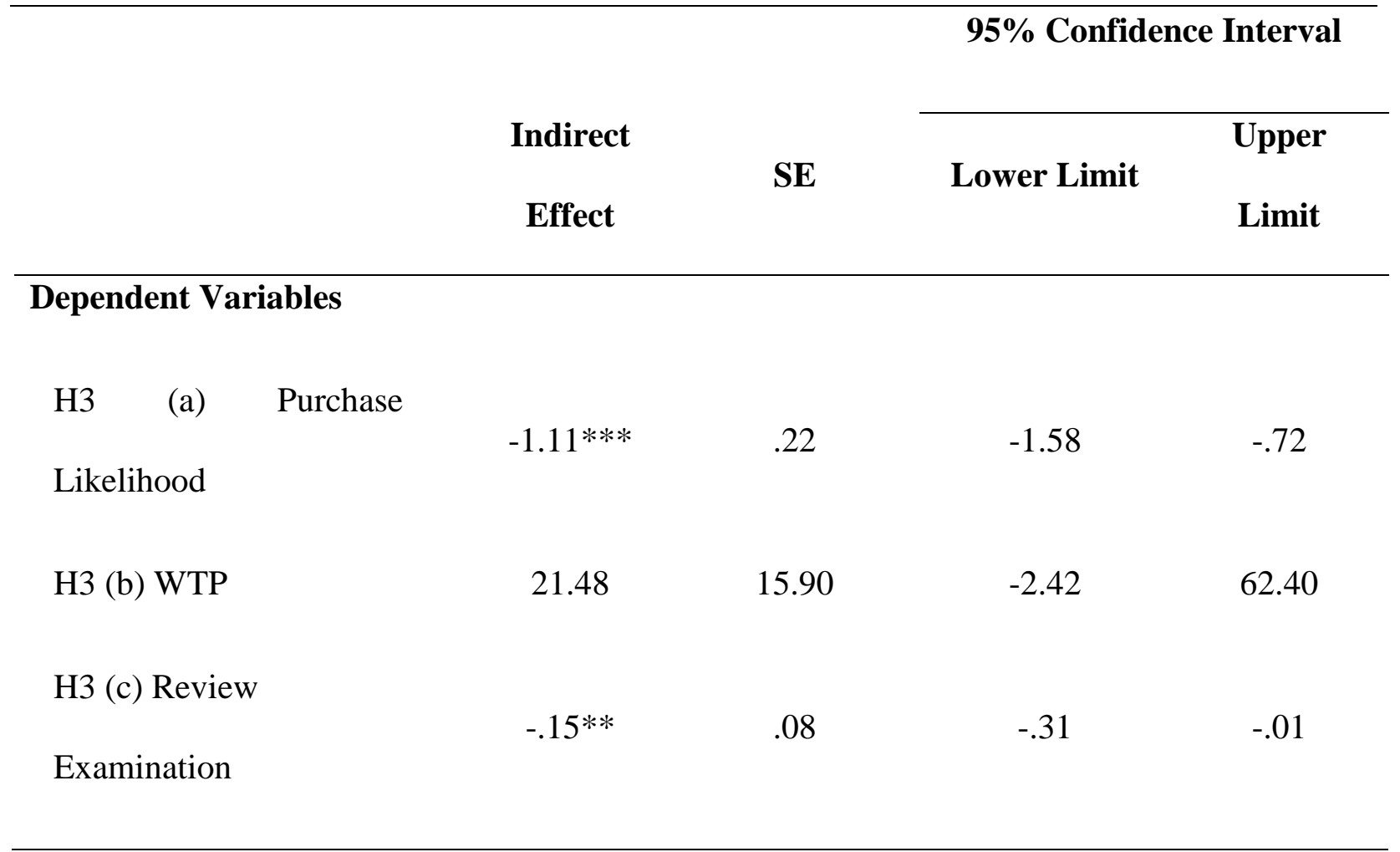

Note: Controlling for product attitude and ethnicity

${ }^{* * * *} p<.001,{ }^{* *} p<.05$ 
TABLE 2

Study 2: The Effect of Value Congruence on Consumer Outcomes

\begin{tabular}{|c|c|c|c|}
\hline \multirow[b]{2}{*}{ Independent Variables: } & \multicolumn{3}{|c|}{ Univariate $F$ Values and $\eta^{2}$} \\
\hline & Purchase Likelihood & Willingness to Pay & $\begin{array}{c}\text { Review } \\
\text { Examination }\end{array}$ \\
\hline \multicolumn{4}{|l|}{ Main Effects } \\
\hline Value Congruence (VC) & $27.13 * * *(.13)$ & ns & ns \\
\hline Shopping Motive (SM) & ns & ns & $9.13^{* *}(.05)$ \\
\hline \multicolumn{4}{|l|}{ Interaction Effects } \\
\hline $\mathrm{VC} * \mathrm{SM}$ & $9.34 * *(.05)$ & ns & $6.49 *(.03)$ \\
\hline
\end{tabular}




\section{Appendix A}

\section{Study 1: Value Congruence/Non-Congruence Scenarios}

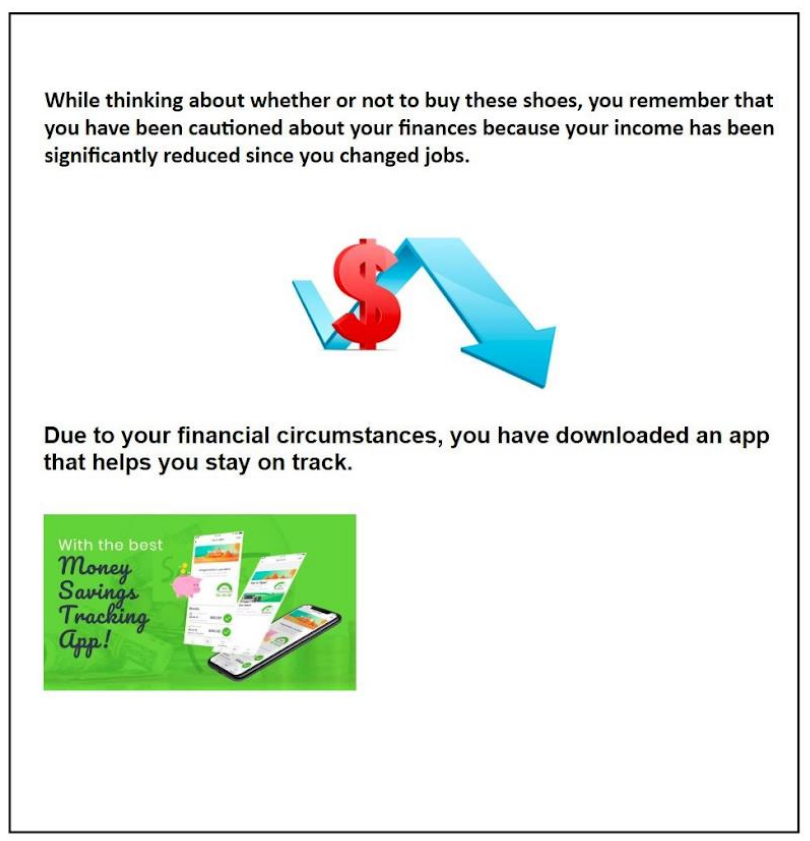

While thinking about whether or not to buy these shoes, you remember that at a recent health checkup, your doctor cautioned you about your health because you have gained weight.

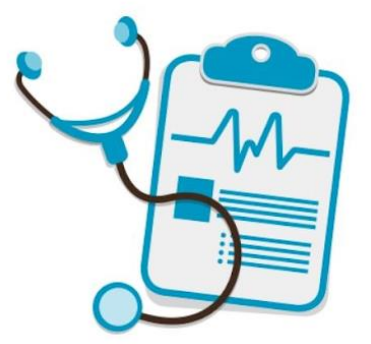

Due to your health circumstances, you downloaded an app that helps you stay on track.

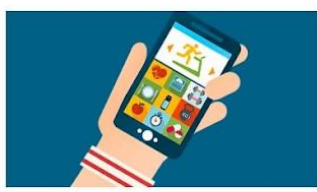




\section{References}

Adaval, Rashmi (2001), "Sometimes It Just Feels Right : The Differential Inconsistent Product Information," Journal of Consumer Research, 28(june), 1-17.

Alba, Joseph W. and Elanor F. Williams (2012), "Pleasure Principles: A Review of Research on Hedonic Consumption," Journal of Consumer Psychology, 23(1), 2-18, http://dx.doi.org/10.1016/j.jcps.2012.07.003.

Babin, BJ, WR Darden, and Mitch Griffin (1994), "Work and/or Fun: Measuring Hedonic and Utilitarian Shopping Value,” Journal of Consumer Research, 20(March 1994), 644-57, http://www.jstor.org/stable/2489765.

Buchanan, David R (2008), “Autonomy, Paternalism, and Justice : Ethical Priorities in Public Health," Health Policy and Ethics, 98(1), 15-21.

Cheema, Amar and Rajesh Bagchi (2011), “The Effect of Goal Visualization on Goal Pursuit : Implications for Consumers and Managers," Journal of Marketing, 75(2), 109-23.

Choi, Jungsil, Yexin Jessica Li, Priyamvadha Rangan, Promothesh Chatterjee, and Surendra N. Singh (2014), "The Odd-Ending Price Justification Effect: The Influence of Price-Endings on Hedonic and Utilitarian Consumption," Journal of the Academy of Marketing Science, $42(5), 545-57$.

Dhar, Ravi and Klaus Wertenbroch (2000), "Consumer Choice Between Hedonic and Utilitarian Goods," Journal of Marketing Research, 37(1), 60-71.

Duhachek, Adam, Nidhi Agrawal, and DaHee Han (2012), "Guilt Versus Shame: Coping, Fluency, and Framing in the Effectiveness of Responsible Drinking Messages," Journal of Marketing Research, 2437, 1-14.

Gefen, David, Elena Karahanna, and Detmar W. Straub (2003), "Trust and TAM in Online Shopping: An Integrated Mode," MIS Quarterly, 27(1), 51-90.

Goswami, Shanta (2014), "Shaming Punishments," The Encyclopedia of Criminology and Criminal Justice, 2110-15, http://www.ncbi.nlm.nih.gov/pubmed/8822306.

Han, Dahee, Adam Duhachek, and Derek D Rucker (2015), "Distinct Threats, Common Remedies : How Consumers Cope with Psychological Threat," Journal of Consumer Psychology, 25(4), 531-45.

Hayes, Andrew F (2013), Introduction to Mediation, Moderation, and Conditional Process Analysis, New York, NY: The Guilford Press.

Higgins, E. Tory (1987), "Self-Discrepancy: A Theory Relating Self and Affect.," Psychological Review, 94(3), 319-40, http://doi.apa.org/getdoi.cfm?doi=10.1037/0033-295X.94.3.319.

Inman, J Jeffrey, Russell S Winer, and Rosellina Ferraro (2009), "The Interplay Among Category Characteristics, Customer Characteristics, and Customer Activities on In-Store Decision Making," Journal of Marketing, 73(September), 19-29.

Kalnikaite, Vaiva, Jon Bird, and Yvonne Rogers (2013), "Decision-Making in the Aisles: Informing, Overwhelming or Nudging Supermarket Shoppers?," Personal and Ubiquitous 
Computing, 17(6), 1247-59.

Khan, Uzma, Ravi Dhar, and Klaus Wertenbroch (2005), "A Behavioral Decision Theoretic Perspective on Hedonic and Utilitarian Choice," Inside Consumption: Frontiers of Research on Consumer Motives, Goals, and Desires, 1, 144-65.

Kivetz, Ran and Anat Keinan (2006), "Repenting Hyperopia: An Analysis of Self-Control Regrets," Journal of Consumer Research, 33(2), 273-82.

Kivetz, Ran and Itamar Simonson (2002), "Earning the Right to Indulge : Effort as a Determinant of Customer Preferences Toward Frequency Program Rewards," Journal of Marketing Research, XXXIX(May), 155-70.

Kronrod, Ann and Shai Danziger (2013), “'Wii Will Rock You!' The Use and Effect of Figurative Language in Consumer Reviews of Hedonic and Utilitarian Consumption," Journal of Consumer Research, 40(4), 726-39, http://www.jstor.org/stable/info/10.1086/671998.

Leach, Colin Wayne and Atilla Cidam (2015), "When Is Shame Linked to Constructive Approach Orientation? A Meta-Analysis.," Journal of Personality and Social Psychology, 109(6), 983-1002, http://doi.apa.org/getdoi.cfm?doi=10.1037/pspa0000037.

Leith, Karen P and Roy F Baumeister (1998), "Empathy, Shame, Guilt, and Narratives of Interpersonal Conflicts: Guilt-Prone People Are Better at Perspective Taking," Journal of Personality, 66(1), 1-38.

Luetge, Christoph (2006), "An Economic Rationale for a Work and Savings Ethic? J. Buchanan's Late Works and Business Ethics," Journal of Business Ethics, 66(1), 43-51, http://search.ebscohost.com/login.aspx?direct=true \&db=bth\&AN=21908833\&site=ehostlive \&scope $=$ site.

Mandel, Naomi, Derek D. Rucker, Jonathan Levav, and Adam D. Galinsky (2017), “The Compensatory Consumer Behavior Model: How Self-Discrepancies Drive Consumer Behavior," Journal of Consumer Psychology, 27(1), 133-46.

Mishra, Arul and Himanshu Mishra (2011), "The Influence of Price Discount Versus Bonus Pack on the Preference for Virtue and Vice Foods," Journal of Marketing Research, 48(1), 196-206, http://journals.ama.org/doi/abs/10.1509/jmkr.48.1.196.

Niedenthal, Paula M, J. P. Tangney, and Igor Gavanski (1994), " If Only I Weren't "versus" If Only I Hadn't': Distinguishing Shame and Guilt in Counterfactual Thinking.," Journal of Personality and Social Psychology, 67(4), 585-95.

Okada, Erica Mina (2005), "Justification Effects on Consumer Choice of Hedonic and Utilitarian Goods," Journal of Marketing Research, 42(February), 43-53.

Oliver, Richard and Robert A. Westbrook (1993), "Profiles of Consumer Emotions and Satisfaction in Ownership and Usage," Journal of Consumer Satisfaction, Dissatisfaction and Complaining Behavior, 6, 12-27.

Oppenheim, L. (2008), “Guilt,” Journal of the American Psychoanalytic Association, 56(3), 967-77, http://apa.sagepub.com/cgi/doi/10.1177/0003065108323463. 
Rucker, Derek D. and Adam D. Galinsky (2008), "Desire to Acquire: Powerlessness and Compensatory Consumption," Journal of Consumer Research, 35(2), 257-67.

Rucker, Derek D., Adam D. Galinsky, and David Dubois (2012), "Power and Consumer Behavior: How Power Shapes Who and What Consumers Value," Journal of Consumer Psychology, 22(3), 352-68, http://dx.doi.org/10.1016/j.jcps.2011.06.001.

Smith, Richard H, J Matthew Webster, W Gerrod Parrott, and Heidi L Eyre (2002), "The Role of Public Exposure in Moral and Nonmoral Shame and Guilt.," Journal of personality and social psychology, 83(1), 138-59.

Tangney, J. P. and Rhonda L. Dearing (2002), Shame and Guilt, New York, NY: The Guilford Press.

Tangney, J. P., Paula M Niedenthal, M V Covert, and D H Barlow (1998), "Are Shame and Guilt Related to Distinct Self-Discrepancies? A Test of Higgins's (1987) Hypotheses.," Journal of personality and social psychology, 75(1), 256-68, http://www.ncbi.nlm.nih.gov/pubmed/9686463. 